\title{
The Technical and Economic Feasibility of Establishing a Building System Integration Laboratory
}

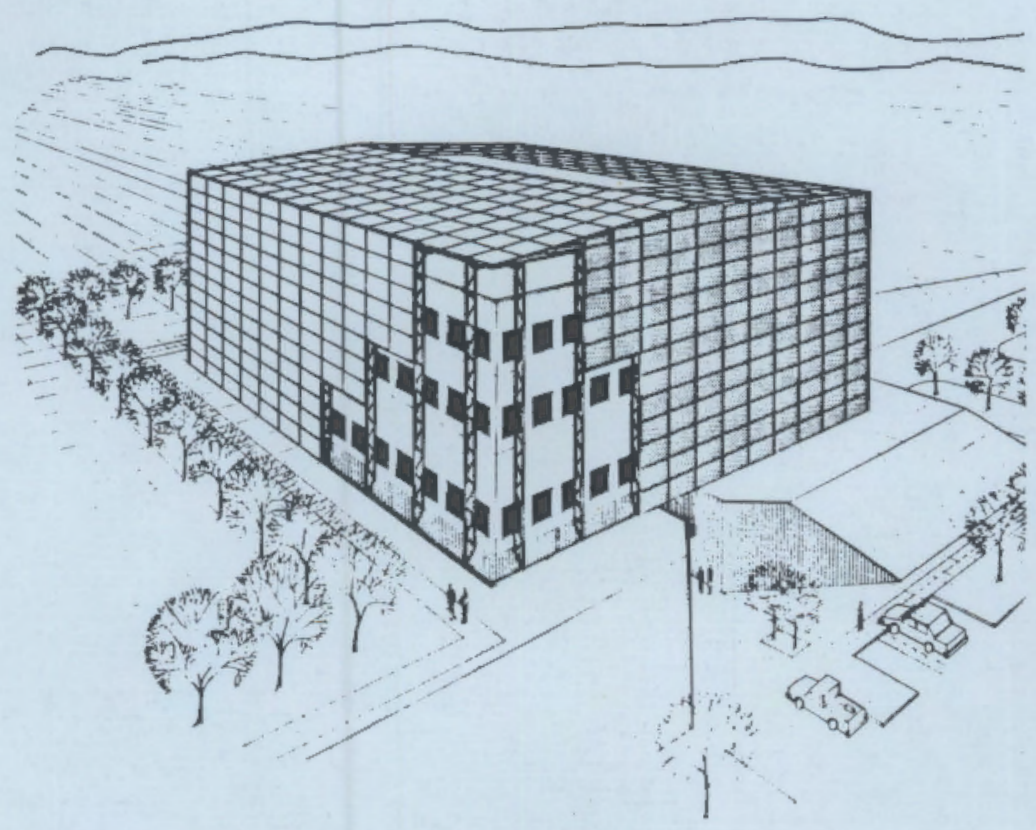

September 1989

Prepared for the U.S. Department of Energy under Contract DE-AC06-76RLO 1830

Pacific Northwest Laboratory Operated for the U.S. Department of Energy by Battelle Memorial Institute 


\title{
DISCLAIMER
}

This program was prepared as an account of work sponsored by an agency of the United States Government. Neither the United States Government nor any agency thereof, nor Battelle Memorial Institute, nor any or their employees, makes any warranty, expressed or implied, or assumes any legal liability or responsibility for the accuracy, completeness, or usefulness of any information, apparatus, product, or process disclosed, or represents that its use would not infringe privately owned rights. Reference herein to any specific commercial product, process, or service by trade name, trademark, manufacturer, or otherwise, does not necessarily constitute or imply its endorsement, recommendation, or favoring by the United States Government of any agency thereof, or Battelle Memorial Institute. The views and opinions of authors expressed herein do not necessarily state or reflect those of the United States Government or any agency thereof.

\author{
PACIFIC NORTHWEST LABORATORY \\ operated by \\ BATTELLE MEMORIAL INSTITUTE \\ for the \\ UNITED STATES DEPARTMENT OF ENERGY \\ under Contract DE-AC06-76RLO 1830
}

Printed in the United States of America

Available to DOE and DOE contractors from the

Office of Scientific and Technical Information, P.O. Box 62, Oak Ridge, TN 37831;

prices available from (615) 576-8401. FTS 626-8401.

Available to the public from the National Technical Information Service,
U.S. Department of Commerce, 5285 Port Royal Rd., Springfield, VA 22161.

NTIS Price Codes, Microfiche A01

Printed Copy

\begin{tabular}{|c|c|}
\hline Pages & $\begin{array}{l}\text { Price } \\
\text { Codes }\end{array}$ \\
\hline $001-025$ & $\mathrm{~A} 02$ \\
\hline $026-050$ & $\mathrm{~A} 03$ \\
\hline 051-075 & $\mathrm{A} 04$ \\
\hline $076-100$ & A05 \\
\hline $101-125$ & A06 \\
\hline $126-150$ & $\mathrm{~A} 07$ \\
\hline $151-175$ & A08 \\
\hline $176-200$ & $\mathrm{~A} 09$ \\
\hline $201-225$ & A 10 \\
\hline $226-250$ & A11 \\
\hline $251-275$ & A12 \\
\hline $276-300$ & A13 \\
\hline
\end{tabular}


THE TECHNICAL AND ECONOMIC FEASIBILITY OF ESTABLISHING A BUILDING SYSTEM INTEGRATION LABORATORY

D. B. Crawley

M. K. Drost

B. M. Johnson

September 1989

Prepared for the U.S. Department of Energy under Contract DE-AC06-76RLO 1830

Pacific Northwest Laboratory Richland, Washington 99352 


\section{FOREWORD}

This report is one in a series describing research activities in support of the U.S. Department of Ẽergy (DOE) Building System Integration Research Program. The goal of the program is to develop the scientific and technical basis for improving integrated decision-making during design and construction. Improved decision-making could significantly reduce buildings' energy use by the year 2010 .

The objectives of the Building System Integration Research Program are

- to identify and quantify the most significant energy-related interactions among building subsystems [for example, walls; roofs; windows; heating, ventilation, and air conditioning (HVAC) subsystems and equipment; lighting; power]

- to develop the scientific and technical basis for improving energy-related interactions in building subsystems

- to provide guidance to designers, owners, and builders for improving the integration of building subsystems for energy efficiency.

The lead laboratory for this program is the Pacific Northwest Laboratory. A wide variety of expertise and resources from industry, academia, other government entities, and other DOE laboratories are used in planning, reviewing, and conducting research activities. Cooperative and complementary research, development, and technology transfer activities with other interested organizations are actively pursued. The research repurts prepared for the program are listed in a bibliography at the back of this report.

In this report, the feasibility study of an experimental building system integration laboratory is summarized. Comments about the work described in this report will be appreciated by the authors or program managers.

Drury B. Crawley

Program Manager

Building System Integration

Applied Physics Center

Pacific Northwest Laboratory

Mark L. Bailey

Program Manager

Architectural and Engineering Systems

Building Systems Division

U.S. Department of Energy

Jean J. Boulin

Group Leader

Architectural and Engineering Systems

Building Systems Division

U.S. Department of Energy 
.

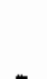




\section{SUMMARY}

On December 22, 1987, the U.S. Congress provided funding to the U.S. Department of Energy (DOE) "to study the feasibility and conceptual design of a whole building system integration laboratory" (Title II of Pub. L. 100-202). A wholebuilding system integration laboratory would be a full-scale experimental facility in which the energy performance interactions of two or more building components, e.g., walls, windows, lighting, could be tested under actual operating conditions. At DOE's request, the Pacific Northwest Laboratory (PNL) conducted the study with the assistance of a technical review panel representing other federal agencies and the academic and private sectors, including professional societies, building component manufacturers, and building research organizations. The results of the feasibility study are presented in this report.

\section{BACKGROUND}

Until FY 1984, DOE buildings research had concentrated on improving the energy efficiency of individual materials, components, or subsystems such as insulation, windows, heating and air conditioning equipment, and lighting. However, since FY 1984, DOE has received funding to explore whether increased attention to the integration of components and subsystems during the design and construction phases of buildings could lead to greater energy savings.

Building system integration research is based on the theory that a building functions most efficiently when it is designed, eonstructed, operated, and maintained to take maximum advantage of the energy performance interactions of its parts. Retrofitting and advanced components cannot make up for a poor design. This research analyzes the combined effects of the building envelope (walls, roofs, and foundations), beating, ventilating, and air-conditioning (HVAC) equipment, service hot water equipment, lighting, occupants, and climate on the amount of energy that a building uses. The objective is to improve the energy efficiency of buildings by developing new and better ways to select, combine, and integrate major building components so that together they operate as a more energy-efficient whole. The whole building, then, is designed and constructed as a better and more efficient operating system.

The Building System Integration Research Program was established because it was believed that substantial energy savings improvements were possible in buildings designed to optimize energy efficiency. This belief was based on the results of computer simulations of buildings redesigned for optimal energy savings. These results indicated that significant energy savings were possible in commercial buildings if the operation of the subsystems within those buildings were correctly integrated. For example, a properly designed and constructed commercial building can minimize use of nonrenewable energy for heating and cooling and be $50 \%$ to $70 \%$ more efficient by storing excess energy generated by people, lighting, and equipment for heating and cooling.

Energy conservation standards recently developed by DOE, the American Society of Heating, Refrigerating, and Air-Conditioning Engineers, Inc. (ASHRAE), and the Illuminating Engineering Society of North America (IESNA) are based on the concept of building system integration. Together these organizations have established standards that no longer simply prescribe (e.g., require specific amounts of insulation), but rather evaluate performance in terms of the interaclion of components and climate for any proposed design. Figure 1 illustrates the differences between system integration research and component and subsystem research.

The Building System Integration Research Program has relied primarily on computer analysis tools to study building interactions. However, the results of this approach are limited by the modeling capability and limitations of available computer programs. Even though these computer programs have become increasingly sophisticated, a large margin of error still exists between theoretical and actual application of system integration design strategies. Experimental studies are needed in conjunction with modeling analyses to make future simulation more accurate. 


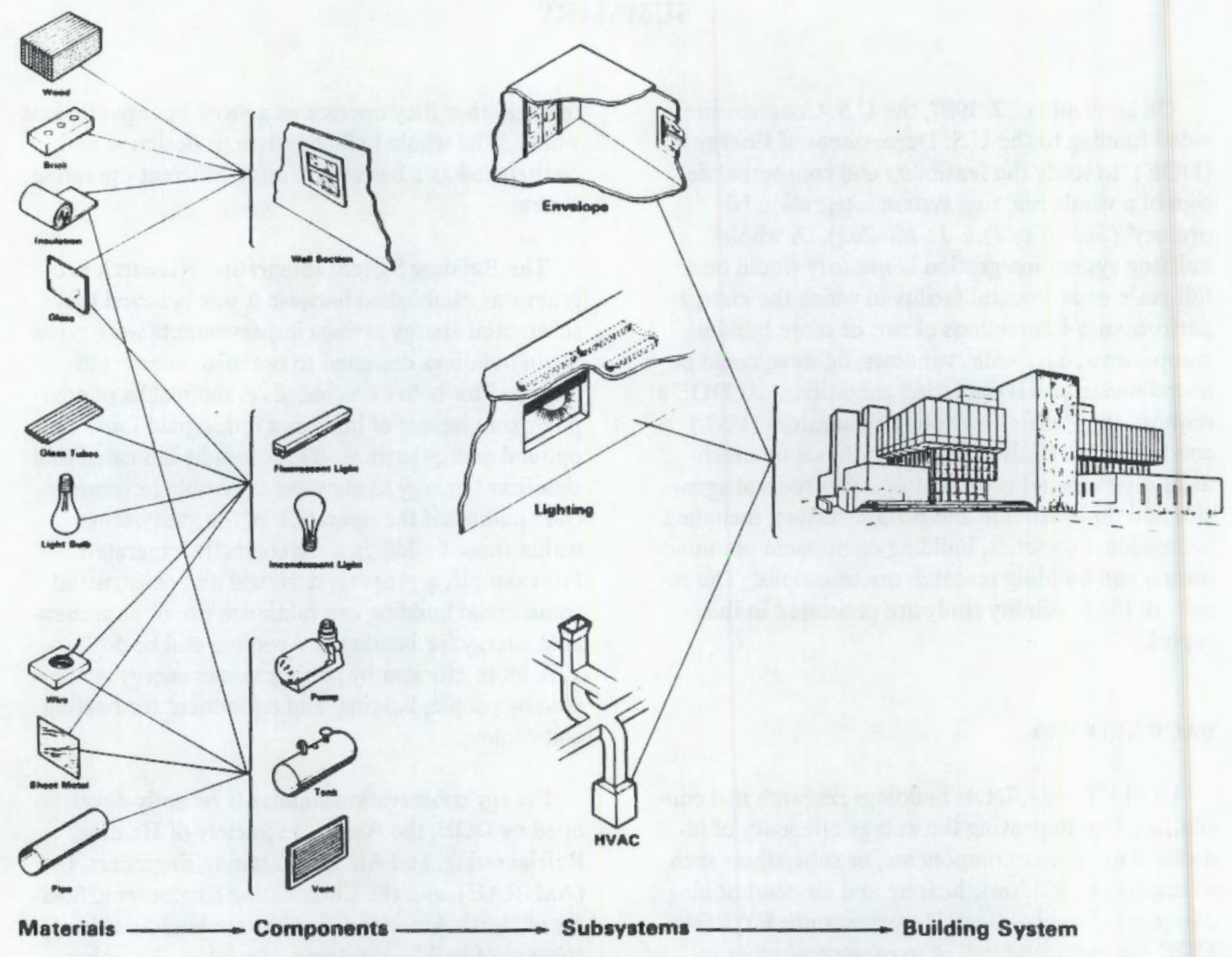

Figure S.1. Building System Integration Research

Recent experimental research projects have examined research hypotheses developed using both computer simulation and laboratory testing. One example is the examination of the interactions between lighting and HVAC subsystems. In many buildings, such as large office buildings, the dominant energy use is due to the lighting and cooling loads. Because lights release heat into the space, a reduction in the lighting load causes a corresponding reduction in the cooling load. However, the issue is more complex. Both lighting power consumption and light output are strong functions of lamp tcmperature. Lamp temperature, in turn, is dependent on the overall room thermal environment, especially air flow conditions and air temperatures near the light fixtures. The room thermal environment is determined by many factors in addition to the heat from the lights; these factors include the operation of fans and heating and cooling equipment, thermostat setpoints, and temperature conditions on exterior surfaces. Current computer codes just cannot handle this complexity. The National Institute of Standards and Technology (NIST, formerly the National Bureau of Standards) is conducting parametric tests of a number of lighting fixture types and HVAC subsystems in a controlled test chamber sized to simulate an office environment, to develop accurate correlations between the two subsystems. Orily then can a computer model and simplified design procedures be developed. The large size of the components being studied in this type of experimental research requires a facility that can more 
adequately handle many component combinations and simulate other actual building conditions, such as weather and occupancy, than is possible in experimental facilities now available to government or private sector researchers. For this reason, the feasibility study was funded to examine whether such a facility is warranted.

A building system integration experimental facility would provide the additional information needed to accurately gauge building energy performance and provide the symbiotic link between simulation and experimentation. A research program based solely on simulation and theory can provide calculations that are drastically wrong and not strong enough to provide a sound foundation to warrant major industry changes. Further, a program based entirely on experimentation would be prohibitively expensive, time-consuming, and unnecessary. The building system integration research program requires both. An experimental facility would allow researchers to interchange building subsystems such as HVAC, lighting, or wall components in a climatecontrolled test facility to examine the optimal combinations for a given climate location. Adding an experimental test facility to the current system integration research program could 1) provide a test bed to enhance iunovation; 2) provide product manufacturers and building designers with the tools necessary to design improved component interfaces, new components with improved and integrated functions, and buildings with optimized components that perform more efficiently; 3 ) increase industry acceptance of new ideas while minimizing expensive demonstration in new buildings with real tenants and productivity requirements; and 4) provide information needed to upgrade computer simulation tools.

As part of this feasibility study, Pacific Northwest Laboratory examined four experimental facility options or approaches to filling the gap in the DOE experimental program. The first option is to use an existing research facility, such as an environmental chamber where different component combinations can be subjected to weather changes. A good example is the test facility at NIST that is being used in the lighting and HVAC study described earlier. The second option is to use existing occupied buildings having the appropriate characteristics to suit the experiments. The third option is to lease or purchase unoccupied buildings having the appropriate characteristics necessary to do the experiments. The fourth option would be to construct a new facility completely outfitted as an experimental facility. In this study, PNL explored the technical, experimental, and economic feasibility of each option. After the preferred alternative was identified, a conceptual design and cost estimate were prepared for that alternative.

The feasibility study findings led to the key conclusions and recommendations presented in the following paragraphs.

Building system integration research has the potential to effect significant savings and improve the overall energy efficiency of commercial buildings. These savings come from increased knowledge of the fundamental operation of building components and subsystems and their interactions. Research resuits can be transferred to architects, engineers, product and component manufacturers, and building owners through new building standards, upgraded computer simulation tools, new product technology, and publications and information databases.

The addition of a building system integration experimental facility would greatly benefit the current research program. The facility would markedly improve the capacity of the building system integration research program and complement existing research methods. It would enable researchers to test a variety of hypotheses in "real-world" applications. Theoretical and actual energy consumption differ widely, even in buildings that are designed with the most sophisticated design methods. It is vital, therefore, that researchers be able to test theories and promising technologies rather than depend on theoretical computer analysis. The information gained from such an experimental facility will help the commercial building industry properly utilize energy conservation technologies and ensure that buildings will function according to design.

Certain characteristics were deemed important for a building system integration experimental facility. The facitity should be

- flexible and capable of serving as a test bed for fundamentaily new concepts 
- capable of close control, i.e., a facility in which the materials and methods of construction are well understood and all of the significant boundary conditions are known and can be controlled and quantified - Only under these conditions, when all variables are known and measured, can observed test results be correlated with test conditions with confidence.

- able to accommodate large components, multiple temperature-control zones, and other energy use characteristics typical of moderate and large commercial buildings.

The private sector and other government research organizations have expressed an interest in using, and could benefit from, a DOE building system integration experimental facility if it were available as a "user facility." Facilities currently available to buildings researchers consist mainly of scalemodel test laboratories and small environmental chambers for testing individual components and subsystems. No research facility on the scale of that examined in this study exists in the United States. Such a facility could be useful to product manufacturers, utility and academic research organizations, national standards groups such as ASHRAE and American Society for Testing and Materials (ASTM), and other government research organizations such as the U.S. Army Construction Engineering Research Laboratory.

A building system integration experimental facility is not needed for residential-scale building system integration research. The study confirmed that there were adequate existing facilities and available test-homes to perform residential building system integration research. The experimental facility would be used to study commercial building system applications.

The construction of a new experimental facility was determined to be the preferred alternative. The study indicated that, although several options exist for developing new building technologies, the most promising is the construction of a new test facility, called a Building System Integration Laboratory (BSIL). This alternative was chosen because of its superior technical, experimental, and economic feasibility.

Pbased construction is feasible. If budget constraints rule out rapid construction of the complete facility, phased construction could be pursued because a substantial amount of research can be conducted in a first-phase structure. The study concluded that the preferred alternative could be constructed in three phases:

- Phase 1 - Construct a three-story test building with a basement (Figure 2), each floor measuring $54 \mathrm{ft}$ by $54 \mathrm{ft}$, at an estimated cost of $\$ 2.7$ million.

- Phase 2 - Expand the test building to $54 \mathrm{ft}$ by $108 \mathrm{ft}$, with the north- and south-facing walls measuring $108 \mathrm{ft}$, for an additional $\$ 2.7$ million.

- Phase 3 - Further expand the test building to its complete dimensions of $108 \mathrm{ft}$ by $108 \mathrm{ft}$ (Figure 3), and add an engineered storage building, for a final increment of \$5.4 million. 

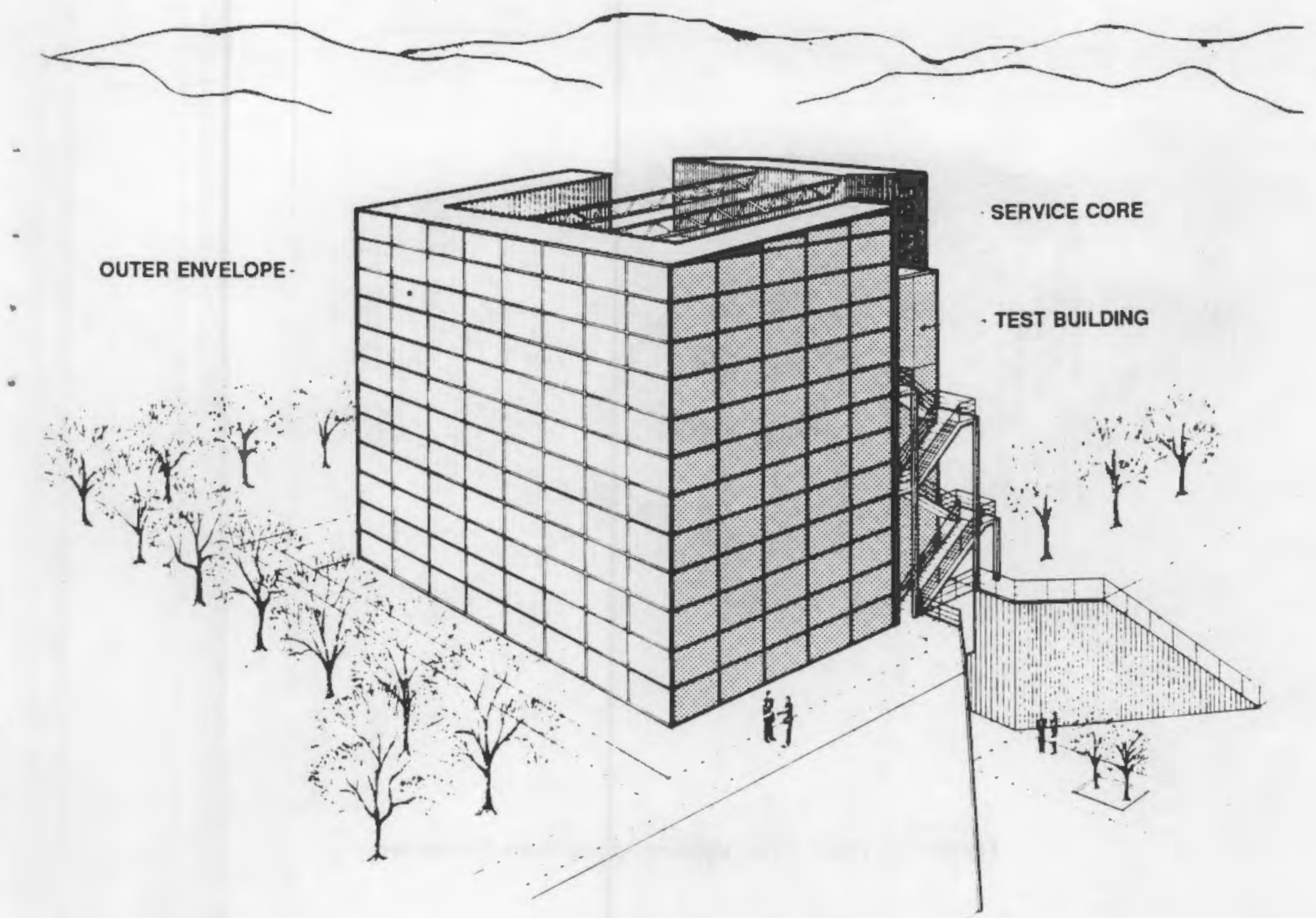

Figure S.2. Phase 1 Test Building Architectural Perspective 

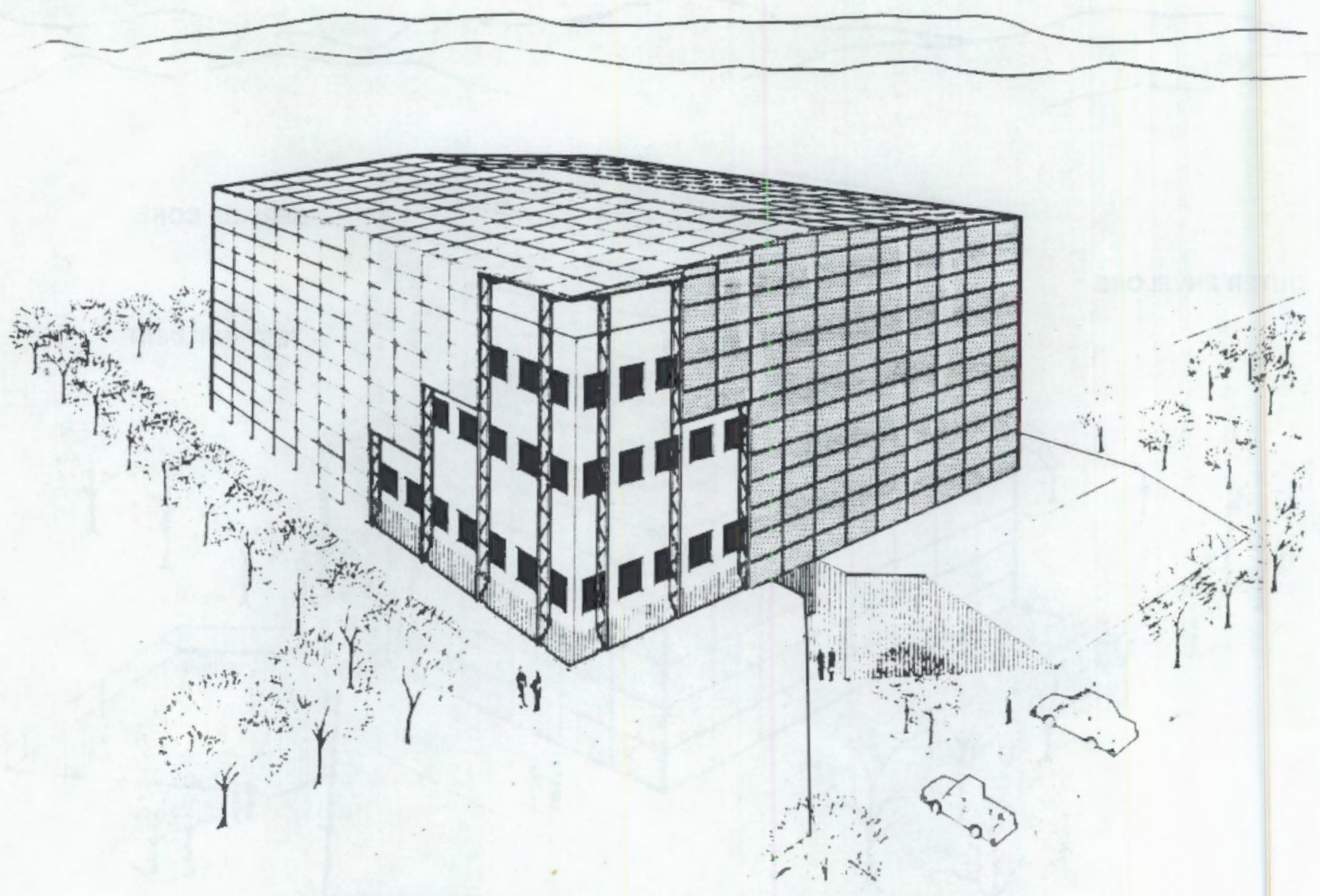

Figure S.3. Phase 3 Test Building Architectural Perspective 


\section{CONTENTS}

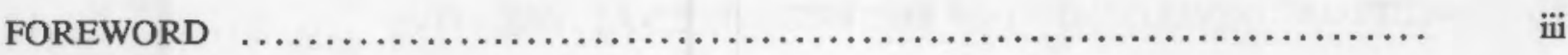

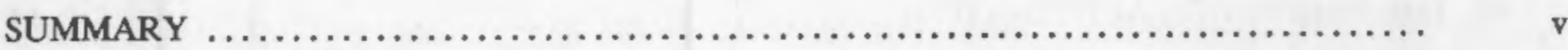

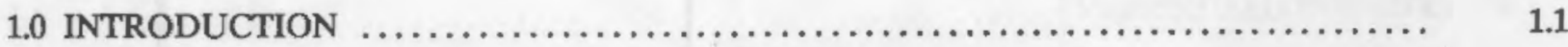

1.1 FEASIBILITY STUDY GOALS AND OBJECTIVES $\ldots \ldots \ldots \ldots \ldots \ldots \ldots \ldots \ldots \ldots \ldots \ldots \ldots$

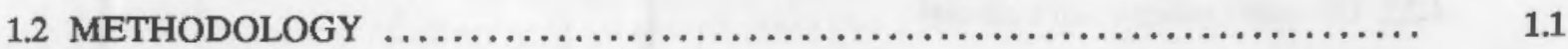

1.3 REPORT ORGANIZATION $\ldots \ldots \ldots \ldots \ldots \ldots \ldots \ldots \ldots \ldots \ldots \ldots \ldots \ldots \ldots \ldots \ldots \ldots \ldots \ldots \ldots \ldots \ldots \ldots, 1.2$

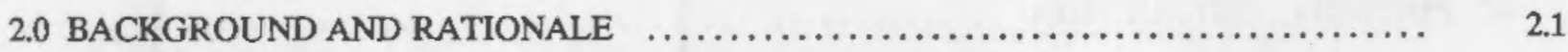

2.1 NEED FOR SYSTEM INTEGRATION RESEARCH $\ldots \ldots \ldots \ldots \ldots \ldots \ldots \ldots \ldots \ldots \ldots \ldots \ldots \ldots \ldots \ldots$

2.2 BUILDING SYSTEM INTEGRATION RESEARCH PROGRAM $\ldots \ldots \ldots \ldots \ldots \ldots \ldots \ldots$

2.3 FEDERAL ROLE IN BUILDING SYSTEM INTEGRATION RESEARCH $\ldots \ldots \ldots \ldots \ldots .2 .2$

2.4 BENEFITS OF EXPERIMENTAL RESEARCH AND AN

EXPERIMENTAL FACILITY $\ldots \ldots \ldots \ldots \ldots \ldots \ldots \ldots \ldots \ldots \ldots \ldots \ldots \ldots \ldots, 2.2$

3.0 BUILDING SYSTEM INTEGRATION EXPERIMENTAL FACILITY

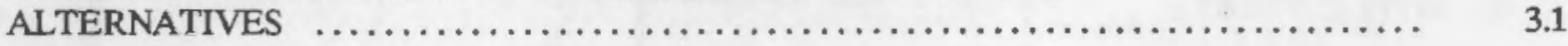

3.1 EXPERIMENTAL RESEARCH SCOPE $\ldots \ldots \ldots \ldots \ldots \ldots \ldots \ldots \ldots \ldots \ldots \ldots \ldots \ldots \ldots \ldots \ldots \ldots \ldots \ldots$

3.2 FOUR ALTERNATIVES FOR ACCOMMODATING EXPERIMENTAL
RESEARCH $\ldots \ldots \ldots \ldots \ldots \ldots \ldots \ldots \ldots \ldots \ldots \ldots \ldots \ldots \ldots \ldots \ldots \ldots \ldots \ldots \ldots \ldots \ldots \ldots \ldots \ldots$

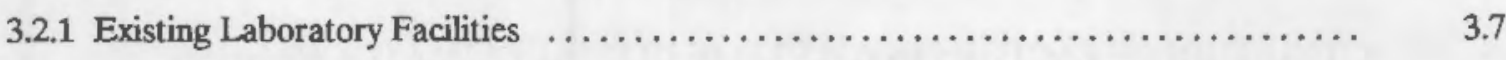

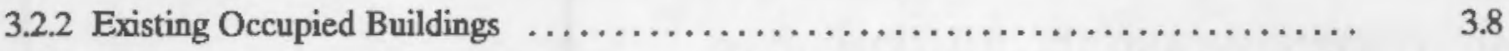

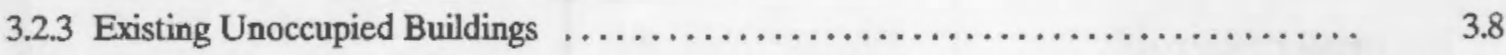

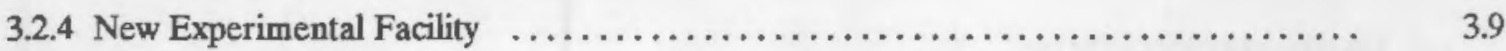

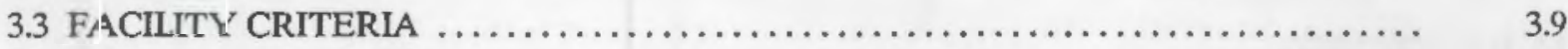

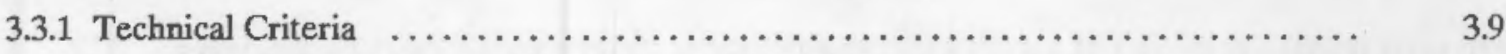

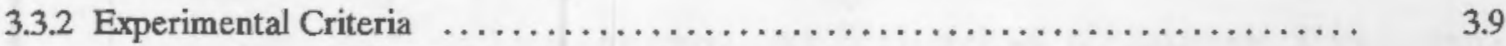

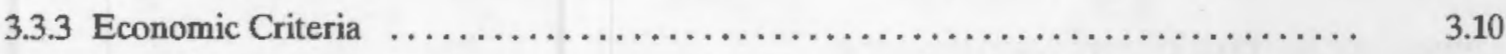

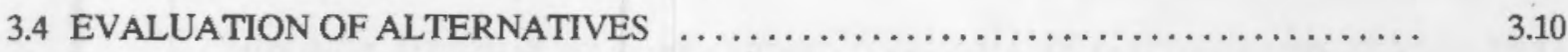

3.4.1 Existing Research Facility $\ldots \ldots \ldots \ldots \ldots \ldots \ldots \ldots \ldots \ldots \ldots \ldots \ldots \ldots \ldots \ldots \ldots \ldots \ldots, \quad 3.10$

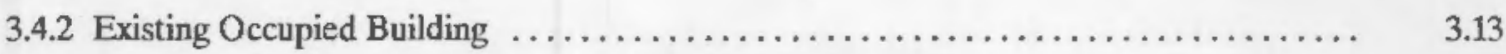

3.4.3 Existing Unoccupied Building $\ldots \ldots \ldots \ldots \ldots \ldots \ldots \ldots \ldots \ldots \ldots \ldots \ldots \ldots \ldots \ldots \ldots \ldots \ldots \ldots \ldots \ldots, \quad 3.15$ 


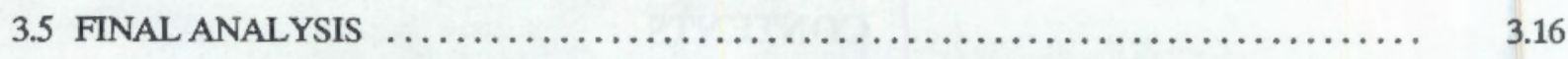

4.0 CONCEPTUAL DEVELOPMENT OF THE PREFERRED ALTERNATIVE $\ldots \ldots \ldots \ldots .4 .1$

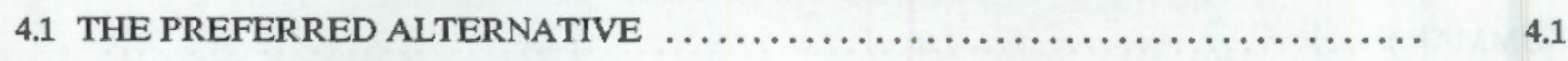

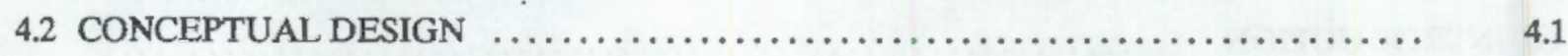

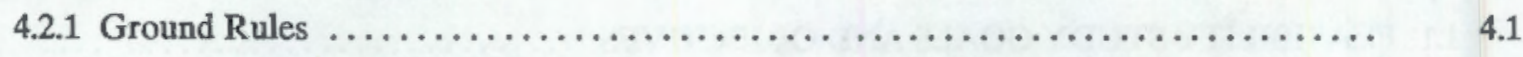

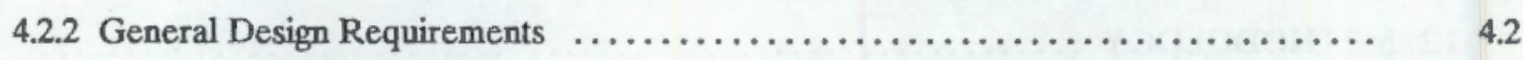

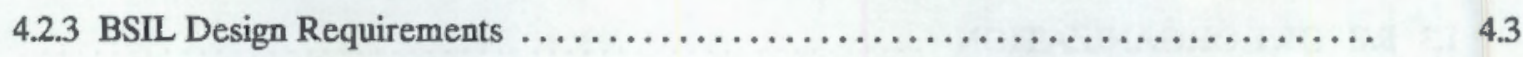

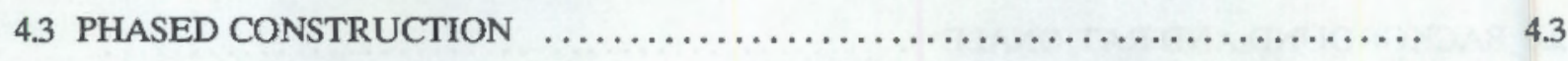

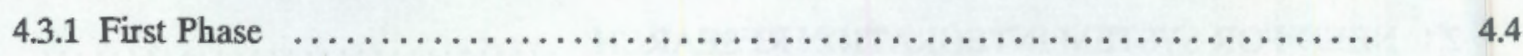

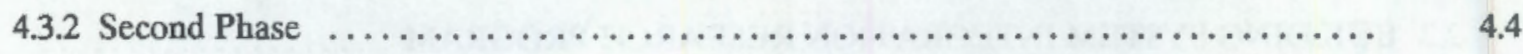

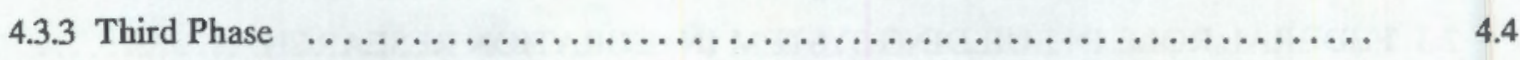

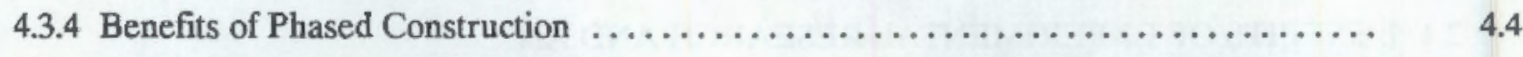

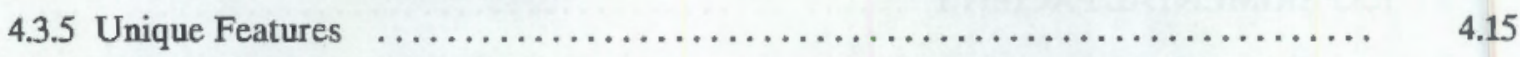

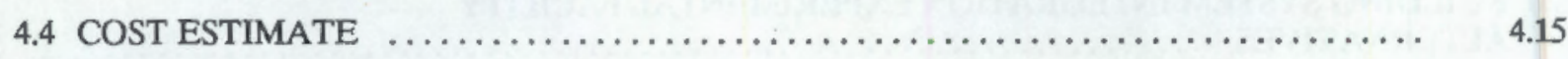

5.0 BENEFITS OF BSIL RESEARCH $\quad \ldots \ldots \ldots \ldots \ldots \ldots \ldots \ldots \ldots \ldots \ldots \ldots \ldots \ldots \ldots \ldots \ldots \ldots \ldots \ldots \ldots \ldots \ldots \ldots \ldots$

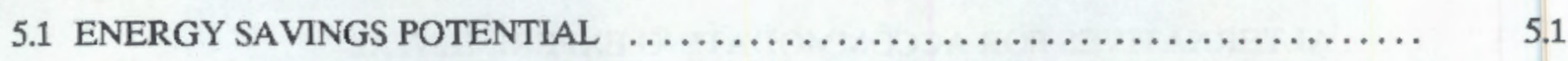

5.2 IMPROVED INTERNATIONAL COMPETITIVENESS $\ldots \ldots \ldots \ldots \ldots \ldots \ldots \ldots \ldots \ldots \ldots \ldots \ldots \ldots$

5.3 MITIGATION OF FACTORS INVOLVED IN GLOBAL CLIMATE CHANGE $\ldots \ldots \ldots \quad 5.1$

6.0 CONCLUSIONS AND RECOMMENDATIONS $\ldots \ldots \ldots \ldots \ldots \ldots \ldots \ldots \ldots \ldots \ldots \ldots \ldots \ldots \ldots \ldots \ldots \ldots \ldots \ldots$

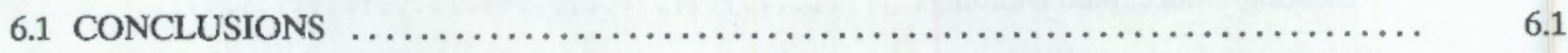

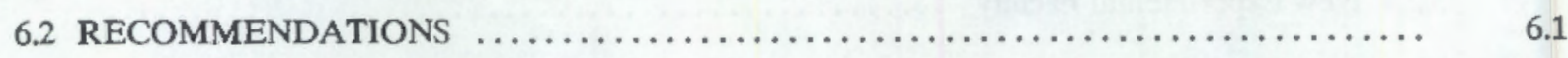

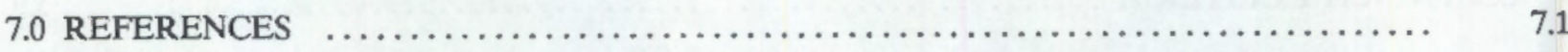

8.0 BIBLIOGRAPHY - BUILDING SYSTEM INTEGRATION RESEARCH REPORTS $\ldots \ldots . \quad 8.1$

APPENDIX A - TECHNICAL REVIEW PANEL PARTICIPANTS $\ldots \ldots \ldots \ldots \ldots \ldots \ldots \ldots \ldots \ldots \ldots \ldots \ldots$

APPENDIX B - THE DESIGN WORKSHOP $\ldots \ldots \ldots \ldots \ldots \ldots \ldots \ldots \ldots \ldots \ldots \ldots \ldots \ldots \ldots \ldots \ldots \ldots \ldots \ldots \ldots \ldots \ldots$

APPENDIX C - CONCEPTUAL DESIGN AND COST ESTIMATE FOR THE BUILDING SYSTEM INTEGRATION LABORATORY $\ldots \ldots \ldots \ldots \ldots \ldots \ldots \ldots \ldots \ldots \ldots \ldots \ldots \ldots \ldots \ldots$ C.1 


\section{FIGURES}

S.1 Building System Integration Research $\ldots \ldots \ldots \ldots \ldots \ldots \ldots \ldots \ldots \ldots \ldots \ldots \ldots \ldots \ldots \ldots \ldots \ldots \ldots \ldots$

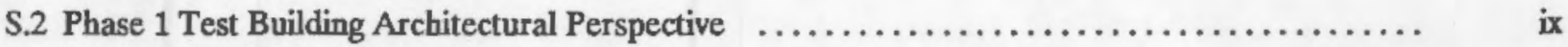

S.3 Phase 3 Test Building Architectural Perspective $\ldots \ldots \ldots \ldots \ldots \ldots \ldots \ldots \ldots \ldots \ldots \ldots \ldots \ldots \ldots \ldots \ldots \ldots, \quad x$

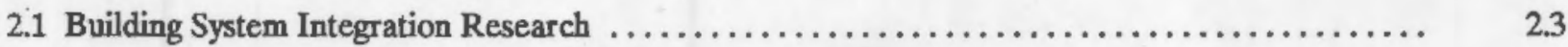

2.2 Comparison of Energy Consumed by Current-Practice Buildings and Buildings with Integr ated Systems $\ldots \ldots \ldots \ldots \ldots \ldots \ldots \ldots \ldots \ldots \ldots \ldots \ldots \ldots \ldots \ldots \ldots \ldots \ldots \ldots \ldots \ldots, 2.4$

4.1 Conceptual Design of the Building System Integration Laboratory $\ldots \ldots \ldots \ldots \ldots \ldots \ldots \ldots \ldots \ldots \ldots \ldots \ldots$

4.2 Architectural Perspective, Phase $1 \ldots \ldots \ldots \ldots \ldots \ldots \ldots \ldots \ldots \ldots \ldots \ldots \ldots \ldots \ldots \ldots \ldots \ldots \ldots \ldots \ldots \ldots, 4.5$

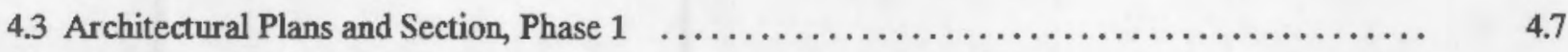

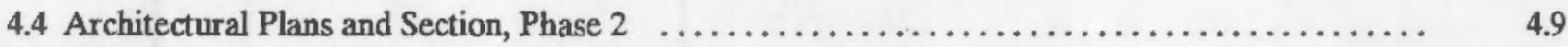

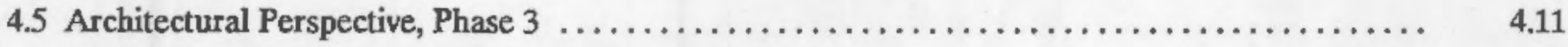

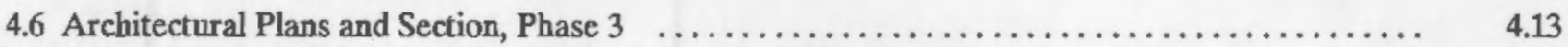

5.1 Building Energy Consumption by Share of Source Fuel, 1984 and $2010 \ldots \ldots \ldots \ldots \ldots \ldots \ldots \ldots$

\section{TABLES}

3.1 Facility Capabilities Required for Building System Integration Research $\ldots \ldots \ldots \ldots \ldots \ldots \ldots \quad 3.2$

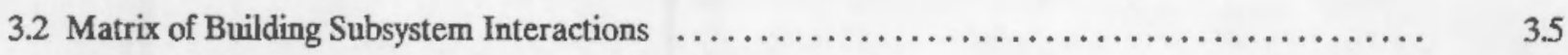

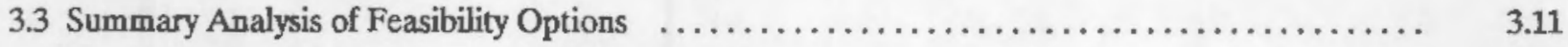

3.4 Estimated Cost of Alternative Facility Concepts $\ldots \ldots \ldots \ldots \ldots \ldots \ldots \ldots \ldots \ldots \ldots \ldots \ldots \ldots \ldots \ldots \ldots$

4.1 The Impact of Phased Construction on the BSIL Research Agenda ................. 4.15

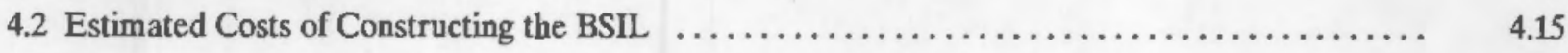




\subsection{INTRODUCTION}

More than $36 \%$ ( 26.9 quads) of the nation's primary energy was consumed in providing services to residential and commercial buildings in 1985 (Office of Buildings and Community Systems 1988). This is equivalent to 12 million barrels of oil per day or the power output from nine hundred 500 -megawatt coal-fired power plants. Although conservation is helping to reduce energy consumption in buildings, the consumption of primary energy is still expected to rise an additional 41\% between 1985 and 2010 (Office of Policy, Planning and Analysis 1985). Obviously, buildings offer a substantial potential for improved energy efficiency with all of the attendant benefits such as improved energy security, improved balance-of-trade, and reduced impact on climatic change.

Past research on building components and subsystems has produced incremental improvements in building energy efficiency. For example, buildings constructed in 1986 will use an average of $5 \%$ to $10 \%$ less energy than comparable buildings built in 1976 (Pacific Northwest Laboratory 1986). However, additional energy efficiency depends on more fundamental improvements. Building system integration research offers the potential for fundamental change. Studies have shown that well-designed buildings usiug integrated systems can reduce energy consumption by between $30 \%$ and $50 \%$ (Stoops et al. 1984).

In recognition of the importance of system integration research, the U.S. Department of Energy (DOE) Office of Buildings and Community Systems (OBCS) established a program to research building system integration. Substantial progress has been made, but additional improvements in building energy efficiency depend on a better understanding of building subsystems interactions. The requirement for experimental investigations of complete integrated subsystems operating with multizone space demonstrated the need for a facility capable of simultaneously testing multiple, full-sized building subsystems.

In fiscal year 1988, the United States Congrcss mandated a study of the feasibility of establishing a laboratory dedicated to research on building system integration issues. In response to that mandate,
DOE requested the Pacific Northwest Laboratory $(\mathrm{PNL})^{(\mathrm{a})}$ to conduct the feasibility study of a Building System Integration Laboratory (BSIL). This report documents the PNL study.

\subsection{FEASIBILITY STUDY GOALS AND OBJECTIVES}

The goal of the study was to determine the technical and economic feasibility of establishing a building system integration experimental facility and to develop a conceptual design of a whole-building system integration laboratory. This was accomplished by achieving three primary objectives:

- Determine the need for an experimental facility. The feasibility study explored whether a need exists for such a facility. Answers were sought for two related questions: Is building system integration research required? If so, would an experimental facility significantly contribute to advancing research goals?

- Explore several alternatives. Four alternatives were investigated to determine which was most viable in terms of the relevant economic and technical criteria established by the determination of need.

- Develop a conceptual design and cost estimate for a preferred alternative. If a research laboratory is needed, what should it look like? How much would it cost? Would that cost be reasonable in light of the benefits the experimental facility would yield?

\subsection{METHODOLOGY}

The feasibility study consisted of two activities: review of system integration research needs and development of a conceptual design and cost estimate for the BSIL. A technical review panel assembled by DOE assisted in the completion of both activities.

(a) Operated by Battelle Memorial Institute for the U.S. Department of Energy under Contract DE-AC06-76RLO 1830. 
Valid assessment of a multidiscipline facility such as the BSIL depends on having a wide range of technical advice on building system integration research needs and techniques. The technical review panel was assembled by DOE to ensure that the feasibility study considered the most complete and accurate information on these subjects. The panel comprised representatives from professional societies, universities, equipment manufacturers, and laboratories involved in buildings research.

Building system integration research needs were evaluated by reviewing the status of research in this area and determining where additional research is required. The assessment of research needs included a review of current research activities and advice from the panel.

The conceptual design and cost estimate were produced by an architectural/engineering company, Kaiser Engineers, based on a set of functional criteria developed by PNL in conjunction with the technical review panel. These functional criteria, presenting the design requirements for the BSIL, were developed from the capabilities required to meet the building system integration research needs identified by the review of current research activities.

\section{REPORT ORGANIZATION}

The needs for building system integration research and an experimental facility are discussed in Section 2. In Section 3, four options for conducting building system integration research in an experimental facility are presented and analyzed. Design and cost estimates for the preferred alternative are described in Section 4. The long-term effects and benefits of an experimental facility are discussed in Section 5. Conclusions and recommendations of the study are noted in Section 6.

Detailed supporting information is contained in three appendixes. The technical review panel mernbers and their affiliations are listed in Appendix A. The results of a design workshop in which concepts were developed for the preferred alternative are presented in Appendix B. The architect/engineer's report on the conceptual design and cost estimate is presented in its entirety in Appendix C. 


\subsection{BACKGROUND AND RATIONALE}

The energy consumed by buildings is a very large part of the total energy consumption in the U.S. economy. In 1987, residential and commercial buildings consumed over $36 \%$ of all energy consumed in the United States. This is equivalent to 12 million barrels of oil per day or the power output from nine hundred 500-megawalt coal-fired power plants.

Between 1975 and 1987, energy use per square foot dropped by $25 \%$ in new residential buildings and by $13 \%$ in new commercial buildings (Energy Information Administration 1989, p. 39, Table 13). However, because of the predicted large increase in residences and commercial building square footage between now and the year 2010, building energy use is predicted to increase by $41 \%$. Therefore, something must be done to curb energy use and still allow for the predicted growth of the sector.

This section provides important background for the need to take such action. In addition, it describes a DOE research thrust designed to help meet that need.

\subsection{NEED FOR SYSTEM INTEGRATION RESEARCH}

Although the number of residences has increased by $22 \%$ in the last 12 years, residential primary energy consumption has risen by only $4 \%$, mainly because of a $25 \%$ reduction in heating energy use. Higher prices for energy have also played a role, but a greater interest in saving energy and the use of energy-conserving products, such as insulation, better windows, and more efficient furnaces and heat pumps, have become marketable items for home builders.

A few homes have been constructed to use $50 \%$ to $70 \%$ less heating energy, but most homes built today do not. Therefore, a significant potential still exists. With the large increase in electrical energy use in southern-tier states, builders are looking for ways to reduce cooling energy use. Studies indicate that a similar $50 \%$ to $70 \%$ reduction is possible.
Over the same 12-year period, commercial floor space increased by $30 \%$ while primary energy consumption grew by $24 \%$. Therefore, newer commercial buildings have not achieved the same efficiency as newer residential buildings. There are many reasons for this: energy costs are passed on to tenants; technological advances are more rapid in residential-size equipment and energy conservation measures; and commercial buildings are much more complex and, hence, harder to design, construct, and operate.

Making advances in building energy conservation is difficult because of the way in which buildings are designed, tested, and constructed. Consider the differences between the typical design and construction of commercial buildings and automobiles. Automobiles go through several cycles of design and are extensively tested and evaluated before they enter the marketplace. In addition, their lifetime is short. Once on the market, cars are independently tested and reported on by consumer magazines. This information is then fed back into the design process. Conversely, commercial buildings are uniquely designed and built; a building's lifespan is 5 to 10 times that of an automobile. There is no testing or evaluation of design and construction beforehand; that would be cost-prohibitive. Nor is there any postoccupancy testing of a building's performance. Any advances in design or construction techniques penetrate the market very slowly when compared to the automobile industry. Therefore, it is inportant that designers and builders have good advance information to optimally select, integrate, and interface building components. The role of the DOE Building System Integration Research Program has been to develop and transfer such information.

\subsection{BUILDING SYSTEM INTEGRATION RESEARCH PROGRAM}

Building system integration research studies how the interactions of multiple building subsystems (such as the building envelope, equipment, and lighting), occupants, and climate affect the amount of energy a building uses. The goal of the research 
is to maximize the cost-effective use of energy in buildings by understanding and quantifying the energy flows between and among building subsystems so that they may be optimized on a whole-building life-cycie cost basis instead of by analyzing subsystems individually.

The objectives of the DOE building system integration research are

- to provide the experimental means to understand and quantify the energy flows among building subsystems so that they may be optimized on a wbole-building basis (instead of on a subsystemby-subsystem basis)

- to provide the means to develop, test, and document the performance of new building subsystems that synergistically combine to provide more efficient use of energy in buildings

- to provide verification of and improvements to the energy computer simulation programs that model the performance of these interactions and advanced concepts through the detailed and applicable understanding of the physics of energy transport through buildings.

Figure 2.1 illustrates the relationship of building system integration research to other types of building sciences research. At the first level is material and component research that improves the performance of individual building materials and components such as insulation, lamps, and heat pumps. The second level of research considers these elements combined into subsystems, such as the building thermal envelope, lighting, and heating, ventilating, and air conditioning (HVAC) subsystems. The third level of interaction (and complexity) is building system integration research that seeks to optimize the energy efficiency of all building subsystems in an effective whole-building system.

\section{FEDERAL ROLE IN BUILDING SYSTEM INTEGRATION RESEARCH}

Considerable privately-sponsored research is done at the first and second levels shown in Figure 2.1 because it leads to new products, equipment, and materials. For example, the insulation and lighting industries have responded to higher energy prices by improving and marketing more efficient products. There is also substantial governmentsponsored research in these areas. For 15 years, DOE has funded programs that have been directed at technology and product innovation, such as heat pumps, windows, materials testing, and new lamps and ballasts.

At the third level, however, very little private research is under way because there has been no focal point for this type of research. Improvements are likely to require changing more than the product line of a single manufacturer. Companies are more likely to concentrate on their own products and profitability. Consequently, there is less opportunity for a single vendor to benefit from the system integration improvements. However, the potential remains for energy and cost savings from the optimal synthesis of components and materials into an integrated working building. The problem is discovering which changes to building design, construction, and operation make the most energy sense and then working with a cross section of industries that would have to inplement the changes to make them work. DOE is the only focal point for this type of broad research.

Preliminary examinations demonstrate that the energy requirements of commercial buildings can be cut by more than half through a better understanding of system integration. These advances would have little or no effect on first cost if properly selected building subsystems are integrated into the design process (Stoops et al. 1984). Figure 2.2 compares the energy consumption of well-designed buildings with integrated subsystems to that of several buildings using current practices. If this level of energy savings were realized in the existing commercial building stock, 3 to 6 quads of energy could be saved each year. In new construction, the energy savings would be 3 to 4 quads per year by the year 2010.

\subsection{BENEFITS OF EXPERIMENTAL RESEARCH AND AN EXPERIMENTAL FACILITY}

The current Building System Integration Research Program consists of three components: 1) simulating the thermal interactions of innovative integrated building system designs; 2) simulating building performance in the development of "energy 


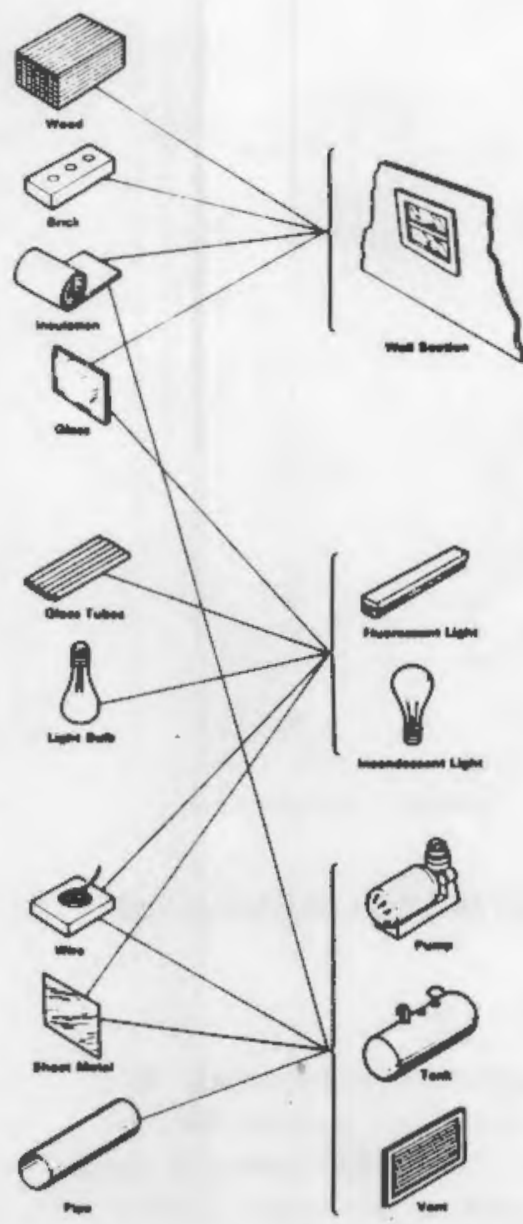

Materials

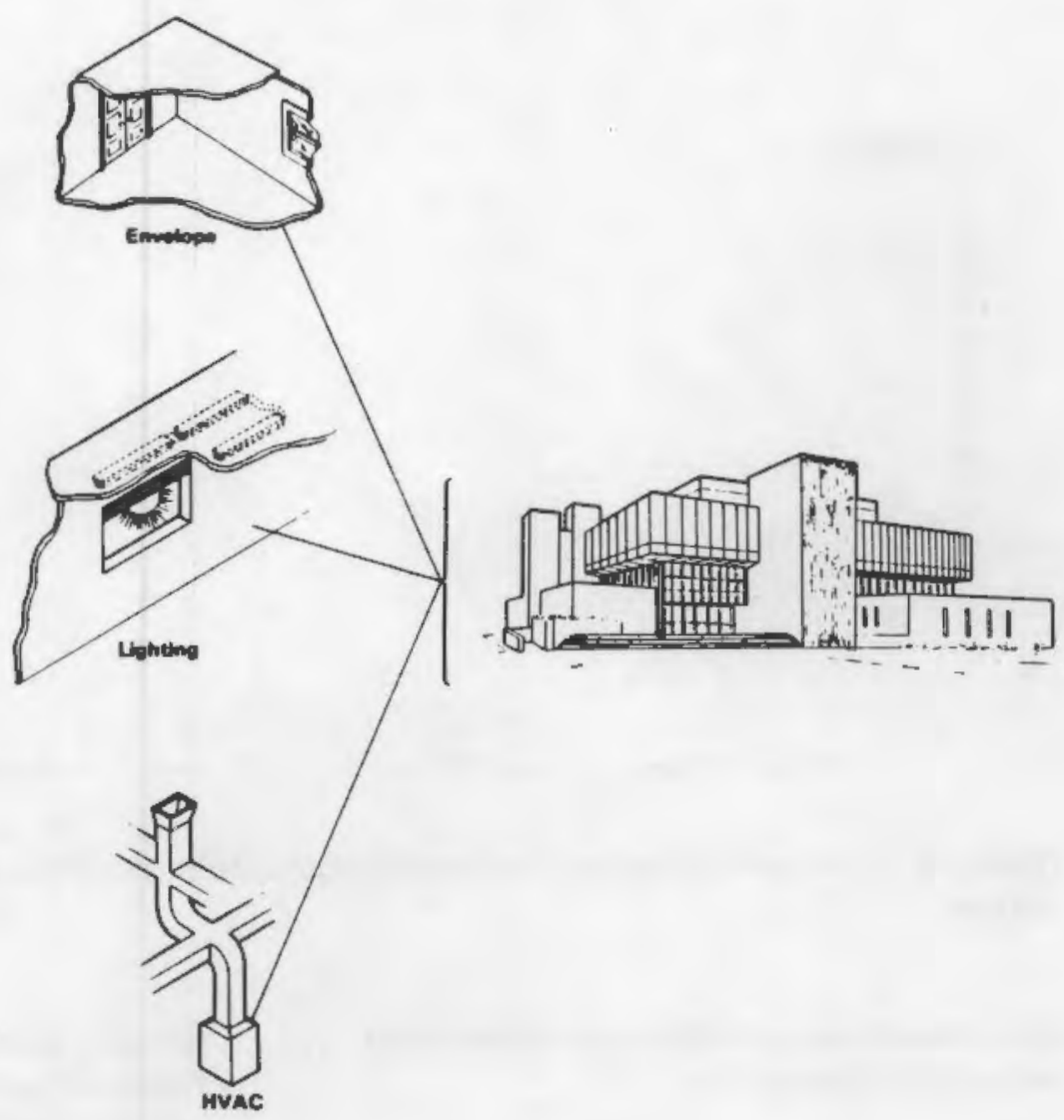

Subryatoms
Building System

Figure 2.1. Building System Integration Research

use targets"; and 3) developing advanced computer simulation codes and knowledge-based computer systems for building design and operation. All three activities depend on computer simulation, and it is becoming increasingly necessary to complement these activities with experimental investigations. The computer models are based on theoretical assumptions; their output is only as good as the data that creates them.

Building simulation tools have significantly advanced the building design process. However, numerous studies have shown that actual energy use of buildings exceeds the energy use predicted by the simulation tools, frequently by more than $50 \%$ (Norford et al. 1986; Piette 1986). The greatest difference occurs where there is an attempt to model new design approaches. Recent research has shown that simulations do not accurately predict where energy is used in a building (Heidell and Taylor 1985). These findings undermine the confidence of innovative building designers in these tools when they wish to use them for other than conventional design solutions. Experimental building system integration research can improve simulation tools by developing new models for building subsystem interactions and by more accurately characterizing critical variables. The significant energy savings potential discussed in this report represent fundamental changes from current design and construction practice that have not yet become common practice. Common practice will change only when 


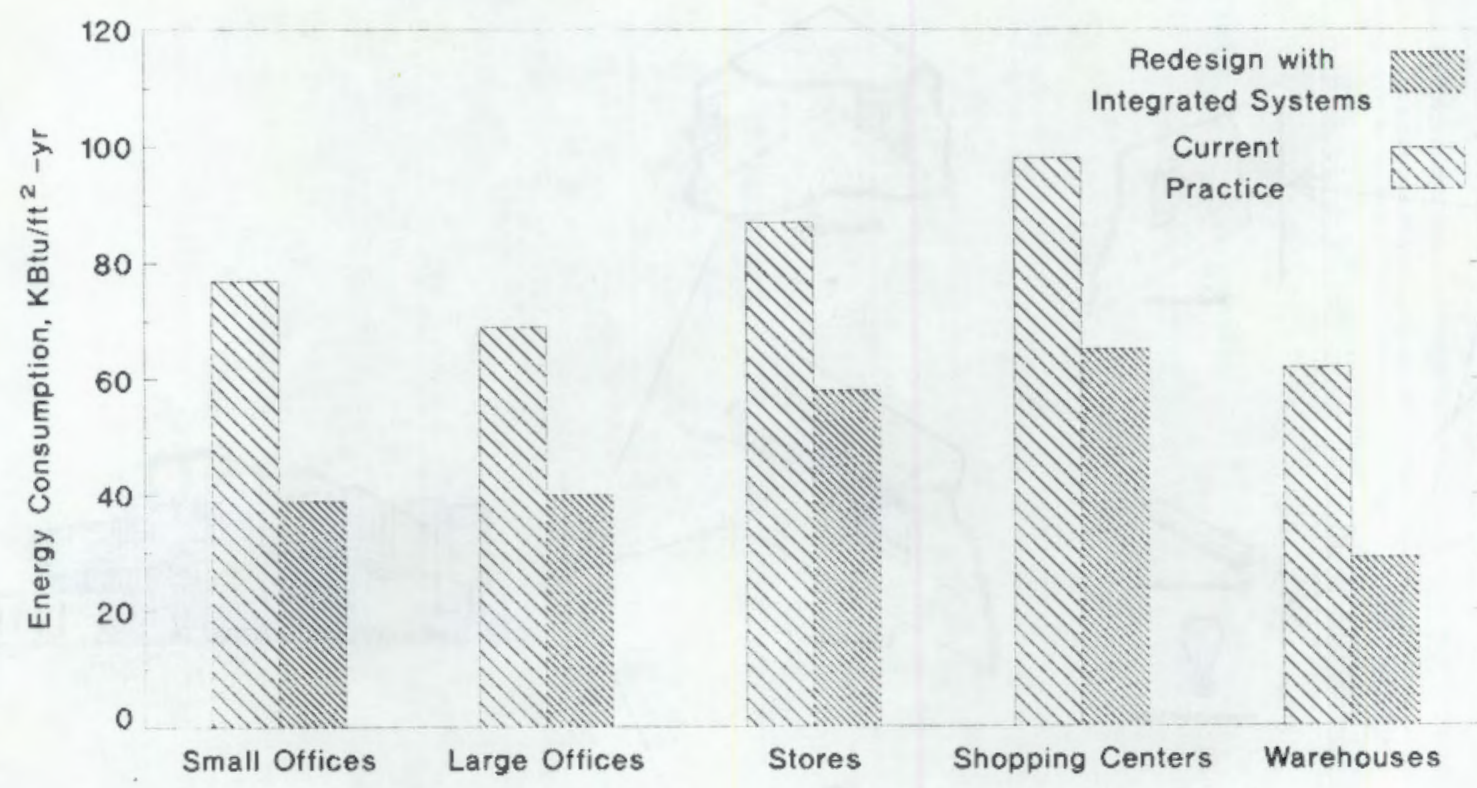

Figure 2.2. Comparison of Energy Consumed by Current-Practice Buildings and Buildings with Integrated Systems

designers have more confidence in research data and computer design tools.

An example of a design strategy with good but yet unproven energy conservation potential is a water loop heat pump that uses the mass of a structure for thermal energy storage (Marseille et al. 1989). This concept may not meet existing building codes and standards because it varies so much from current practice. Building designers are reluctant to use such innovations as the water loop heat pump based only on the results of computer simulation. Acceptance of fundamental change in design and construction practice by the building community is more likely to occur when data is available from experimental testing that demonstrates the viability and reliability of new products and systems.

A building system integration experimental facility is needed to advance and complement the existing research program in building system integration. This facility would be the nation's primary site for building system integration research.

A building system integration experimental facility is a research facility capable of identifying and characterizing the energy interactions of multiple, full-scale building subsystems to determine the functional energy relationships between the subsystems. System integration experimental research conducted in a dedicated experimental facility would benefit the energy performance of new buildings in several significant ways:

- The building industry would gain an understanding of building physics and integrative issues through testing conducted under actual conditions. This would help alleviate the industry's skepticism about the DOE research based solely on computer analysis.

- Incremental improvements can result from studies using current computer simulation programs and on what is learned by monitoring existing buildings. However, new breakthroughs will need the capabilities of an experimental facility where controlled conditions can be established and experiments conducted that can apply to many occupancy and climatic patterns.

- An experimental facility would enable researchers to isolate subsystem effects and other subsystem unknowns. 
- An experimental facility would provide the capability for testing concepts not currently allowed by building codes and standards.

- An experimental facility would serve as a test bed for new systems, providing a valid way of proving the technology for innovative systems. The information derived from experiments in closely monitored actual applications would belp reduce designer reluctance and, thus, could speed the entry into the marketplace for most new building technologies.

- An experimental facility could be used to study and develop intelligent building controls. While many companies offer lighting and HVAC controls that could potentially save a great deal of energy, designers are still reluctant to use the controls because little information has been published on how to properly design for and place such controls.

- The concepts to develop the so-called "Zero Energy Use" buildings of the future can be studied only on a whole-building level.

Without such an experimental facility, the transfer of technology from conceptual idea to commercial reality would probably not occur for radically new subsystem integration concepts, because they will engender high risk and very likely will not fit within the product line of a particular sector of the building industry. This role within the DOE Building System Integration Research Program is the primary justification for the building system integration research facility. 


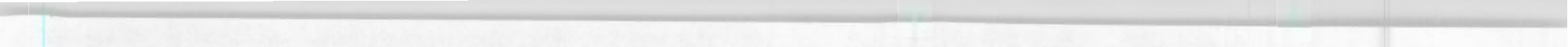




\subsection{BUILDING SYSTEM INTEGRATION EXPERIMENTAL FACILITY ALTERNATIVES}

\begin{abstract}
A four-step approach was used to identify and evaluate alternatives for providing an experimental facility for building system integration research: 1) develop the scope of experimental research that needs to be carried out; 2) establish alternative approaches for conducting that research; 3 ) establish criteria for evaluating the alternatives; and 4) evaluate the alternatives. These four steps are described in this section.
\end{abstract}

\subsection{EXPERIMENTAL RESEARCH SCOPE}

A technical review panel was convened; its membership comprised industry representatives, academic and government researchers, and research administrators (see Appendix A). The panel developed a research agenda of candidate building system integration research tasks that would benefit from the establishment of a building-scaled experimental facility, formulated an approach to accomplish the tasks, and developed specific criteria for a building system integration experimental facility. This information was then reorganized in terms of research categories being used in the current Building System Integration Research Program.

Several steps were taken in formulating the research agenda. Before they met, the panel members were sent a questionnaire asking them to list important system integration research issues. A summary was prepared using the questionnaire responses. In a workshop session, the panel refined the list of research issues. Building system integration research needs were evaluated by reviewing the status of current research and determining what additional research is required. The panel then developed a formal research agenda and an assessment of the effects of an experimental facility on such research (Drost, Johnson, and Crawley 1989). The purpose of the research assessment and agenda was to determine if there are sufficient meaningful building system integration research topics to continue the research program and to further explore the need for an experimental facility.

The formal research agenda was composed of seven research activities:
1. HVAC design and selection for optimized building performance - This research would produce a methodology for addressing the HVAC subsystems in an optimized building. PNL researchers have estimated that building system integration research in the heating, ventilating, and air conditioning area has the potential to reduce building energy consumption by 0.9 quad per year by the year $20000^{(z)}$ The research requires experiments to determine how the HVAC subsystems interact with other building subsystems, followed by the development of a procedure to optimize the HVAC subsystems in the context of the whole building operation, one in which the output of the HVAC subsystems is constantly varying as the result of the controls imposed upon them. This research product would help the HVAC industry produce energy-efficient designs that are based on a complete understanding of how the HVAC subsystems interact with the building envelope, structure, interior partitions (specifically the air flow patterns throughout the building), and lighting.

2. ventilation optimization procedure development - This research would analyze interzone air flows and develop procedures for maximizing air exchange in occupied zones while minimizing the use of ventilation air. Optimization of ventilation systems will become increasingly important because of growing concerns about indoor air quality. Increasing the use of outside air for ventilation will increase energy consumption.

3. testing integrated system designs - The goal of this activity would be to solicit and test innovative integrated building systems such as the waterloop heat pump subsystem integrated with thermal storage capability in the structure of the building.

4. analytical methods for transient effects - This research would analyze the fundamentals of transient effects, i.e., the rate of change of temperatures throughout the building as the result of

(a) 1987 draft report, Pacific Northwest Laboratory, Richland, Washington. 
changes in external temperatures, insolation, wind, HVAC input, and internal gains from equipment usage, and develop methods that describe the phenomena. Transient effects are not simulated well with the energy simulation computer programs currently available because of simplifying assumptions that are made to handle the analysis. Nevertheless, transient effects have a significant effect on system performance. Research on this issue would improve the building industry's capability to account for transient effects.

5. computer program code verification and algorithm development - This research would evaluate existing whole-building computer programs and use the experimental capabilities of the facility to develop new algorithms to improve computer program accuracy. Existing computer programs often give conflicting results. Improvements in the predictive capabilities of existing codes would markedly increase their usefulness.

6. testing of building components - This research would focus on the full-scale testing of building components in a facility capable of measuring the effect of the components on the whole building and its interacting subsysterns. A recurring problem in the building industry has been the difference between predicted and installed performance of building components. The development of more realistic test protocols for component testing would be a significant step toward eliminating this variation.

7. operation and eontrol strategy development The objective of this activity would be to develop and test innovative control strategies for integrated building systems. Specific activities would include improving control logic used in energy management and control systems. Research on control strategies is recognized as having great potential for improving building energy performance (Claridge 1986).

At a second workshop, attended by a subcommittee of the panel, a series of design criteria and concepts for an experimental facility was prepared.

This subcommittee identified how the proposed research agenda would influence the design of the experimental facility. The factors include the size, complexity, and frequency of modifications to the experimental facility; complexity of phenomena being investigated; required isolation from ambient conditions and other internal effects; number of subsystems being simultaneously tested; and limitations imposed by building codes and standards.

The factors were then grouped into three general categories: flexibility, control, and scale. Flexibility refers to the capability to test fundamental new concepts and the ease of making modifications so that a wide variety of experiments can be conducted. Control refers to the capability to ensure carefully managed experiments where both ambient conditions and internal design features can be monitored. Scale indicates that an experimental activity would best be conducted at or near full-scale.

The results of the categorization process are summarized in Table 3.1. Flexibility is required for six of the seven primary research activities. Control is required by all seven activities, while large-scale testing is desirable for five of the seven activities. These results showed that building system integration research will require all three capabilities: flexibility, control, and large scale.

A third workshop, attended by the full panel, was held to review the preferred conceptual design for a facility. This conceptual design was developed from the design criteria previously speeified. The panel recommended which items on the research agenda

Table 3.1. Facility Capabilities Required for Building System Integration Research

\begin{tabular}{|c|c|c|c|}
\hline \multirow[b]{2}{*}{ Research Activity } & \multicolumn{3}{|c|}{ Required Capability } \\
\hline & Flexibility & Control & Lange Scale \\
\hline HVAC optimization & $\mathrm{x}$ & $\mathbf{x}$ & $\mathrm{X}$ \\
\hline Ventilation optimization & $\mathrm{x}$ & $\mathrm{x}$ & $x$ \\
\hline $\begin{array}{l}\text { Integrated systems } \\
\text { testing }\end{array}$ & $\mathbf{x}$ & $\mathrm{X}$ & $\mathrm{x}$ \\
\hline Transient effects & $\mathrm{x}$ & $\mathrm{x}$ & - \\
\hline Code verification & - & $\mathrm{X}$ & $\mathrm{X}$ \\
\hline Component field-testing & $\mathrm{x}$ & $\mathrm{x}$ & - \\
\hline $\begin{array}{l}\text { Control strategy } \\
\text { development }\end{array}$ & $x$ & $\mathrm{x}$ & $x$ \\
\hline
\end{tabular}


required a facility built especially for experimentation as opposed to items that could be researched in existing laboratory facilities or in occupied or unoccupied leased buildings.

In a subsequent independent effort, a matrix of energy-related building subsystems was prepared to identify significant energy-related interactions (Table 3.2). The matrix identifies the interactions between only two subsystems. It does not consider more complex interactions between or among multiple building subsystems such as the interactions between windows, lighting, heating, ventilating, and cooling subsystems. It was felt that the matrix was sufficiently complete to establish reasonable criteria for an experimental faeility. This matrix was first used to reevaluate interactions identified by the technical review panel. The list was used to check the experimental requirements established by the panel. The interactions listed in Table 3.2 can be easily related to the research agenda identified by the technical review panel.

Most of the interactions listed in the matrix address the physics of energy interchange between subsystems. For example, the interaction between the HVAC subsystem and the building envelope subsystem involves the physics of heat transfer between convecting air, both forced and natural convection, and the building envelope and any internal surfaces of different air temperature. Another example, the interactions between internal building partitions and the building envelope, includes radiant heat transfer between two surfaces at different temperatures. The rigorous mathematical treatment of all the energy interchanges between subsystems would make the analysis extremely complex and unwieldy. Thus, one of the principal objectives of the experimental facility is to validate algorithms that are used in energy simulation computer programs as simplifying assumptions of the more rigorous mathematical expressions of the physics involved.

Similarly, there is a continual flux of energy between subsystems; i.e., the building is seldom at thermal equilibrium. However, most building energy computer programs do not analyze the energy situation as a transient but rather as a series of quasi-steady-state situations. This fact may contribute significantly to the poor capability of most of the computer programs to predict the energy use by individual subsystems.

A second objective of the experimental facility is to provide data to guide the development of improved transient analysis methods. More than half of the interactions noted in Table 3.2 are related to the energy exchange implications of air movement throughout the building. Again, the rigorous mathematical description of open air flow in buildings has received little research attention because of the complexity involved. Instead, algorithms approximating the effects of air movement have been used. The consequence has been an incomplete understanding of the performance of HVAC systems, as contrasted to HVAC components.

A third objective of the experimental facility is to develop the methodology to optimize HVAC subsystems in concert with the other building subsystems. At present, the methodology to evaluate the HVAC subsystem performance within the building environment, much less their optimal design, is not available.

Ventilation optimization is closely related to HVAC optimization because the efficiency of ventilation directly affects the ventilation air flow and the energy required to condition fresh air that is brought into the system. Although ventilation is an integral part of the HVAC subsystem and is not considered a separate optimized independently of the HVAC subsystem. Moreover, ventilation optimization will seemingly require the capability to describe the three-dimensional hehavior of open air flow, including the effects of temperature and concentration of various pollutants.

An integral part of optimizing the HVAC subsystem for the transient type of operation required in a large commercial building is the control strategies. Included in the successful operation and control strategy will also be consideration of humidity, indoor air quality, and occupant productivity. The development of innovative control strategies is a fifth objective of an experimental facility.

Because the matrix of two-system interaction in Table 3.2 does not include the interactions of more than two subsystems, it does not identify any 

Table 3.2. Matrix of Building Subsystem Interaction.

HIVAC

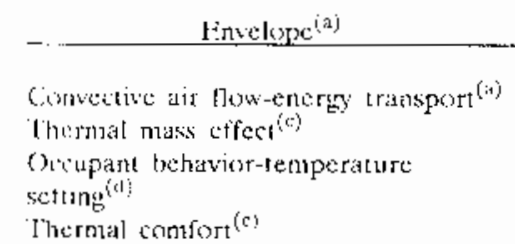

Service Walter Ileating

Thernal energy storige and
Iratsport

Windows

$$
\text { Eineryy gain/loss }(k)
$$

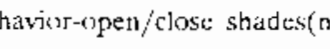

L.jphting

Partitions$$
\begin{aligned}
& \text { lighhing and encrgy distribution } \\
& \text { Occupant behavior-choicc of lighting }
\end{aligned}
$$$$
\begin{aligned}
& \text { Occupant belavior-choice of lighting } \\
& \text { source (ly? }
\end{aligned}
$$

Convective air flow-cnergy transpor (b)

Convective air flow-encrgy transpor
Thernal comfor ${ }^{(t)}$ Radiant heat
exchange

Thermal comfort
Thernal bridgigg
(t)

Ccilings/Floors

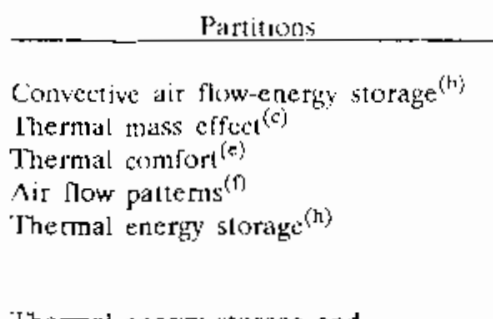

Thermal cheryy storage and

Solar encrgy transport and storage $e^{(0)}$

(inging as a

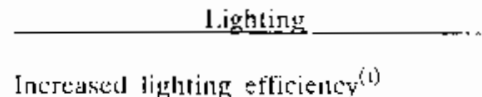

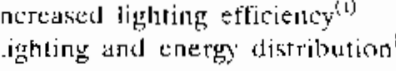

Themal mass effect
Themnal confort

Air now patterns ${ }^{(1)}$ Tenperalure

stratitication (k)

Thermal e
transport $^{(h)}$

Solar encrgy transport and storage ${ }^{(0)}$ Convective air flow
Thernal comfor ${ }^{(e)}$

Lightting and encrgy distribution ${ }^{(0)}$

Convective air now-energy trasport

Thernal comfort ${ }^{(e)}$ Radiant heat

Envelope column indudes occupant influcnec on subsystem interactions, where appropriate

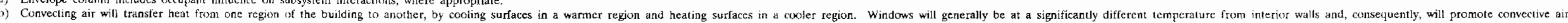

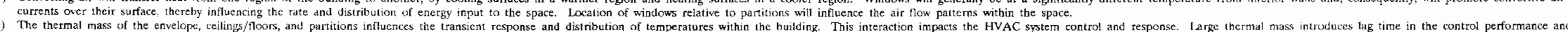

dampens tocupant

(e) Air temperatures requested/set by occunulsts are influenced by the teniperalures of enclosing surfaces (as well as air tempcrature) due to radiant heat loss/gain to the occupants.

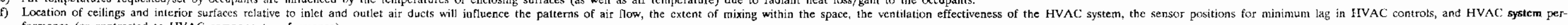

(g) Thermal stratification (warm air near the ceiling and cool ains

(the floor) may occur, reducing ventilation efficiency and affecling energy use unless provisions are made to either achieve complete air mixing (i.e., uniform temperaturc and compusition) in the space or achieve "plug flow"

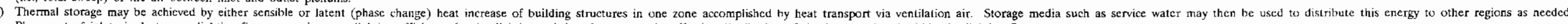

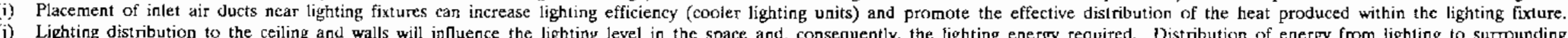

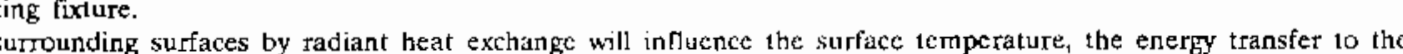

Windows generally differ significanilly from exterior walls with respect to thermal properrics. Insolation through windows will markedly affect energy distribution and utilization within the structure.

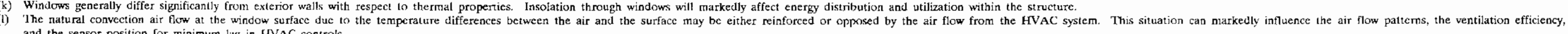

Wccupant behavior, eg the us windory surfaces may be teduced hy evapotation into the air flowing over the surface.

the opening of windows, will signiticantly affect the impact of windows on energy usc.

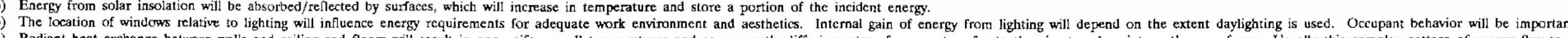
Connections between the ceiling/lloors and the envelope may form regions of tapid heat transport because materials may have higher thernal conductivities than surrounding regions, thus creating anomalous heat loss/gains in isolated locations. 
fundamentally new approaches for synergistic interactions berween subsystems. Nevertheless, a sixth and possibly the most important objective of the experimental facility would be the testing of subsystem arrangements that would involve fundamental changes from current design approaches. As an example, many commercial buildings have opposing heating and cooling demands between internal and perimeter spaces. They also frequently face perimeter demands for beating in the morning and cooling in the afternoon. The efficient storage of excess energy for later use or transfer to an area of demand can save significant energy. Using one subsystem to do multiple tasks, such as a water loop beat pump system integrated with thermal storage in the building's structural components, shows promise in making this possible. Other examples, listed without elaboration, include

- Laminar-flow ventilation, from plenums located in the floor and ceiling, to greatly improve ventilation efficiency and greatly reduce fresh air makeup

- heat pipes, perhaps built into the partitions to transport heat from one zone of the building to another with very low temperature difference, to keep the building more nearly isothermal.

A seventh objective of the experimental facility, as identified by the technical review panel, was the development of protocols for the testing of building components. Component testing can best be done in the whole-building environment, but a valuable test facility should not be tied up with testing of components. The more productive use of a wholebuilding experimental facility would be in developing test protocols that minimize, or account for, subsystem interactions. Actual component testing should bc conducted in smaller, existing facilities.

\section{FOUR ALTERNATIVES FOR ACCOM- MODATING EXPERIMENTAL RESEARCH}

Four alternative approaches to providing facilities for conducting building system integration experiments were developed as a basis for determining the feasibility of establishing an experimental faeility:
1. Use existing laboratory facilities.

2. Use existing occupied buildings.

3. Use existing unoccupied buildings.

4. Build a dedicated experimental facility called a Building System Integration Laboratory (BSIL).

The choice of options for conducting system integration research is controlled by the structural features and capabilities needed to conduct the research. The required capabilities include

- sufficient flexibility to enable testing of fundamentally new concepts, in contrast to concepts that involve only incremental change

- a structural design that ensures complete control of test conditions

- sufficient size to exhibit the thermal characteristics of commercial buildings.

In the following sections, each of the four altemative approaches is described. Included in these descriptions is the extent to which each alternative offers the required capabilities.

\subsubsection{Existing Laboratory Facilities}

The least expensive and most quickly available site for experimental building system integration research would be an existing research facility. For the testing of residential buildings, many such facilities exist across the country, at several universities, government laboratories, and industrial research facilities. As is explained later in this report, the technical review panel concluded that further study of a building system integration laboratory should be focused upon subsystem integration in commercial buildings. To operate efficiently, the existing facility would have to neet several criteria, including the basic criteria discussed above for a building system integration research facility. It would also requirc sufficient floor area and ceiling height to typify multizone transient behavior.

The major advantage to using an existing facility is that the capital cost of constructing or renovating a facility would be avoided. Further, experimental 
support facilities, such as fabrication shops, instrumentation calibration, and repair, would likely be readily available.

Several such facilities exist, although most can accommodate testing on only a small scale. For example, the Florida Solar Energy Center has a unique whole-house facility that is used to conduct passive solar research. The National Institute of Standards and Technology (NIST, formerly the National Bureau of Standards) has an environmental charnber in which building components can be tested. This facility is being used for a DOE-sponsored study of HVAC and lighting interactions in commercial buildings. The National Aeronautics and Space Administration has several environmental chambers, but they are constantly being used for hostile environment testing in the space program. Other laboratories have even smaller-scale facilities, such as the MoWiTT window test chamber at Lawrence Berkeley Laboratory.

With the exception of the Florida facility, existing building science research facilities are dedicated to investigating the interaction of only two subsystems as identified in Table 3.2. A search of university laboratories (American Consulting Engineers Council Research \& Management Foundation 1989) and fedcral laboratories found that no existing facilities satisfy the essential criterion for whole-building system integration research studies of commercial building size, i.e., the criterion of size to typify a representative commercial building's thermal response. Thus, existing laboratory facilities together would be able to carry out only a portion of the whole-building experimental research, and then primarily in residential buildings. The technical review panel considered what portion of the seven highpriority research activities could be carried out in existing facilities. The panel concluded that it would be more efficient and manageable to have a single experimental facility.

\subsection{Existing Occupied Buildings}

This option would incorporate the use of existing buildings having the desigo characteristics that are desirable for study. Portions of the buildings would be leased for experimentation. Instrumentation would be installed in the building, calibrated, and monitored either from a room(s) onsitc or over dedicated or periodically aecessed phone lines from a remote laboratory. Where comparisons between different combinations of building subsystems were of prime interest, multiple buildings would be sought. This could also be done by locating a building in which actual changes could be made to at least some of the building subsystems. For example, several floors might be rented and several different light fixtures types, HVAC terminal outlets, and ceilings might be installed for the series of experiments. In this alternative, it was assumed that building occupants would continue to work in their normal capacity. When the experiments were completed, the building would be returned to its original condition or its condition enhanced, per the provisions of the lease.

Using existing occupied buildings is enticing because the capital expenditure of construction is avoided, the scale of conditions to be studied is appropriate, and actual operating conditions do not have to be simulated. However, this option is less attractive than using existing laboratory facilities or building a new facility, because of 1) the administrative functions of locating and leasing suitable buildings; 2) the limitations on experimental control, experimental reconfiguration, and testing of noncode-approved technologies; and 3) the complexity of conducting experiments in multiple offsite facilities to address the desired range of systems and climatic conditions.

\subsubsection{Existing Unoccupied Buildings}

This alternative is similar to using existing occupied buildings except that the buildings would be unoccupied. The unoccupied building could be an existing structure or a new building designed to include combinations of building subsystems helpful for the experiments. The monitoring in this atternative would likely be done from within the facility or somewhere onsite. This alternative also presumes some ability to change the characteristics and combinations of building subsystems beyond what might be possible in occupied buildings. The building might be leased or purchased initially and then sold when the experiments were completed. The building could be a new federal building where rescarchers could provide initial inpul to the design process and then test the resulting building operation. However, federal buildings are built to support agency missions, and prompt occupancy is usually an overriding factor. The drawbacks of this option are 
the same as those for the existing occupied building option: 1) the administrative efforts required to locate and lease suitable buildings; 2) the limitations on experimental control experimental reconfiguration, and testing of technologies that do not meet current codes and standards; and 3 ) the complexity of conducting experiments in multiple offsite facilities.

\subsubsection{New Experimental Facility}

This option is similar to the first except that the facility would be built specifically for the research, or an existing facility would be substantially altered to meet the requirements of experimentation. This option assumes that ancillary support facilities would be included or located nearby. The drawbacks of this option are the initial capital funding required and the implied long-term commitment of operating funds.

\section{FACILITY CRITERIA}

Based on the analysis of the needed experimental research, criteria were developed against which to evaluate each of the four alternatives. The criteria were divided into three categories: technical, experimental, and economic. Technical criteria address such questions as size of facility, number of foors, flexibility of configuration, and type and combinations of subsystems. Experimental criteria addrcss instrumentation, monitoring, and control of experiments. Economic criteria consider the relative costs of each alternative.

\subsubsection{Technical Criteria}

The four alternatives were compared on the basis of three separate aspects of the technical criteria:

- the existence, availability, and constructability of the type of facility needed to carry out a significant part of the research agenda

- the nature of the barriers or restrictions that arc likely to exist with each alternative

- the flexibility to make configuration changes that are possible with each alternative.
The following are typical of the questions considered during the analysis of the four options:

- Existence, availability, and constructability - Do facilities or buildings with appropriate characteristics exist, and are they readily available for modification to accommodate building system integration experimental testing? This would include facilities or buildings that have been previously used for experimentalion on wholebuilding thermal effects. For those facilities or buildings identified, questions were asked regarding how they were obtained for experimentation, whether they were appropriate for experimentation, and what technical problems were encountered. In addition, the panel studied whether a new facility could be readily designed and constructed to meet the criteria.

- Restrictions on building use - Regulations common to existing buildings or facilities should not pose significant restrictions to the proposed experimental program. Were there restrictions (e.g., code and zoning restrictions) on existing buildings, that would make it difficult to locate or use them for experimental purposes?

- Flexibility to configuration changes - Facilities or buildings should have subsystems that can be readily changed or altered to facilitate experimentation. Is it possible or difficult to change or modify building subsystems to obtain comparablc results?

\subsubsection{Experimental Criteria}

The experimental criteria against which the four altematives werc evaluated were

- the case of obtaining supporting facilities

- thc ease of installing and maintaining instrumentation and maintaining the desired test environment

- the ease of setting up and breaking down experiments

- the degree of experimental control that could be achicved. 
Support Facilities. It was determined that support facilities should be available to house researchers and to be used to establish experiments, design and construct experimental apparatus, and calibrate and repair instruments and sensors.

Instrumentation, Monitoring, and Test Environment. Sensor installation, wiring, and maintenance should be readily accomplished. Monitoring, early detection of data errors and interruptions, and early correction of problems should also be readily accomplished. The desired test environment should be readily attainable and relatively unaffected by conditions in the rest of the building so that test conditions would be stable.

Sequential Operations. Experiments should be able to be readily set up and broken down. The physical arrangement of the facility should enable researchers to set up the experiments in a minimum amount of time.

Experimental Control. The physical design should enable researchers to isolate the experiments from extraneous factors and to control or isolate the variable factors so that their significance can be quantilied.

\subsubsection{Economic Criteria}

The three economic criteria for comparing the four alternatives were

- initial cost of the facility or building

- setup and decommissioning costs

- operating costs.

Initial Cost. The facility or building acquisition costs are those incurred in the design, construction, and remodeling or other preparation costs. If restoration to existing conditions is anticipated, that cost was also included.

Facility Setup Costs. Cost for setting up and decommissioning the experimental apparatus in each facility or building is included in this category. For facilities that are leased and not dedicated to the experimental program, this cost can be very significant.
Operating Costs. Included are leasing and experimentation costs: preparation, setup, instrumentation, monitoring, maintenance, breakdown, and changeover costs. Travel and per diem costs for staff on travel status for offsite testing are also included here.

\subsection{EVALUATION OF ALTERNATIVES}

The four alternatives were evaluated against the technical experimental, and economic criteria described in Section 3.3. The results of that evaluation are summarized in Table 3.3 and discussed in this section.

\subsubsection{Existing Research Facility}

\section{Technical Criteria}

Existence, Availahility, and Constructability. A number of building science researcb facilities are dedicated to investigating the interaction of two building subsystems in combinations as described in Table 3.2. The need for a facility to investigate the integration of the total building system was established by the technical review panel and confirmed by the process outlined in Section 3.1. The ideal accommodation would be an cxisting rescarch facility that offers sufficient floor area and ceiling height to typify multizone transient behavior. However, a search of university laboratories (American Consulting Ergineers Council Rescarch \& Management Foundation 1989) and federal laboratories was not successful in locating such a facility.

The following summarizes those portions of the building system integration research agenda that could be clone within existing facilities:

- HVAC oplimization methodology - in the developmeat and verification of models that allow optimization of HVAC systems in concert with other building subsystems, to investigate HVAC/ control and lighting/HVAC interactions, as well as solir gain impacts on HVAC performance

- ventilation optimization - studies of the effects of desigr alternatives on ventilation efficiency, the developments of an Lasy-10-use threc- 
Table 33. Sumnary Analysis of Feasibility Options

Alternative 1
Existing Research Facility

\section{IFCIINICAL CRIIIRIA}

Availability - No existing facilities with full capahility. Preliminary

\section{EXPERIMENIAI, CRTIRRI}

Existing facilities could be used where appropriate to conduct the

\section{BOONOMIC CRIERIA}

The use of existing research facilities to conduct the preliminary phases
building system integration research would be the most cost-effective

sulding system integration research would be
altemative for those portions of the program.
Aiternative 2
Fxisting Ocrupies

Availability - Principal criteria are sufficient plan area and height to hout $7000 \mathrm{fr}^{2}$ plan area minimum). Enerey-related choracteristis of haterials and subsystems must be known. Research would be limized by (a) to incremental changes

Use Restrictions - Potential conflicts with other tenants and

maintenance of test environment.

Mernbility to Configuration Change - Probable that retrofititing and the
ise of mullipile siles will bc required.

Suppont Facilities - Satisfactory if leased building is located near a university or rees.
operaling cosits.

Instrumentation, Monitoring, and Testing Ervironment - Depends on may conflict with normal building operations. Instrumentation difficult. Sequential Operations - Depends on arrangements with other tenants. May require short, intensive testing periods or long unattended tests
with remote metering. Low Dexibility will limit extent of testing in a single facility.

Experimental Control - Difficult; may connict with normal building operation.

Initial Cost - Includes costs of locating, determining consiruction deta contracting, and modifying to testing condiltons. Se

Operating Costs - In addition to nomal program costs, must consider costs of buliding leasing, of - site travel and livig, local service suppor added star tenants more materiats required. Lower productivity.

See Table 3.2 for comparison of example scenarios.
Altemative 3

Hnoccupied Buildin

Alternative 4

Availability - Principal criteria are sufficient plan area and height to to have features included in initial design. Enerig-related characterist of all materials and subsystems must be known. Researrh still limited by butding exxles - hence rescarch limited to increncontal changes

Use Restrictions - Necd to maintain habilability of the rest of the building may compromise test environmen.

Mexibitity to Configuration Change - May design capability for easier retrofits. May require several sites

Support Facilities - Similar to occupied building. Much enhanced by

Instrumentation, Monitoring, and Testing Hnvironment - Better than in facilities and extent of telemetering important. Instrumentation difficul but less so than in oxcupied building.

Sequential Operations - Retter than in occupied building because operating schedule would not conflict with commercial users of the building Low Dexilibity will limit extent of testing in a single building.

I'xperimental Control - Better than in occupied building

Initial Cost - Similar to occupied building. Modification may be more

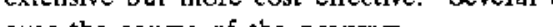

Operating Cosis - Similar to occupied huilding. Rental costs may be
higher because there may be no other tenant. Provides a potentially higher because there may be no other

Sec Table 3.2 for comparison of example scenarios. ability - BSLL design requires innovative features 10 reasons. Could be built with cude variances to allow testing of radically new concepts. Energy-related characteristics known for the total system.

Use Restrictions - Facility fully dedicated to this purpose so no conllicts

Iicxibility to Configuration Change - Greatest nexibility - Interior paritions. hoors and ceilings, and exterior facade can be reconfigured. Easy access to energy distribution system for convenient changes to

Support racilities - BSL would be located at a research facility.

Jetrumentation, Monitoring, and Testing Hnvironment - BSIL would be dedicated lab and capable of maintaining test environment by using of Cever Sequential Operations - Conversion to widely different
wrations can be accommodated within the single facility.

Experimental Control - BSII, designed to facilitate. Initial Cost - Capital cost of BSIL facility at program start is higher
than with use of existing buildings.

operating Cass-sere costs, lower staft Operating Cossts - Significantly lower because no lase
requirement, travel, matcrials. Higher productivity.

See Table 3.2 for comparison of example scenarios 

dimensional model for open flow of air, and the development of appropriate objective functions for ventilation optimization

- field testing of integrated systems - preliminary small-scale testing

- analytical methods for trunsient effects - preliminary studies of transient load impacts on equipment size and whole-building performance rather than a series of independent steady-state situations

- computer program verification and algorithm development - initial development to handle unusual conditions such as floating temperatures and convective effect in atria

- testing of building components - specific tests on new components to identify potential twosubsystem interactions

- innovative operating and control strategies limited preliminary studies of feasibility.

In each of the areas, existing facilities would lack the capability to assess the total building system integration and the impact on energy utilization, but could provide initial studies that would provide more information about the problem.

\subsubsection{Existing Occupied Building}

\section{Technical Criteria}

Existence, Availability, and Constructability. Existing occupied buildings would have to provide adequate size, construction characteristics, and operational flexibility to be considered. Critical features include the following:

- Complete construction details must be available to be able to understand and stipulate all energyrelated characteristics of structural materials and assemblies.

- The floor area and ceiling height must be sufficient to typify multizone building energy transient behavior:
- three or more floors

- plan area of roughly $7,000 \mathrm{ft}^{2}$ minimum.

If several buildings with these characteristics could be found and sufficiently dedicated to building system integration research, significant results could be obtained in the following areas:

- HVAC optimization methodology development as applied to conventional building design, e.g., the determination of system coefficient of performance and the effect of operation and control strategies on improving this characteristic

- ventilation optimization procedure development as applied to conventional buildings, i.e., establishing design procedures for achieving the greatest turnover of air in the occupied zone with the minimum use of ventilation air

- computer program verification and algorithm improvement and development for existing wholebuilding computer codes

- developing the capability to analyze large building performance as a continuous transient system, including all significant interaction between conventional subsystems.

A number of such buildings would be needed in order to confirm the configurational effects in the tasks noted above because of the difficulty of acquiring an occupied building in which the interior configuration can be periodically changed to carry out the experiments. It has been difficult in the past to locate buildings of the appropriate physical characteristics and which are available for relatively nonintrusive experimentation. The DOE Hotel/Motel and Restaurant demonstration projects and the Post-Occupancy Evaluation of Office Lighting projects all experienced difficulties in locating buildings of appropriate characteristics.

The principal drawbacks to the use of an existing occupied building as the experimental facility are 1) the limitation of research to concepts and configurations that are now being built; 2) the need to maintain experimental control; and 3) the degree to 
which existing use can be altered or occupants can be disrupted by the experimentation (Gillette and Brown 1986; Hill et al. 1981). These drawbacks are discussed below.

The ability to consider significantly new approaches to improve the energy efficiency of commercial buildings, which may depart from current design convention and building codes, would be lost in this scenario. Thus, results in system integration research would be limited to incremental, evolutionary changes in subsystem design; radical new, revolutionary approaches would not have a testbed for the evaluation and demonstration phase so essential to effecting technology transfer to the commercial market. The principal incentive for building system integration research would be lost if its implementation is limited to the use of existing buildings designed for commercial occupancy. The technical review panel recommended that all consideration of eventual commercial occupancy be dropped in the development of the concept of a new dedicated experimental facility. The panel felt it would compromise the objectives of the program and add unnecessary capital cost in light of the probability that use of the facility for research would continue indefinitely.

Another difficulty in conducting an experimental task within an existing occupied building is the conflicts that would arise between the use of the building and the maintenance of the required test environment (Hill et al. 1981). Although the results of the experimental tasks must eventually be applied to occupied buildings and account for the impacts of building use on the interactions of the subsystems and the total system optimization, the initial data must avoid this. It must be obtained in a controlled environment, to isolate the effects from subsystem and occupant-behavior interactions. Once the former has been established, the latter can be more easily included into the understanding of total system behavior.

It may be difficult to locate a facility in which the existing use can be altered to the extent necessary to carry out even the studies of an evolutionary nature and achieve those limited objectives of the major building system integration research tasks.
To accomplish a significant portion of the experimental tasks, e.g., to be able to confirm configurational effects in the interaction of building subsystems, the facility should also have

- reconfigurable interior walls and partitions, floors, and ceilings

- a reconfigurable exterior envelope, i.e., variable window types and placement, variable exterior wall construction, variable solar interactions with both building envelope and interior

- accessible energy-distribution service area for HVAC ducts, electrical wiring, and alternative energy sources such as gas or hot water.

Reconfiguration by remodeling and retrofitting of an existing building is an option, but normally an expensive one unless this capability were included in the original building design. It also carries the potential for atypical interfacing with the existing construction. The alternative to having these capabilities in a single existing facility is to conduct the tasks in a number of well-characterized buildings. However, the chances of locating and acquiring several such facilities are considerably less than locating a single adequate building for a selected experiment.

\section{Experimental Criteria}

Support Facilities. Support facilities should be available to design and construct experimental apparatus, and to calibrate and repair instrument sensors. If the existing facility is located at a university or other research facility, this criterion would present no obstacle. At any other site, it could be a relatively high operating cost requirement.

Instrumentation, Monitoring, and Test Environment. The installation, wiring, and maintenance of sensors should be easily accomplished to accommodate the conduct of the studies. Again, the proximity to a research establishment would be beneficial for cost-effective operation. Monitoring and early detection and correction of data errors should be easily accomplished, requiring either onsite surveillance or telemetering to a data processing location. 
Again, isolation of the test facility from the location of the research staff will add cost.

Sequential Operations. Experiments should be easily set up and broken down. Unless the existing facilities are totally dedicated to experimental tasks, the tasks must be staged in such a way as to utilize either a short period of intense effort or a longer time of unattended operation. High productivity will be more difficult to achieve under these circumstances.

Experimental Control. The facility must permit the isolation of experiments from extraneous factors. However, in the occupied building, maintaining the required isolation will be difficult; attempts to do so may conflict with normal building operation.

\section{Economic Criteria}

Initial Cost. The high capital cost of a new facility is avoided by the use of an existing building, but other upfront or peripheral costs for locating and contracting for appropriate buildings, establishing building construction details, remodeling, or other preparation must be considered. Examples include adapting the building to the testing configuration, possibly a significant cost because of the lack of flexibility in configuration control, and decommissioning and restoring of the building.

Operating Costs. Operating costs will be highly dependent on the location and use-permit arrangements. If the facility is remote from an existing research facility, the cost of conducting the rescarch will be significantly higher. In addition to normal project costs of preparation, setup, instrumentation, monitoring, maintenance, breakdown and changeover, the following costs must be considered in evaluating a remote facility:

- real estate rental costs of a leased or purchased building

- multiplier costs for multiple sites where a single building cannot represent the needed conditions or cannot be modified to run other experiments

- higher materiais eosts (than for a dedicated lab) because reuse of materials and components will be considerably more difficult and cosily
- multiple experimental sites because additional research staff will likely be needed to carry on a program at two or more sites

- travel costs to and from an experimental site and per diem

- contract support costs required by remote sites to contract and train local site technicians to maintain support of the experiments and to purchase services for such items as sensor calibration

- transmission of data from experimental sites to a central site for analysis.

\subsubsection{Existing Unoccupied Buildiug}

\section{Technical Criteria}

The significant differences, with respect to technical criteria, between the existing occupied building alternative and the unoccupied building alternative are the greater freedom the program would have to 1) arrange for certain design features to be incorporated into the original design of the building, probably at the incremental cost of these modifications; 2) conduct the test program without being encumbered with interfacing with the commercial occupants; and 3) alter the facility to accommodate the test requirements.

Existence, Availability, and Constructability. The same criteria would apply as in the previous alternative, except for the possible opportunity to gain access to a wider range of building types and features for testing. The technical review panel suggested that one approach to obtaining the use of new buildings, with specific desirable features, as a temporary experimental facility would be to establish a federal program that would offer favorable construction loan rates to builders who would be willing to incorporate these features and lease back to the government, under favorable conditions, a portion of the building prior to commercial occupancy. Another approach would be to use new federal buildings, as they are constructed and then occupied, as test facilities.

As with existing occupied buildings, the use of an unoccupied new building would limit the research to concepts and configurations that are currently being 
built or, at most, are evolutionary extensions of current construction practice. Radical departures from existing building codes and standards would probably not be possible. Consequently, experimentation or innovation would not be possible. The scope of work that could be accomplished would be essentially the same as that achievable with the use of existing occupied buildings.

Restrictions on Building Use. The potential conflict between the occupants of the building and the need to maintain the required test environment would be considerably less in this situation. However, the test program could not embody conditions that would make the rest of the building less habitable, unless the total building were leased during the testing period.

Flexibility to Configuration Changes. The singular difference between the use of an unoccupied, leased building and an occupied building is that the agreements of the former could be completed prior to completion of construction and, consequently, there may be the opportunity to incorporate design features of particular interest to the experimentation program. Both would have similar problems of configurational flexibility, unless the needed features had been considered during the early stage of construction while there were still opportunities to build added flexibility into the building design.

\section{Experimental Criteria}

To conduct expanded research in leased, unoccupied portions of a building rather than in occupied buildings would reduce the experimental difficulties because the interaction with commercial users would be markedly reduced.

Support Facilities. The response is similar for both the unoccupied and occupied alternatives. Both alternatives would lead to less costly operations if located at a university or other research facility where the need to set up completely selfsufficient support facilities would be minimized.

Instrumentation, Monitoring, and Test Environment. The use of an unoccupied portion (or total) of an existing building would be a much more favorable operating environment because the researchers would not be required to interface with building occupants or deal with "housekeeping" problems.
Nevertheless, the proximity to a research establishment would be beneficial for cost-effective operations, and isolation of the test facility from the location of the staff would add significantly to the cost.

Sequential Operations. Using an unoccupied existing building would be much more convenient than occupied buildings because the operating schedule would not be as constrained by the interface with the occupants of the building. Sequential tests could be staged more conveniently.

Experimental Control. Maintaining the required isolation of experiments from extraneous factors would be easier in an unoccupied existing building. However, the extent of control would be limited by the existing building's design features.

\section{Economic Criteria}

Initial Cost. Again, the high capital cost of a new facility would be avoided, but the other upfront costs described in the use of an occupied building must be considered. There may be a tendency to incorporate more custom features, which would increase these costs. However, these costs may be counterbalanced by somewhat lower costs of modification, because it would be done either in conjunction with the building's initial construction or later in the program in the absence of occupants.

Operating Costs. The use-permit arrangement would differ significantly between unoccupied and occupied facilities. The rental charges are likely to be considerably higher in the case of the unoccupied building, because the testing program would be the only tenant for that portion of the building. However, the establishment of a program of enlistment that provided upfront advantages for the builders or building owner could be the important factor in reducing those costs.

Higher program costs are again foreseen if the buildings are some distance from the home base of the research staff.

\subsection{FINAL ANALYSIS}

The comparisons of the four alternatives resulted in the following final analysis. 
- Even if research were limited to incremental improvements in building system integration and conducted in existing buildings (either occupied or unoccupied), the cost of using leased facilities would ultimately exceed that of a dedicated new facility. This stems from the need for many such leased facilities to overcome the limited flexibility of available facilities, the higher cost of offsite operations, and the facility rental costs. A scenario comparing the cost of the three alternatives for using existing leased buildings, as opposed to a dedicated new facility, is summarized in Table 3.4. The assumptions on which the costs are based are described in the footnotes to Table 3.4.

- A significant portion of building system integration research can be done in existing experimental facilities. This is where most experimental research is carried out now. However, this work involves the interaction of a limited number of subsystems, generally only two. For

Table 3.4. Estimated Cost of Alternative Facility Concepts

\begin{tabular}{|c|c|c|c|c|}
\hline \multirow[b]{2}{*}{ Cost Category. } & \multirow{2}{*}{ Explanation } & \multicolumn{3}{|c|}{ Altematives } \\
\hline & & $\begin{array}{l}\text { Building System Integration } \\
\text { Laboratory, } \$ \text { million }\end{array}$ & $\begin{array}{l}\text { Existing Occupied } \\
\text { Building } \$ \text { million }\end{array}$ & $\begin{array}{l}\text { Existing Unoccupied } \\
\text { Building, \$ million }\end{array}$ \\
\hline \multicolumn{5}{|l|}{ Initial Cosis } \\
\hline Capital Project & (a) & 10.8 & - & - \\
\hline Contracted Space & (b) & - & - & - \\
\hline Search and Contract & & - & $0.05 /$ site & $0.05 /$ site \\
\hline Modifications & & - & $0.50 /$ site & $0.50 /$ site \\
\hline Restoration & - & $0.50 /$ site & $0.50 /$ site & \\
\hline \multicolumn{5}{|l|}{ Operating Costs } \\
\hline Rent & (c) & - & 0.30 & 0.50 \\
\hline Staff Labor & (d) & 0.65 & 0.75 & 0.75 \\
\hline Materials & (e) & 0.20 & 0.30 & 0.30 \\
\hline Capital Equipment & (f) & 0.10 & 0.10 & 0.10 \\
\hline Travel & (g) & 0.03 & 0.15 & 0.15 \\
\hline Contracted Support & (h) & - & 0.20 & 0.20 \\
\hline Telemetering & (i) & - & $\underline{0.10}$ & $\underline{0.10}$ \\
\hline Subtotal Operating Costs & & 0.98 & 1.90 & 2.10 \\
\hline Present Worth Revenue Requirement & (j) & 18.20 & 17.90 & 19.20 \\
\hline
\end{tabular}

(a) Capital Project - $\$ 10.8$ million - The conceptual cost estimate of the BSIL.

(b) Contracted Space - Assumes the cost of locating and contracting space is $\$ 50$ thousand, modifications are $\$ 500$ thousand, and restoration is $\$ 500$ thousand.

(c) Rent - OCCUPIED BLDG is based on $30,000 \mathrm{ft}^{2}$ at $\$ 10 / \mathrm{ft}^{2}$-yr. UNOCCUPIED BLDG is assumed to be $60 \%$ higher because no other tenant would be in the building during the testing program.

(d) Staff Labor - BSIL - Assumes 5 full-time employees (FTEs); EXISTING BLDG - A 25\% increase in required staff is assumed, to account for the inefficiencies of offsite work.

(e) Materials - BSIL - $\$ 200$ thousand/yr. EXISTING BLDG assumes $\$ 300$ thousand/yr because of the lack of flexibility to recover material from one site to use on the next site.

(I) Capital Equipment - Assumes a similar amount for each case, approximately $\$ 100$ thousand.

(g) Travel - BSIL - Assumes 10 man-wreeks of offsite travel and 10 trips across country. EXISIING BLDG - Assumes half-time offsite for 3 staff members.

(h) Contract Support - BSIL - None required. EXISTING BLDG - Assumes contracting and training required for two local technicians plus support services for instrument maintenance and calibration.

(i) Telemetering - BSIL - None required. EXISTING BLDG - \$100 thousand for data loggers, terminals, and dedicated phone lines.

(j) Present Worth Revenue Requirement - Assumes capital costs at front end of a project are equal to their present worth revenue requirement. Phased contracting of leased space is discounted at $8 \% / \mathrm{yr}$. Operating costs are similarly discounted at $8 \% / \mathrm{yr}$. BSIL - Assumes one-time construction of the entire project.

EXISTING BLDG - Assumes five sites being contracted in Years 0, 2, 4, 6, 8, with capital and renovation cost discounted at the $8 \%$ rate. 
total building system integration research, larger facilities capable of typifying multizone building energy transient behavior are required.

- The size criteria can be met through the use of leased facilities, either occupied or unoccupied. However, although these approaches avoid the capital cost of a new dedicated facility, they have several significant drawbacks.

- Of the seven areas of research categorized as the most important for advancing building system integration, five require a dedicated, flexible facility such as the BSIL to achieve the ultimate program objectives. Reliance on leased facilities would limit research, particularly on innovation.

- The use of leased facilities may compromise the validity of results because of uncertainty about the testing environment, construction materials, or methods, and the difficulty of maintaining constant experimental conditions.

- Factors that would influence the selection of either leased space or a dedicated experimental facility in which to conduct a given piece of research include the following:

- changeability at large scale - Research that requires large-seale changeability will favor the use of a dedicated experimental facility. Research that does not require either changeability or a large scale will favor leased buildings.

- control of complex conditions - Research that requires the control of complex external and internal conditions will favor a dedicated experimental facility.

- isolation of effects in multi-effect problems - Research that requires the isolation of specific effects in a multi-effect problem will favor a dedicated experimental facility.
- integrative issues - Research that involves the investigation of issues associated with integration of separate building systems will favor a dedicated experimental facility.

- required facade modifications - Research that requires substantial modification of the building facade will best be done in a dedicated experimental facility.

- size and complexity of required modifications - Research that requires small scale or simple changes can best be done in leased buildings. Research that requires substantial or complex modifications would best be done in a dedicated experimental facility.

- isolation - Research that requires carefur isolation from surrounding spaces will favor a dedicated experimental facility, while research that is less sensitive to isolation will favor leased buildings.

- incremental and fundamental change Leased space will be most appropriate for investigating concepts that result in incremental change. A dedicated experimental facility would be favored for investigating approaches that result in fundamental change and innovation.

- very large subsystems - Research on very large subsystems, systems that exceed the capabilities of a dedicated experimental facility, could not be conducted at an experimental facility and would be best conducted in leased space.

not allowed by existing building codes Research that involves modifications not allowed by building codes would favor a dedicated experimental facility. 


\subsection{CONCEPTUAL DEVELOPMENT OF THE PREFERRED ALTERNATIVE}

The functional criteria that were developed for evaluating the four alternatives established the ground rules and design requirements for the overall design of the preferred alternative--called a Building System Integration Laboratory (BSIL). This section describes, in detail, the study used to develop the physical concept of the BSIL. Physical specifications, proposed floor plans, building elevations, and cost estimates are provided.

\subsection{THE PREFERRED ALTERNATIVE}

The BSIL alternative is a newly-built, dedicated experimental structure designed for large-scale experiments of combinations of full-scale building components under controlled conditions. The exterior walls and roof of the BSIL would be an environmental chamber under which full-scale experiments involving buildings with up to a three-story facade, including opaque walls, windows, and doors, and portion of the roof, skylights and hatches, could be conducted. The BSIL would also be designed to permit the exposure of these experiments to ambient (local climatic) conditions when this is feasible and practical. The BSIL envelope design would permit sequential testing of a number of separate experiments under several seasonal conditions over short periods of time. Thus, experiments would not be limited to summer and winter testing seasonal changes, nor would they depend on the vagaries of year-to-year climatic changes. Thus, the BSIL would have three separate components: 1) an cxternal shell that could simulate desired climate conditions; 2) an internal structure that would allow for several concurrent experiments and a quick change of components; and 3) an onsite support facihity to house research staff and support functions.

The internal structure of the BSIL would be designed to support envelope components of experiments and flexibly house experiments involving a wide variety of internal space configurations, exposures, conditions, and occupancies found in commercial buildings. In addition, the BSIL structure would be designed to support easy changeout of various heating, ventilating, air conditioming, lighting, power, hot water and control components for different experiments. Finally, the BSIL would be designed to provide for flexibility in instrumentation and monitoring of the various combinations of components and spaces involved in the experiments and the rapid changeout of instrumentation for prompt sequencing of experiments.

\subsection{CONCEPTUAL DESIGN}

The conceptual design of the BSIL, as shown in Figure 4.1, includes an exterior shell that encloses a climate-controlled space (annulus) over the roof and around three sides of a three-story structure that will flexibly support and house the required large-scale experimental testing. Portions of the BSIL exterior shell could be removed to expose an experiment to ambient (local climatic) conditions. The structure to support the experiments is $100 \mathrm{ft}$ by $100 \mathrm{ft}$ in the interior floor plan on each level. Portions of the second-and third-level floors of the structure could be removed to simulate atrium conditions. A basement houses mechanical equipment and immediate support activities. A service core runs vertically the full height of the BSIL, providing access, utilities, and chases for vertical runs for experiment components. There would also be a separate 50 -ft by 100 -ft onestory storage building for storing experimental components and BSIL shell panels while not in use.

\subsubsection{Ground Rules}

The scope of the BSIL design study was defined by three ground rules:

- site - The conceptual design should not be sitespecific; rather, the design should be suitable for a wide range of possible sites and climates. Thus, an outer building shell that can control climate variables should be designed into the structure.

- support facilities - It was assumed that support facilities, such as most office space, conference rooms, and computer services, would be located in existing structures and would not be included in the BSIL design. 


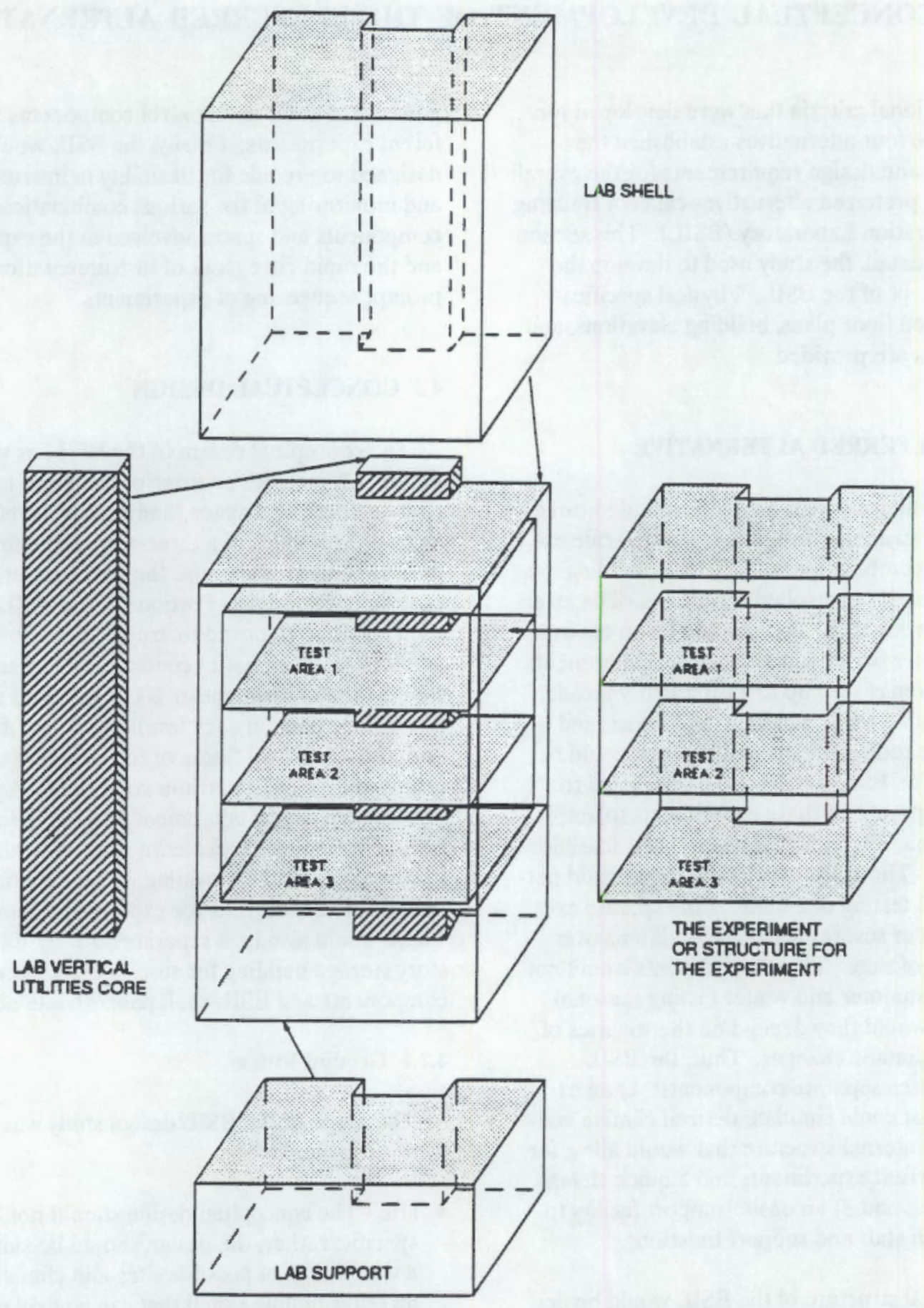

Figure 4.1. Conceptual Design for the Building System Integration Laboratory

- instrumentation - The BSIL design should include provisions for instrumentation, hut it was assumed that expenses associated with data collection would be met by individual research projects.

\subsubsection{General Design Requirements}

The functional criteria for a facility in which to conduct building system integration research included three components: 1) a climate-controlled external shell; 2) a flexible interior structure; and 
3) a separate storage building. Based on these criteria, the following general design requirements were established:

- experimental facility height - The external shell of the facility should have three above-ground floors and a basement. Optimal testing requires three above-ground floors. A ground floor is needed to simulate ground coupling and building entrance effects. The middle floor is needed to simulate a typical floor in a commercial building, while the top floor is needed to investigate issues involving interactions with the roof. Support services should be located in the basement.

- experimental facility floor areas - The facility should have floor dimensions to accommodate $100-\mathrm{ft}$ by $100-\mathrm{ft}$ test areas. The minimum floor dimensions are dictated by the need for tests involving experiments with building perimeter external zones ( $30 \mathrm{ft}$ each) and the requirements for an internal zone measuring $40 \mathrm{ft}$ by $40 \mathrm{ft}$. This floor area facilitates research on external zones with variable zone depth, as well as interactions between the external and internal zones.

- internal structure - The internal structure of the facility should be designed to accommodate several different types of window and wall configurations.

- external shell - The external shell should be designed to alternate between serving as an environmental chamber and exposing the wall and window facades, which hang on the internal structure, to ambient conditions.

A separate $5000-\mathrm{ft}^{2}$ storage building should be located close to the main facility. This building should be an inexpensive structure in which to store major building and experimental components.

\subsubsection{BSIL Design Requirements}

The BSIL external shell should be designed to selectively expose or isolate experiment-related walls and roof constructions from ambient conditions. Sections of the BSIL external shell should be removable so that any sections of the wall or roof being tested can be exposed to ambient conditions. The annulus or space between the external shell and the interior structure should be designed to be conditioned to maintain constant controllable temperature, humidity, and air velocities on the test building exterior.

The configuration of the interior structure, which supports the facade being tested, should be easily altered so that a variety of materials, components, and designs can be tested. Provisions should be included to allow for variable window types, window shading, and facade thermal characteristics.

The BSIL interior structure should include space for three above-ground floors and a basement. The above-ground floors should provide test space while the basement would allow for vehicle access, limited office space, a shop, room for electronic equipment, and test assembly areas. A freight elevator should extend the entire height of the entire structure for transporting large preassembled components to the above-ground test spaces. Some of the aboveground floors should be renovable to create a multifloor space, to allow investigations of atria and other large spaces. Provision should be made to vary the ceiling height of the ground floor. The configuration of other internal walls and partitions in the above-ground floors should also be easily alterable.

The interior structure of the BSIL should be designed so that the configuration of lighting, HVAC, electricity, and utilities is easy to modify. It should be designed to also allow an experimental configuration for occupancy similar to that of an operating commercial office building.

The separate $5000-\mathrm{ft}^{2}$ storage building should be constructed onsite, hut should he located far enough away from the main structure to prevent interference with the climatic effects on tests.

\subsection{PHASED CONSTRUCTION}

Immediate construction of a complete facility requires a substantial capital outlay. An alternative approach is to construct a BSIL in phases. Phased construction would reduce the initial capital cost of the facility and allow for future expansion to the final dimensions. Research projects would be grouped and given priority to accommodate phased construction. 
The technical review panel investigated this approach and explored a three-phase construction plan was explored. The initial phase would create a structure with a basement and three above-ground floors with interior structure dimensions of approximately $50 \mathrm{ft}$ by $50 \mathrm{ft}$. The second phase would then expand the facility to an interior structure space approximately $100 \mathrm{ft}$ by $50 \mathrm{ft}$, permitting tests in the next level of priority and complexity to be run. The third and final construction phase would result in the full-sized BSIL with approximate interior structure dimensions of $100 \mathrm{ft}$ by $100 \mathrm{ft}$. The completed BSIL could accommodate studies requiring simultaneous multi-oriented facades and exterior zones.

A design was developed that allows for phased construction if funding constraints held back construction of the complete facility. Each phase is briefly described in the following paragraphs. The phased design package is described in more detail in Appendix C.

\subsubsection{First Phase}

The design for the BSIL first phase consists of three above-ground experimental floors, a basement with an exterior shell on two sides and on the roof, an interior structure of $50 \mathrm{ft}$ by $50 \mathrm{ft}$, and a vertical service core and penthouse. This results in a 54-ft by 54-ft internal structure test area on each of the three above-ground floors. The service core includes a stairway, elevator, mechanical shaft, and a mechanical and electrical room. A service support area located in the basement includes the main entry, facility control room, a mechanical room, and the service core. The BSIL external shell encloses the south facade and two-thirds of the east and west facades. The external shell is separated from the interior test structure by an 8 -ft annular space. A temporary external stairway is included for emergency egress. A perspective of the first phase of the BSIL is shown in Figure 4.2. Plan and elevation views of the first-phase structure are shown in Figure 4.3.

\subsubsection{Second Phase}

The second phase of construction doubles the available interior structure test area on each aboveground floor to $108 \mathrm{ft}$ by $54 \mathrm{ft}$. It also adds a material assembly area, shops, and storage in the basement. The service core is expanded to include an enlarged mechanical and electrical room and a second stairway. The BSIL external shell encloses the south facade and two-thirds of the east and west facades. The external shell on the west facade of the first-phase structure would be relocated to the west facade of the second-phase structure. Plan and elevation views of the second phase are shown in Figure 4.4.

\subsubsection{Third Phase}

The third construction phase would complete the BSIL. The dimensions of each floor are expanded to $108 \mathrm{ft}$ by $108 \mathrm{ft}$, doubling the area available for experimentation. It adds a second mechanical room, storage, shipping and receiving area, loading dock, and offices to the service support area in the basement. The BSIL external shell would be extended to enclose all four facades and the roof of the test building. The separate storage building would be constructed as part of the third phase. A perspective of the complete facility is shown in Figure 4.5; plan and elevation views are presented in Figure 4.6.

\subsubsection{Benefits of Phased Construction}

The effect of phased construction on the research agenda is summarized in Table 4.1. As indicated, the structure created by each construction phase will support a significant portion of the total research agenda.

In the first-phase structure, useful research can be conducted in each of the seven areas of the system integration research agenda discussed in Section 3 . The relatively small size of the first-phase BSIL will not affect the evaluation of transient effects or the development of protocols for component testing because these efforts can be conducted on a small scale.

The primary benefits of the second-phase structure are its larger size and increased surface area enclosed by the BSIL external shell, which will enable researchers to conduct an increased number of simultaneous tests. The second phase also adds the capabilities to investigate atria and to test moderately-sized internal zones.

The third-phase structure will support the complete research agenda. The floor area available 


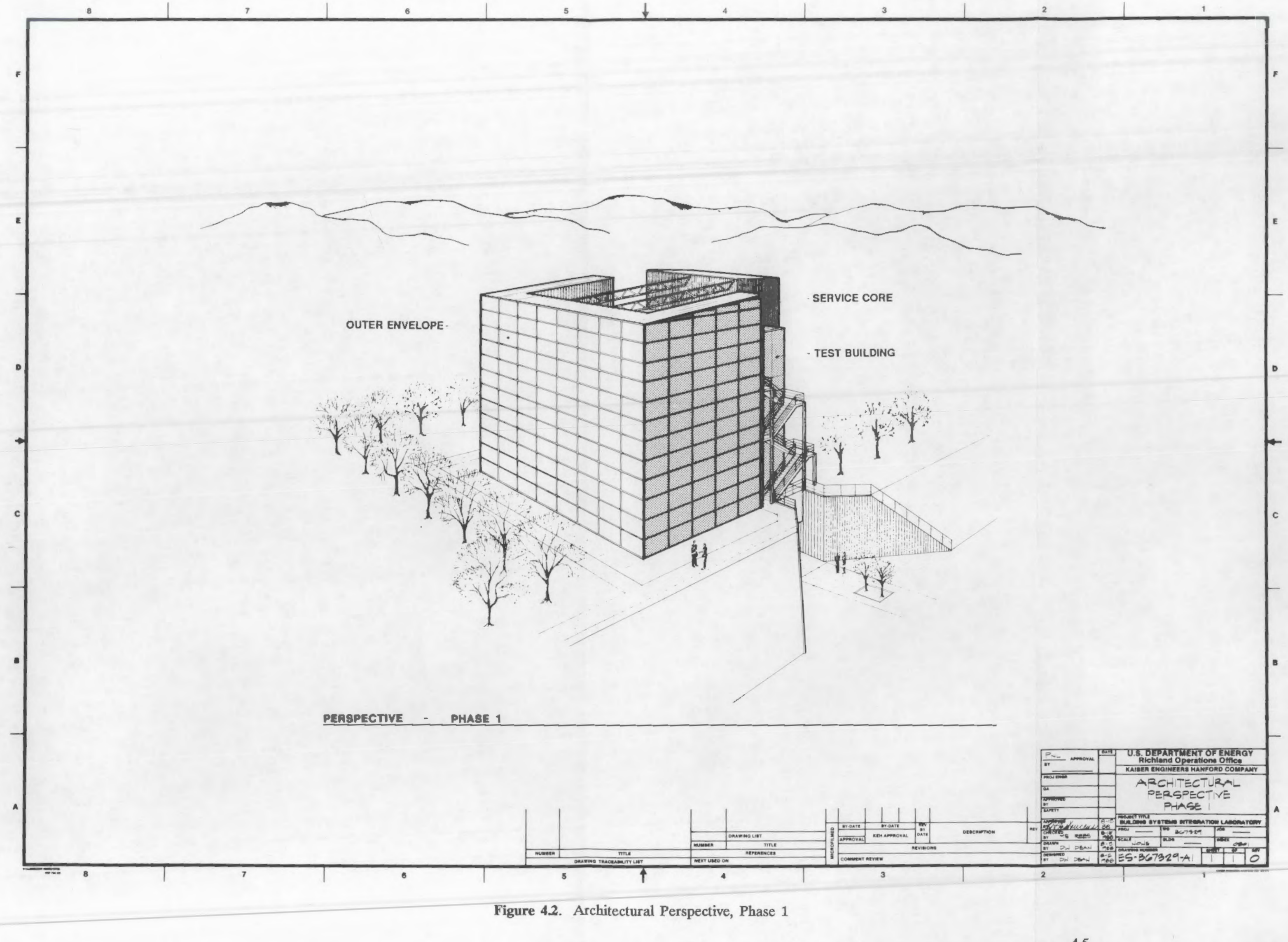




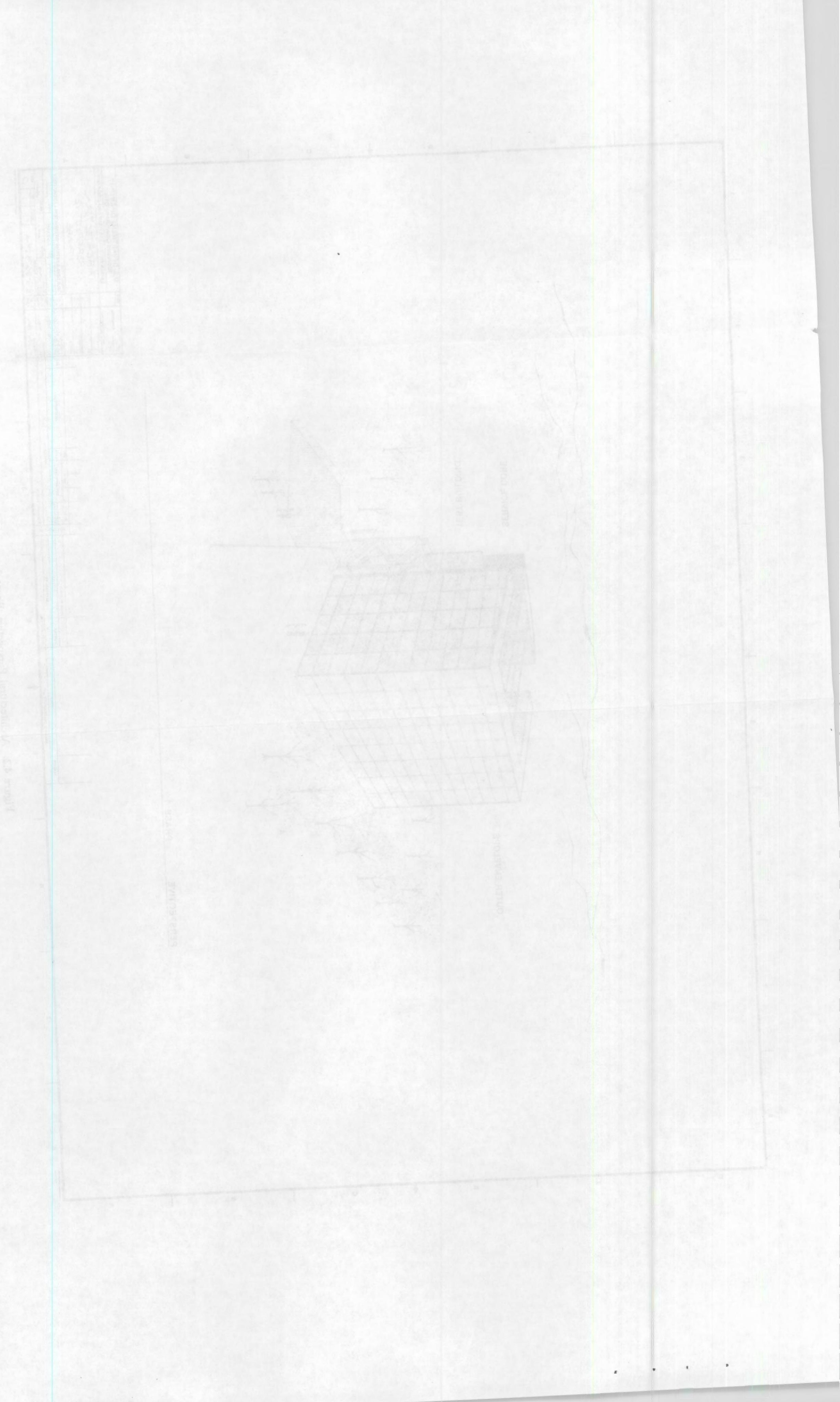




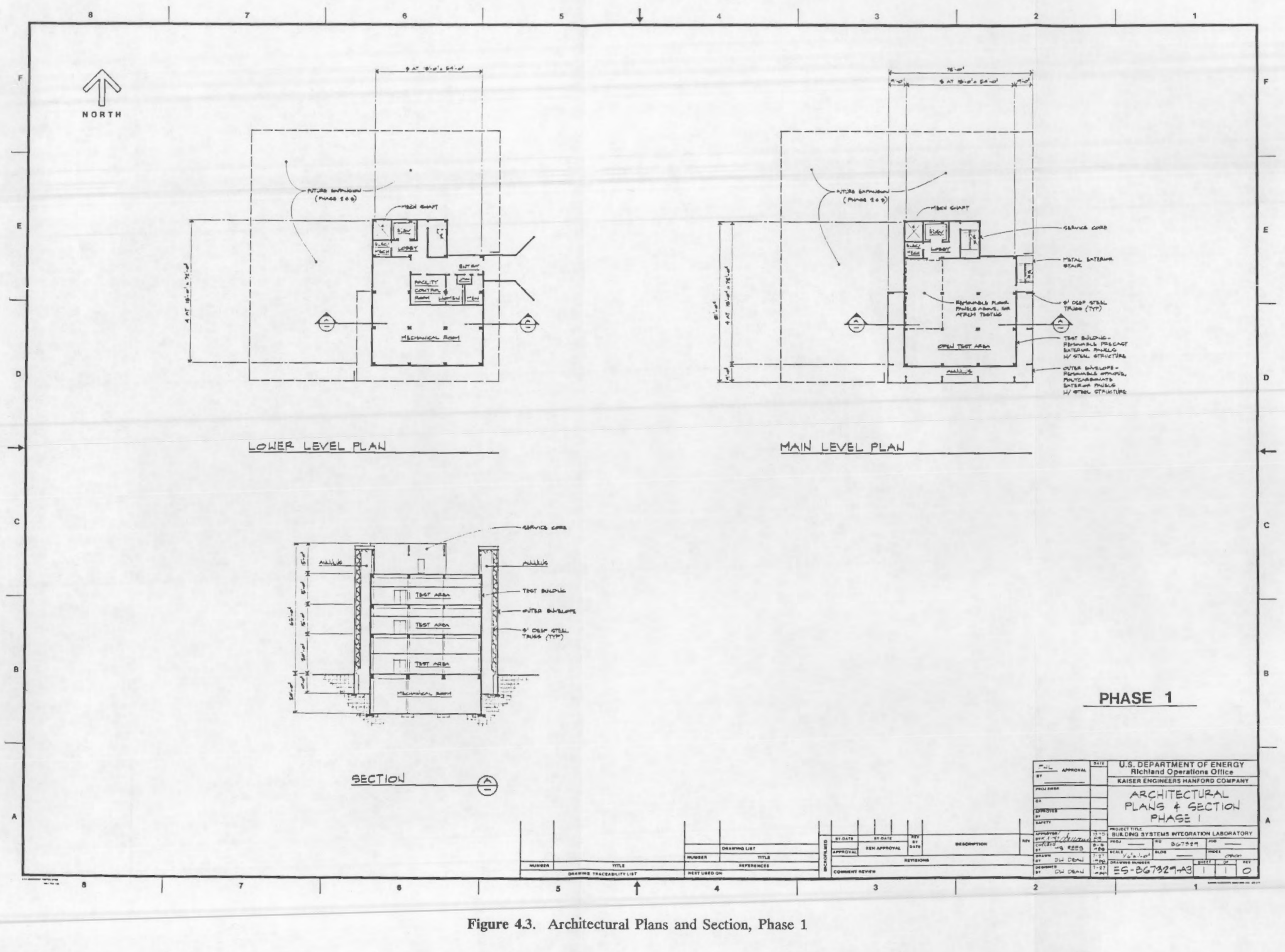





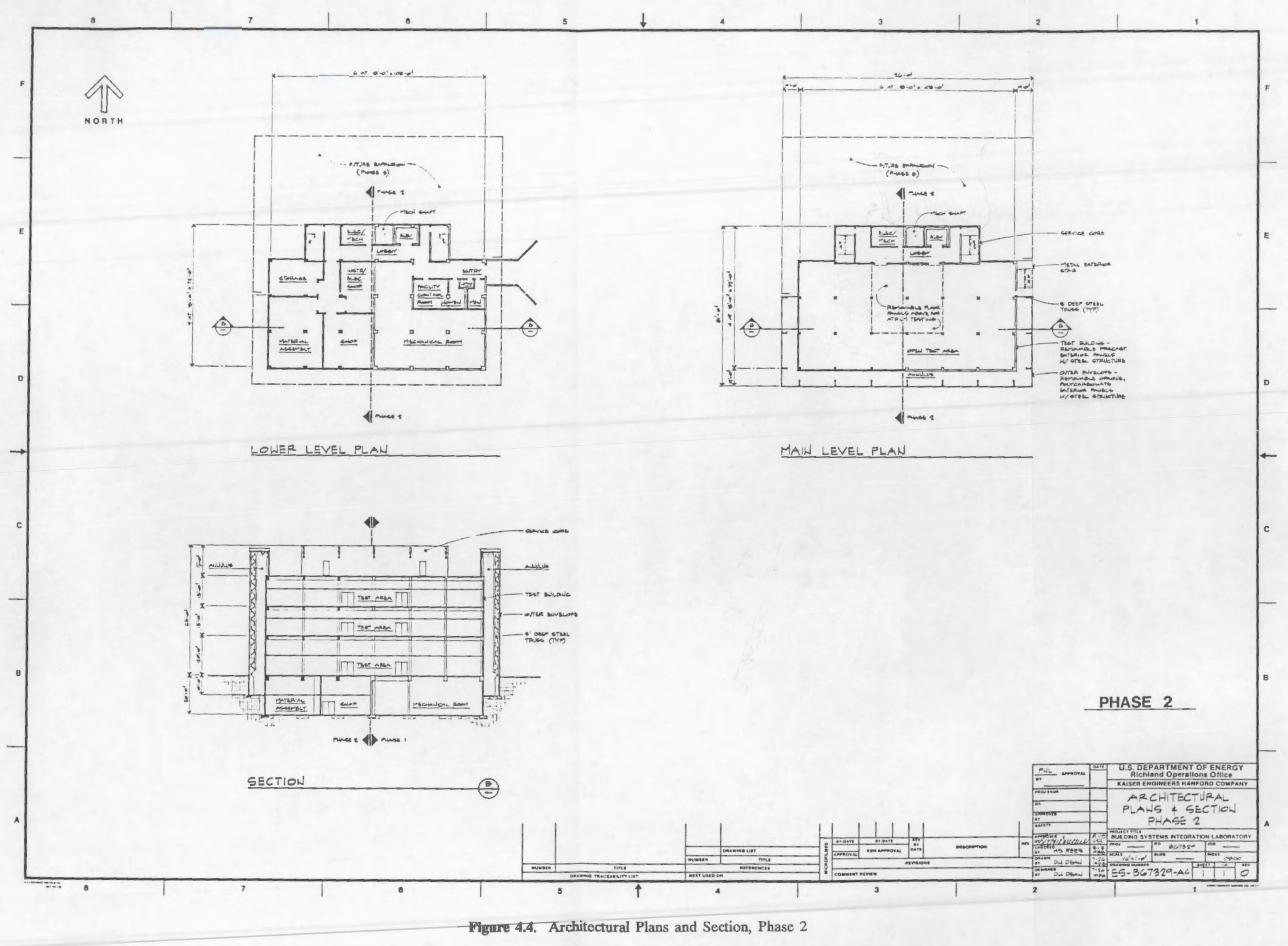





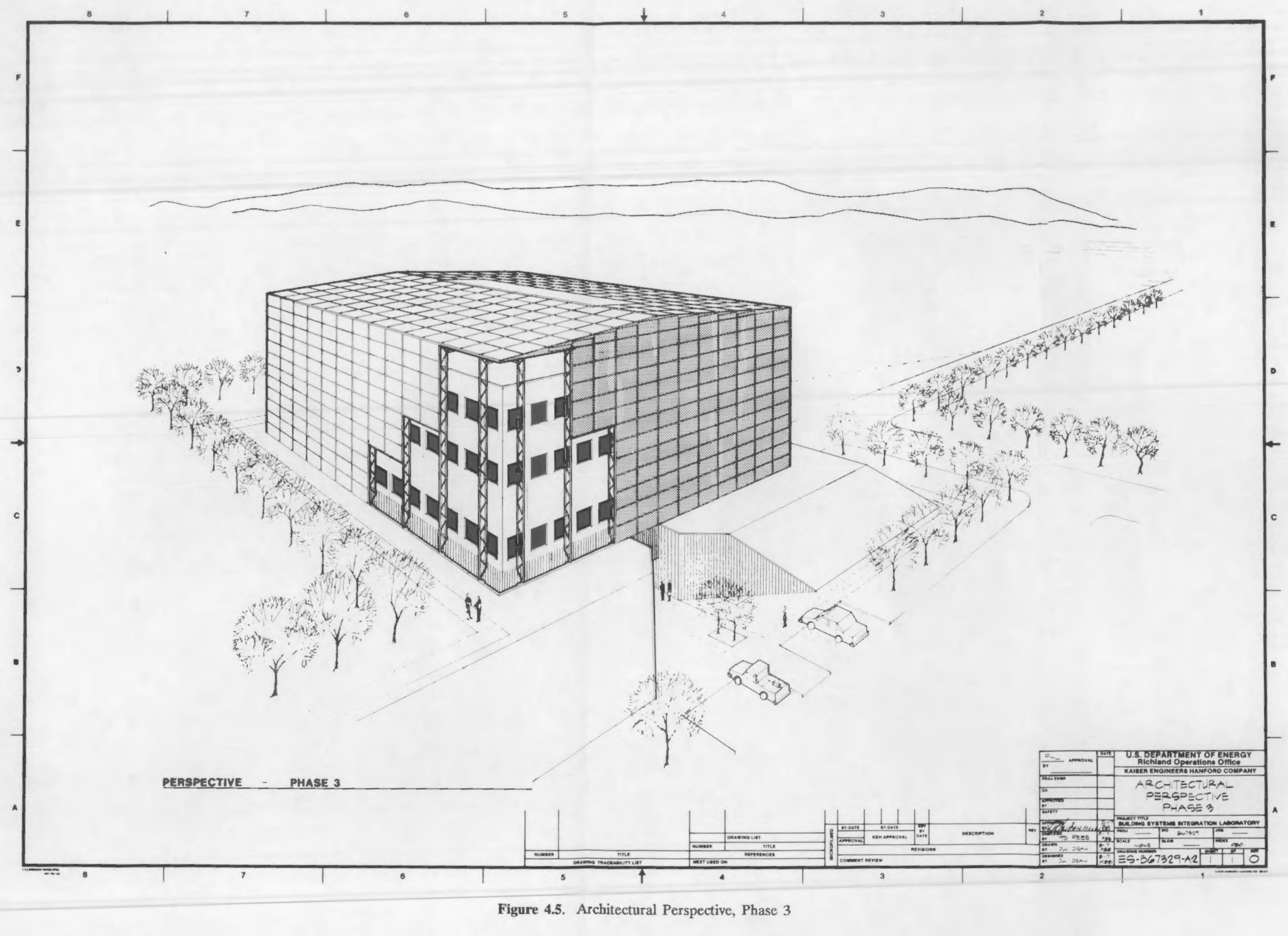





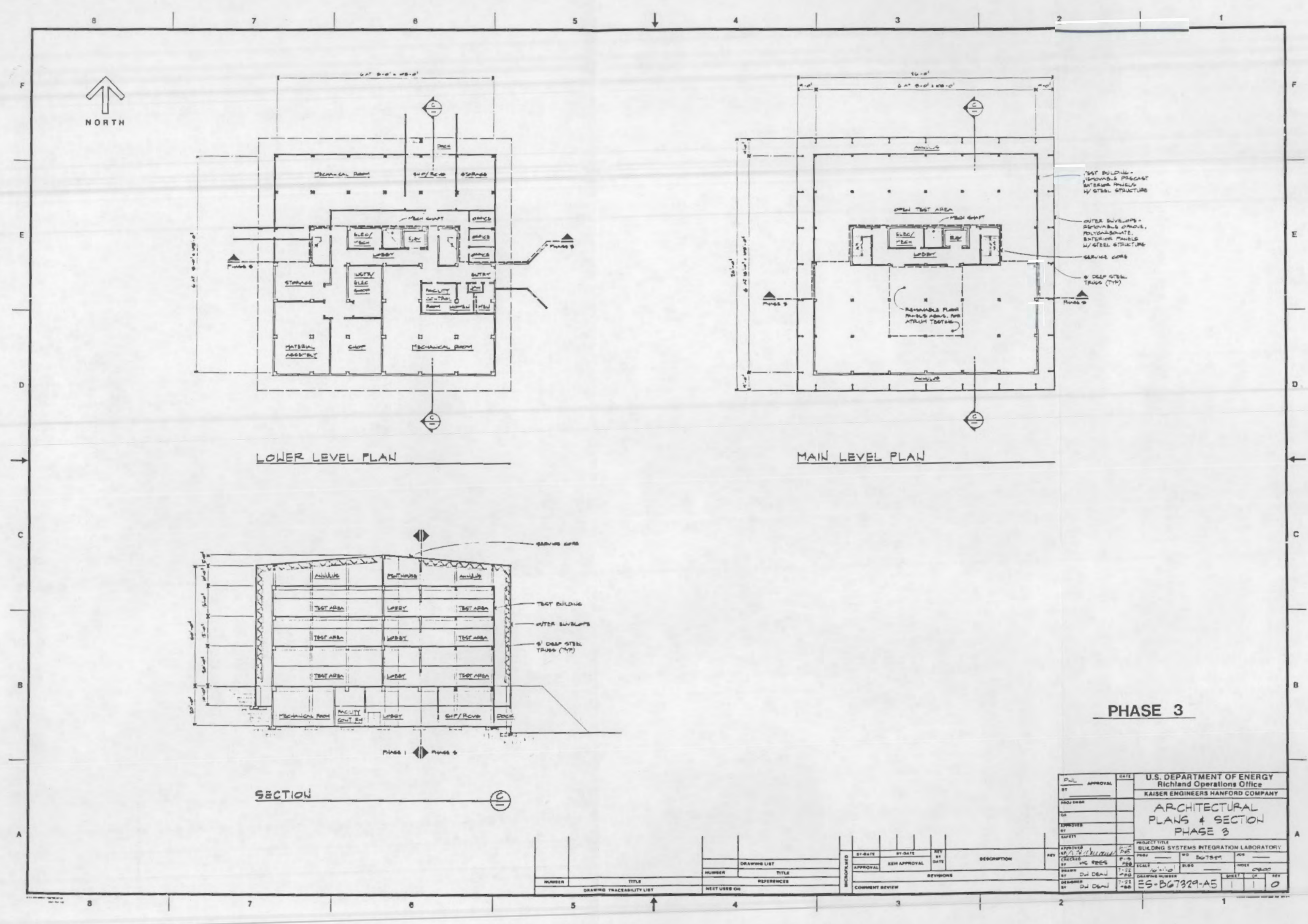

Figure 4.6. Architectural Plans and Section, Phase 3 

Table 4.1. The Impact of Phased Construction on the BSIL Research Agenda

\begin{tabular}{|c|c|c|c|}
\hline Rescarch Activiry & Phase 1 & Phase 2 & Phase 3 \\
\hline HVAC optimization & 2 & 2 & 1 \\
\hline Ventilation optimization & 2 & 2 & 1 \\
\hline $\begin{array}{l}\text { Test integrated sub- } \\
\text { systems }\end{array}$ & 2 & 2 & 1 \\
\hline Transient eflects & 1 & 1 & 1 \\
\hline Code verification & 2 & 2 & 1 \\
\hline Subsystem-test protocols & 1 & 1 & 1 \\
\hline Control strategies & 2 & 2 & 1 \\
\hline \multicolumn{4}{|c|}{$\begin{array}{l}\text { NOTES: } 1 \text { - All required capabilities are availabie at this phase. } \\
2 \text { - Useful research can be conducted at this phase. } \\
\text { 3- Research of limited usefulness can be conducted at } \\
\text { this phase. }\end{array}$} \\
\hline
\end{tabular}

for testing will be double that of the second phase, increasing the number of simultaneous tests. The complete interior structure test area would be enclosed by the elimate-controlled external shell. This will allow controlled tests on roof and nosth wall interactions. External and internal zones with maximum dimensions can be investigated.

\subsection{Unique Features}

Although phased construction would initially limit the experimental facility capabilities, several unique features would be available during all three phases. These features are listed below.

\section{- nexibility}

- internal fexibility - The configuration of the ceilings in the test area will be altcrable, as will partitions, allowing testing in a wide range of internal configurations.

- facade Mexibility - The configuration of the wall and window components on the interior structure can be altered or replaced for testing the interactions of various combinations of opaque wall and window characteristics with other subsystems and their effect on building system performance.

- equipment flexibility - The configuration of the test building will include easily altered HVAC, lighting, electrical, and instrumentation subsystems.

- control

- controlled exposure to ambient conditions The BSIL shell envelope can be used to selectively expose portions of the test building facade to ambient conditions or to control conditions using a zone-specific HVAC system in the (anoular) space between the external shell and the test areas of the internal structure.

- scale

- three floors allowing investigations of roof, intermediate floor, and ground interactions

- external and internal zones.

\subsection{COST ESTIMATE}

The cost of the experimental facility was estimated on the basis of the overall design. The cost estimate assumes that engineering expenses will be $25 \%$ of the direct cost and that contingency expenses will be $30 \%$ of the total of direct costs and engineering costs. The costs are summarized by construction phase in Table 4.2. The first and second phases each will cost $\$ 2.7$ million. The third phase will cost $\$ 5.4$ million. The estimated total cost of the completed BSIL is $\$ 10.8$ million.

Table 4,2. Estimated Costs of Constructing the BSIL

\begin{tabular}{|c|c|c|c|c|}
\hline \multirow[b]{2}{*}{ Cost Component } & \multicolumn{4}{|c|}{ Costs, S thousand } \\
\hline & Phase 1 & Phase 2 & Pbase 3 & Total \\
\hline Enginetring & 546 & 533 & 1,079 & 2,158 \\
\hline Site work & 173 & - & - & 173 \\
\hline Test butlding & 1,652 & 1,636 & 3,115 & 6,403 \\
\hline Extemal envelope & 37 & 491 & 1,055 & 1,923 \\
\hline Storagc buildinģ & $=$ & $=$ & 187 & 187 \\
\hline Total & $\widetilde{2.748}$ & 2,660 & 5.436 & 10,844 \\
\hline Total (rounded) & 2,700 & 2,700 & 5,400 & 10,800 \\
\hline
\end{tabular}





\subsection{BENEFITS OF BSIL RESEARCH}

The research performed in a BSIL will bave a direct effect on how buildings are designed, built, and operated. The direct benefits from this research include increasing energy savings, improving international competitiveness, and mitigating some of the conditions related to global climate change. This section will show how the research proposed for a BSIL will contribute these benefits.

\subsection{ENERGY SAVINGS POTENTIAL}

Commercial buildings represent $15.5 \%$ (11.6 quads) of the nation's primary energy consumption. This is equivalent to 5.4 million barrels of imported oil per day or the power output of 400 coal-Fired power plants of 500 megawatts each.

It has been estimated that properly designed buildings with integrated systems can reduce energy consumption by $30 \%$ to $50 \%$ (Stoops et al. 1984). If this reduction could be achieved in new construction, the resulting reduction in national energy consumption would be from 3 to 4 quads in 2010 . This represents a savings of between $\$ 12$ and $\$ 15$ billion in 1988 dollars.

All seven research activities discussed in Section 3 will lead to improved building energy efficiency. Developing new HVAC and ventilation procedures, for example, will improve the energy efficiency of the buildings in which these subsystems operate. Testing of integrated subsystems and components under a range of controlled real-world conditions will help comnercialize more energyefficient technologies, resulting in reduced energy consumption. The development of methods for analyzing transient effects will improve building energy efficiency by including transient effects in design and control algorithms. Code verification will increase the usefulness of simulation tools, rcsulting in inproved designs. Finally, new control strategies will assist in integrating subsystems operating building systems nore efficiently. The combined effect of these research activities is expeeted to significantly improve building energy efficiency.

\subsection{IMPROVED INTERNATIONAL COMPETITIVENESS}

A BSIL will also contribute to improvements in the international competitiveness of the American buildings industry. Research projects involving testing of integrated subsystems and components subsystems, for example, will sesult in products that will provide American vendors with advanced technologies that can be marketed competitively. A BSI will provide a test-bed facility to help vendors develop new control and interface strategies. These strategies can provide a competitive advantage in the international marketplace.

The improved methodologies for envelope, lighting, and HVAC optimization will enable the nation's buildings industry to design buildings with both lower initial costs and lower operating costs. The improved optimization will also lead to individnal components with miore desirable characteristics.

The entire commercial sector in the United States would benefit from a BSIL as well. BSIL research would indirectly improve competitiveness by reducing the cost of owning and operating commercial buildings. In addition, research on worker productivity in a commercial buildings environment bas potential for improving productivity.

\subsection{MITIGATION OF FACTORS INVOLVED IN GLOBAL CLIMATE CHANGE}

By reducing energy consumption, a BSIL would reduce the effluent that contributes to climatic change. This is particularly true because building energy consumption requires electricity, which is often produced by burning coal. The fraction of building energy consumption supplied by electricity is expected to increase from $32 \%$ of direct energy consumption in 1984 to $38 \%$ in the year 2010.

Coal-fired power plants arc projected to provide an increasingly large fraction of electric power generating capacity. Figure 5.1 shows the impact of 

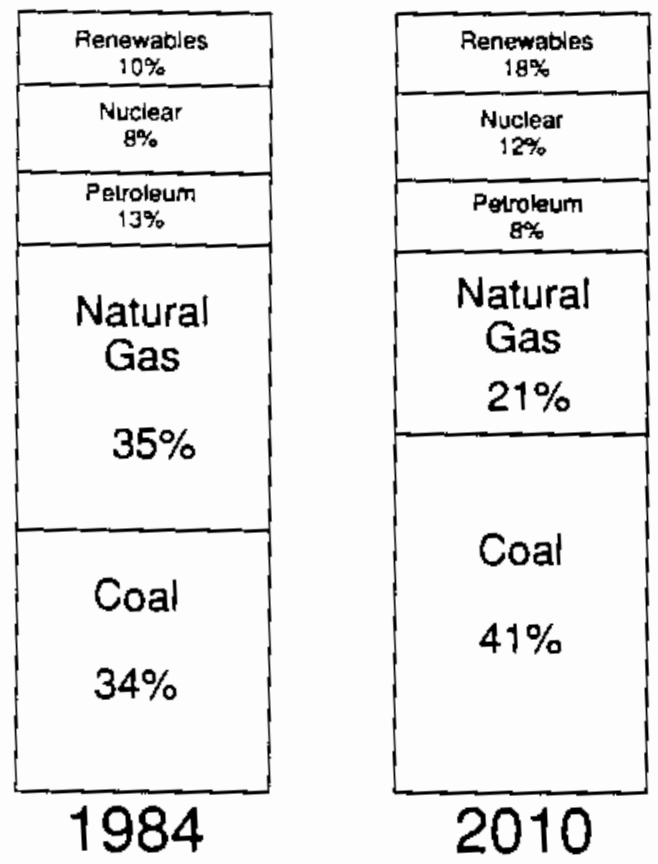

increased coal use on the consumption of primary energy sources. Coal provided $34 \%$ of the primary energy consumed in buildings in 1984, but this fraction will increase to $41 \%$ in 2010 . Coal is a major source of sulfur dioxide and carbon dioxide, both of which are implicated as contributors to the greenhouse effect and global warming. The decreased use of energy potentially realizable from BSIL research will help mitigate these factors.

Figure 5.1. Building Energy Consumption by Share of Source Fueh, 1984 and 2010 


\subsection{CONCLUSIONS AND RECOMMENDATIONS}

The feasibility study yielded several major conclusions and recommendations concerning the Building System Integration Laboratory.

\subsection{CONCLUSIONS}

Regarding the need for a research facility such as a BSIL, the study concluded that

- Building system integration research is needed. The results of this study and other investigations of building science research show there is a critical need for building system integration research. It has been estirnatcd that a properly designed building with integrated building subsystems can decrease a building's energy consumption by between $30 \%$ and $60 \%$.

\section{- A BSIL is needed for effective building system} integration researcb. Although several options are available for conducting system integration research, the study shows that a significant amount of critical research must be conducted in a BSIL for maximum effectiveness. In many cascs, a BSIL is the only viable option for conducting the required research.

- The BSIL could contribute to fundamental improvements in how buildings are designed, built, and operated. Fundamental changes to design, construction, or operation occur infrequently because both initial change and any failure are very costly. Changes to components occur because they can be tested in a laboratory and localized in field tests first. However, component changes result in only incremental changes to building energy use. A BSIL would provide a testbed and demonstration site for more fundamental building-scalc improvements. New approaches to solving the problems facing building designers and operators are more likely to come from a facility specifically dedicated to system integration research.

- A BSIL should focus on commercial huildings. In this study, many residential buildings were identified that can serve as experimental and test facilitics for residential building system integration. Similar facilities did not exist for commercial buildings.

- There will be substantial improvements in building technologies if a BSIL is built that would not occur without such a facility. Developing a BSIL will realize potential energy savings, increase international competitiveness in the buildings industry, decrease costs for building owners and operators, and provide a showcase for new products. The study results clearly indicate that a BSIL is a vital component of building sciences research. Proceeding with its establishment will positively affect the U.S. buildings industry.

Conclusions regarding the technical and economic feasihility of constructing a BSL are based on the conceptual design effort. These include the following:

- A BSIL is technically feasible. The design work shows that a BSIL is technically feasible. The desigu process did not identify any technical problems that would preclude or hinder successful construction and operation of a BSIL.

- A BSIL is costeffective. The cost of the initial phase of a BSIL is estinated to be $\$ 2.7$ million. The cost of a BSIL is reasonable when compared to the advantages to the international competitiveness of the U.S. buildings industry and the estimated $\$ 12$ to $\$ 15$ billion that can be saved by cutting 3 to 4 quads of commercial building enetgy use.

- Phased coustruction is feasible. The design shows that phased construction is technically feasible, despite some limitations to research capability associated with the first two phases of the construction.

\subsection{RECOMMENDATIONS}

The study resulted in cwo recommendations:

- A BSIL focusing on commercial building system integration sbould be built. Such a facility is needed, is feasible, and would bc cost-effective. 
- The BSIL should be built in three phases. Given current budget constraints, phased construction should be undertaken. The first phase should be an extendable, four-story test building approximately 54 feet by 54 feet. Design work should commence as soon as possible. 


\subsection{REFERENCES}

American Consulting Engineers Council Research \& Management Foundation. 1989. Whole-Building Systems Integration Laboratory Survey - Survey of Engineering School Faculty. PNL-6986, Pacific Northwest Laboratory, Richland, Washington.

Claridge, D. E., ed. 1986. Proceedings of a Workshop on Research Needs in HVAC Systems. University of Colorado, Boulder, Colorado.

Drost, M. K., B. M. Johnson, and D. B. Crawley. 1989. First Workshop on the Building System Integration Laboratory. PNL-6991, Pacific Northwest Laboratory, Richland, Washington.

Energy Information Administration. 1989. Nonresidential Building Energy Consumption Survey: Commercial Buildings Consumption and Expenditures 1986. DOE/ELA-0318(86), U.S. Department of Energy, Washington, D.C.

Gillette, G., and M. A. Brown. 1986. Occupant Evaluation of Commercial Office Lighting: Volume 1, Methodology and Bibliography. PRNL/ TM-10264/V1, Oak Ridge National Laboratory, Oak Ridge, Tennessee.

Heidell, J. A., and Z. T. Taylor. 1985. "Comparison of Empirically Measured End-Use Metered Data with DOE 2.1 Simulations." In Building Energy Simulation Conference Notebook, pp. 290-295. Solar Energy Research Institute, Golden, Colorado.

Hill, J. E., W. B. May, Jr., T. E. Richtmyer, J. Elder, R. L. Tibbott, G. T. Yonemura, C. M. Hunt, and P. T. Chen. 1981. Peformance of the Norris Cotton Federal Office Building for the First 3 Years of $O p$ eration. NBS BSS 133, National Bureau of Standards, Washington, D.C.

Marseillc, T. J., B. K. Jobnson, R. P. Wallin, S. A. Chiv, and D. B. Crawley. 1989. Initial Findings:

The Integration of Water Loop Heat Pump and Building Structurol Thermal Storage Systems. PNL-6751, Pacific Northwest Laboratory, Richland,

Washington.
Norford, L., A. Rabl, L. Ryan, J. Spadaro, and R. H. Socolow. 1986. "Energy Use in the Enerplex Office Buildings: A Progress Report." In Large Building Technologies - Proceedings from the ACEEE 1986 Summer Study on Energy Efficiency in Buildings, Volume 3, pp. 3.146-3.159. American Council for an Energy-Efficient Economy, Washington, D.C.

Office of Buildings and Community Systems. 1988. Enengy Conservation Goals for Buildings - A Report to the Congress of the United States. DOE/CE-0224, U.S. Department of Energy, Washington, D.C.

Office of Policy, Planning and Analysis. 1985. Notional Energy Policy Plan Projections to 2010. DOE/PE-0029/3, U.S. Department of Energy, Washington, D.C.

Pacilic Northwest Laboratory. 1986. Building System Integration Research - Recommendations for a U.S. Department of Energy Multiyear Program Plan. PNL-5696, Pacific Northwest Laboratory, Richland, Washington.

Piette, M. A. 1986. "A Comparison of Measured End-Use Consumption for 12 Energy-Efricient, New Commercial Buildings." In Large Building Technologies - Proceedings from the ACEEE 1986 Summer Study on Energy Efficiency in Buildings, Volume 3, pp. 3.176-3.192. American Council for an EnergyEfficient Economy, Washington, D.C.

Stoops, J. L., J. J. Deringer, S. Moreno, and H. P. Misuriello. 1984. Summay Report: The BEPS Redesign of 168 Commercial Buildings. PNL-5123, Pacific Northwest Laboratory, Richland, Wastington. 



\subsection{BIBLIOGRAPHY - BUILDING SYSTEM INTEGRATION RESEARCH REPORTS}

Bowen, W. M., S. Moreno, and A. R. Olsen. September 1982. Climate Selection and Development of Climate Indicators. PNL-4435, Pacific Northwest Laboratory, Richland, Washington.

Pacific Northwest Laboratory. February 1983. Proceedings of the Designing and Managing Energy Conservation Conscious Commercial Buildings Workshop, July 19-20, 1982, Denver, Colorudo. CONF820733, Pacific Northwest Laboratory, Richland, Washington.

Stoops, J. L., J. J. Dcringer, S. Moreno, and H. P. Misuricllo. May 1984. Summary Repon: The BEPS Redesign of 168 Conmercial Buildings. PNL-5123, Pacific Northwest Laboratory, Richland, Washington.

Olsen, A. R., S. Moreno, J. J. Deringer, and C. R. Watson. August 1984. Weather Data for Simplified Energy Calculation, Volume I. Eastem United States: TRY Data. PNL-5143 Vol, I, Pacific Northwest Laboratory, Richland, Washington.

Olsen, A. R., S. Moreno, J. J. Deringer, and C. R. Watson. August 1984. Weather Dato for Simplified Energy Calculation, Volume II. Middle United States: TRY Data. PNL-5143 Vol. II, Pacific Northwest Laboratory, Richland, Washington.

Olsen, A. R., S. Moreno, J. J. Deringer, and C. R. Watson. August 1984. Weather Data for Simplified Energy Calculation, Volume III. Westem United States: TRY Dato. PNL-5143 Vol. III, Pacific Northwest Laboratory, Richland, Washington.

Olsen, A. R., S. Morcno, J. J. Deringer, and C. R. Watson. August 1984. Weather Data for Simplified Energy Calculation, Volume IV. United States: WYEC Data. PNL-5143 Vol. IV, Pacific Northwest Laboratory, Richland, Washington.
Burt Hill Kosar Rittelmann Associates. January 1985. Small Office Building Handbook: Design for Reducing First Costs \& Utility Costs. Van Nostrand Reinhold, New York.

Heidell, J. A., R. P. Mazzucchi, and R. W. Reilly. April 1985. Commercial Building End-Use Energy Metering Inventory. PNL-5027, Pacific Northwest Laboratory, Richland, Washington.

Claar, C., R. P. Mazzucchi, and J. A. Heidell. June 1985. Project on Restaurant Energy Performance End-Use Monitoring. PNL-5462, Pacific Northwest Laboratory, Richland, Washington.

Claar, C., R. P. Mazzucchi, and J. A. Heidell. June 1985. Project on Restaurant Energy Performance End-Use Monitoring: Appendices. PNL-5462, Pacific Northwest Laboratory, Richland, Washington.

Reilly, R. W. January 1986. Recommendations for a Multi-Year Plan for Building Systems Integration Rpsearch. PNL-5696, Pacific Northwest Laboratory, Richland, Washington.

National Association of Home Builders. August 1986. Cutting Casts in Multifamily Housing: Case Studies in Energy Savings. National Association of Home Builders, Washington, D.C.

Heidell, J. A., and J. J. Deringer. February 1987. Developing an Energy Design Tool - Phase I Report. PNL-5709, Pacific Northwest Laboratory, Richland, Washington.

Crawley, D. B, R. S. Briggs, J. W. Jones, W. W. Seaton, J. E. Kaulman, J. J. Deringer, and E. W. Kennett. April 1987. Development of WholeBuilding Energy Design Tangets for Commencial Buildings - Phase 1 Planning Volume 1: Final Report. PNL-5854 Vol. 1, Pacific Northwest Laboratory, Richland, Washington.

Note: The Pacific Northwcst Laboratory research reports and conference proceedings listed in this bibliography are available from National Technical Information Service, U.S. Department of Commerce, 5285 Port Royal Road, Springrield, VA 22161. All other documents listed may be obtained directly from the publishers. 
Crawley, D. B., R. S. Briggs, J. W. Jones, W. W. Seaton, J. E. Kaufman, J. J. Deringer, and E. W. Kennett. September 1987. Development of WholeBuilding Energy Design Targets for Commercial Buildings - Phase 1 Planning Volume 2: Technical Report. PNL-5854 Vol. 2, Pacific Northwest Laboratory, Richland, Washington.

Brambley, M. R., D. B. Crawley, D. D. Hostetler, R. C. Stratton, M. S. Addison, J. J. Deringer, J. D. Hall, and S. E. Selkowitz. December 1988. Advanced Energy Design and Operating Technologies ResearchRecommendations for a U.S. Department of Energy Multi-Year Program Plan. PNL-6255, Pacific Northwest Laboratory, Richland, Washington.
Marseille, T. J., B. K. Johnson, R. P. Wallin, S. A. Chiu, and D. B. Crawley. January 1989. Initial Findings: The Integration of Water Loop Heat Pump and Building Souctural Mass Storage Systems. PNL6751, Pacific Northwest laboratory, Richland, Washington.

Crawley, D. B., M. K. Drost, and B. M. Johnson. September 1989. The Technical and Economic Feasibility of Establishing a Building System Integration Laboratory. PNL6971, Pacific Northwest Labor atory, Richland, Washington.

Note: The Pacific Nortbwest Laboratory research reports and conference proceedings listed in this bibliography are available from National Technical Information Service, U.S. Department of Commerce, 5285 Port Royal Road, Springfield, VA 22161. All other documents listed may be obtained directly from the publishers. 
APPENDIX A

TECHNICAL REVIEW PANEL PARTICIPANTS 


\section{APPENDIX A}

\section{TECHNICAL REVIEW PANEL PARTICIPANTS}

Dwight Beranek

Headquarters, USACE

Attention: CEEC-EE

20 Massachusetts Avenue NW

Washington, DC 20314-1000

Mort Blatt

Subprogram Manager of Commercial

Building Systems

Electric Power Research Institute

3412 Hillview Avenue

P.O. Box 10412

Palo Alto, CA 94303

James R. Brodrick

Gas Research Institute

8600 West Bryn Mawr Avenue

Chicago, IL 60631

Charlie Claar

Associate Professor

Pennsylvania State University

104 Engineering A

University Park, PA 16802

Larry Flowers

Solar Energy Research Institute

1617 Cole Boulevard

Golden, CO 80401

Carol Gardner

U.S. Department of Energy

Forrestal Building

1000 Independence Avenue SW

Washington, DC 20585

Harry Gordon

Burt Hill Kosar Rittelmann Associates

1056 Thomas Jefferson Street NW

Wasbingion, DC 20007
Daie L. Herron

U.S. Army Construction Engineering

Research Laboratory

Attention: CER-ES

2902 Newnark Drive

Interstate Research Park

Champaign, IL 61820

Doug Hittle

Department of Mechanical Engineering

Colorado State University

Fort Collins, CO 80521

Karl Johnson

Electric Power Research Insuitute

3412 Hillview Avenue

P.O. Box 10412

Palo Alto, CA 94303

Mike Karnitz

Oak Ridge National Laboratory

P.O. Box X

Oak Ridge, TN 37831

Joseph Klems

Lawrence Berkeley Laboratory

Building 90, Room 3111

One Cyclotron Road

Berkeley, CA 94720

Jan Kreider

Civil Engineering ECOT-34

University of Colorado

Regent Road

Campus Box 7

Boulder, CO 80309

Ian lewin

President

Lighting Sciences

7830 East Evan Road

Scottsdale, AZ 85260 
Neil R. Patterson

Trane Company

Building 17-2

3600 Pammel Creek Road

La Crosse, WI 54601

Joe Pouzar

Manager of Special Projects

NASA Jobnson Space Center

Houston, TX 77058

Richard Rittelmann

Senior Vice President

Burt Hill Kosar Rittelmann Associates

400 Morgan Center

Butler, PA 16001

James Smith

U.S. Department of Energy

Forrestal Building

1000 Independence Avenue SW

Washington, DC 20585

Ray Sterling

University of Mirnesota

CME Building, Room 790

500 Pillsbury Drive SE

Minneapolis, MN 55455

Steve Treado

National Institute of Standards

and Technology

Building 226, Room A-313

Gaithersburg, MD 20899

Jack Warner

Research \& Management Foundation

American Consulting Engineers Council

1015 15th Street NW, Suite 802

Washington, DC 20005

\section{Design Workshop Participants}

Joe S. Bush

Kaiser Engineers

872 45th Avenue

San Francisco, CA 94121

Drnty B. Crawley

Pacific Northwest Laboratory

P.O. Box 999

Richland, WA 99352

M. Kevin Drost

Pacific Northwest Laboratory

P.O. Box 999

Richland, WA 99352

Doug Hittle

Dcpartment of Mechanical Engineering

Colorado State Unjversity

Fort Collins, CO 80521

Jan Kreider

Civil Engineering ECOT-34

University of Colorado

Regent Road

Campus Box 7

Boulder, CO 80309

Neil R. Patterson

Trane Company

Building 17-2

3600 Pammel Creek Road

La Crosse, WI 54601

Jack Warner

Research \& Management Foundation

American Consulting Engineers Council

1015 15th Street NW, Suite 802

Washington, DC 20005 
APPENDIX B

THE DESIGN WORKSHOP 


\section{APPENDIX B}

\section{THE DESIGN WORKSHOP}

The design workshop was held to define the capabilities needed in the BSIL and to generate creative approaches to their design. The workshop participants were a subset of the technical review panel and are identified in Appendix $A$. The workshop took place on April 25 and 26, 1988, in Washington, D.C.

The design meeting consisted of four activities. First, the resuits of the first technical review panel workshop were presented and discussed. Second issues related to the need for the BSIL were discussed. The discussion identified reasons for building and not building a BSIL. These discussions focused attention on the unique features required in a BSIL. Following the general discussion, the group subdivided into four-person design teams that developed independent design approaches to the BSIL. Finally, each design team presented its concept to the other teams for comment and discussion.

The design workshop produced two important results: a list of reasons for building and not building the BSIL and a series of design concepts for the facility.

\section{CONSTRUCTION RATIONALE}

The development of conceptual designs depended on having some agreement on the capabilities required in a BSIL. Required capabilities were identified from the results of the first technical review panel workshop and by a general discussion held during the design meeting. The general discussion involved the identification of reasons for building and not building a BSIL.

The participants identified the following reasons for not building a BSIL:

- Tests can be done onsite, in other labs, and on a small scale.
- Too much time will be spent on setting up and taking down tests in a BSIL to produce useful results.

- Technology transfer is already taking place.

- Getting whole-building system data is almost impossible.

- Scarce dollars would be expended without educating the next generation of designers.

- Problems result from poor communication between users and laboratories.

The participants also developed a list of reasons to build the BSIL. These include the following:

- Zero energy use buildings can be studied only on a whole-building level.

- Incremental improvements will result from studies on existing buildings; new breakthroughs will need the capabilities of a BSIL.

- The BSIL will serve as a tesi bed for new systems.

- A BSIL will provide the capability for testing concepts not allowed by building codes.

- The building industry will gain an understanding of building physics and integrative issues.

- A BSIL will provide the capability for isolating system effects and other system unknowns.

- A BSIL will provide the capability for studying and developing inteltigence for building controls.

- A BSIL represents an investment in the future of buildings. 
- Test results from a BSIL will be more credible than tests at separate-effects facilities.

\section{DESIGN CONCEYTS}

Two design teams independently developed concepts for a BSIL. One of the teams also investigated the integration of a BSI with field testing in leased or purcbased unoccupied commercial buildings.

All the proposed designs included a number of common features that were incorporated into the prelininary design of the BSIL. These features are

- a thermally guarded test building, in which the thermal guard is provided by an external envelope that will allow selective and controlled exposure of the envelope to the environment

- a structure with at least three floors, with minimum dimensions of $100 \mathrm{ft}$ by $100 \mathrm{ft}$ for each floor
- easily reconfigurable internal partitions, operating systems (lighting, electrical, HVAC), and external facade

- ancillary facilities with office space, conference rooms, storage, and computer facilities.

The design workshop participants concluded that a whole-buildings research program should be structured as follows:

- The BSIL should be one part of a whole-building research program. The program should include coordination, technology transfer, and research, and should be conducted at a BSIL, existing facilities, and universities.

- Where appropriate, the BSIL should be supplemented by whole-building research in leased and purchased unoccupied buildings. 
APPENDIX C

CONCEPTUAL DESIGN AND COST ESTIMATE FOR THE BUILDING SYSTEM INTEGRATION LABORATORY 


\author{
ENGINEERING REPORT \\ BUILDING SYSTEMS INTEGRATION LABORATORY
}

Prepared for

PACIFIC NORTHWEST LABORATORY

August 1988

For the U.S. Department of Energy Contract DE-AC06-87RL10900

Prepared by

KAISER ENGINEERS HANFORD COMPANY Richland, Washington

KEH-88-46

B67329

\title{
RAIGEFA ENGINEERS
}




\section{APPROVAL}

KEH-88-46

ENGINEERING REPORT

FOR

BUILDING SYSTEMS INTEGRATION LABORATORY

Prepared by

KAISER ENGINEERS HANFORO COMPANY

Richland, Washington

for

PAC IFIC NORTHWEST LA8ORATORY

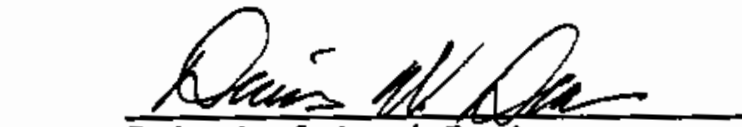

Principal Lead Engineer

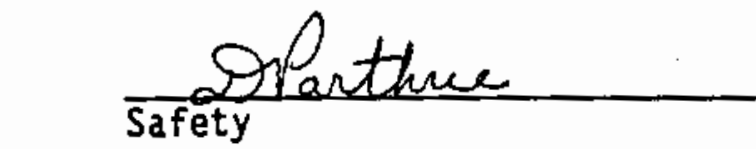

fa chief Design Engineer

Project Manager

Pacific Northwest Laboratory

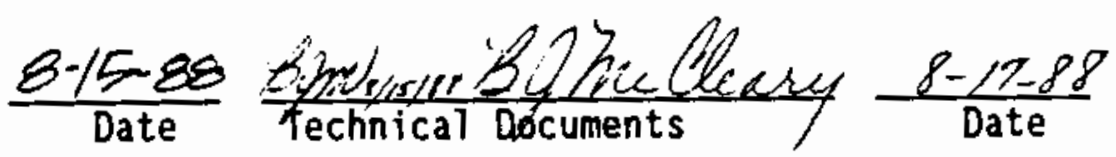

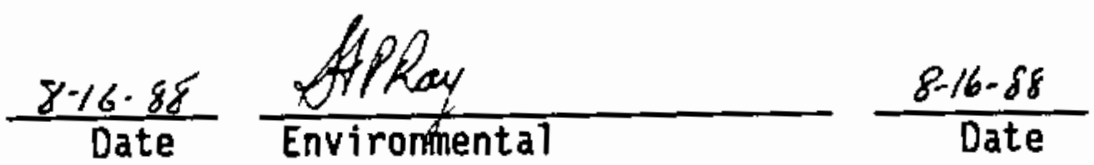

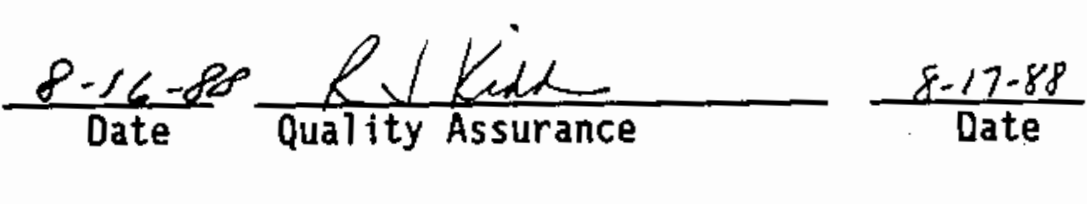

\section{Date}




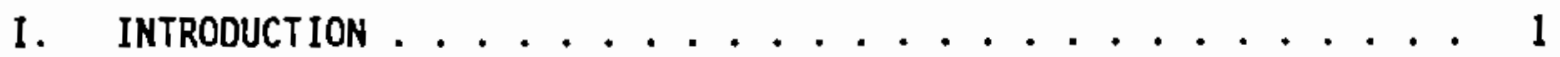

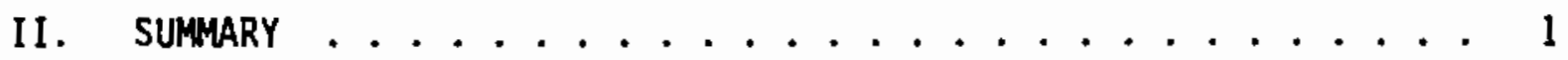

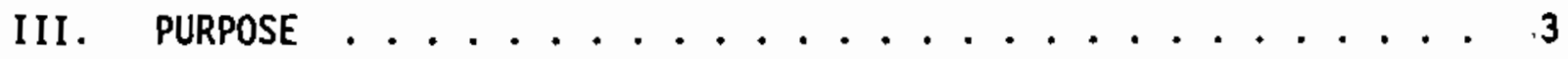

IV. DESCRIPTION $\ldots \ldots \ldots \ldots$

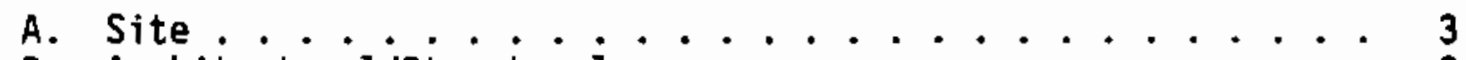

B. Architectural/Structural ............. 3

C. Mechanical ................. 8

D. Electrical .................. 10

\section{APPENDICES}

Appendix A. Cost Estimate

Appendix B. Sketches 


$-$




\section{ENGINEERING REPORT \\ BUILOING SYSTEMS INTEGRATION LABORATORY}

\section{INTRODUCTION}

A Building Systems Integration Laboratory (BSIL) is being established by the U. S. Department of Energy (DOE) to investigate issues related to complete building systems, their integration and interactions. As compared to other building research facilities, the BSIL will concentrate on problems that can only be addressed by considering a complete building rather than an isolated zone or subsystem. The BSIL will be open to all DOE contractors, other government agencies and laboratories, and to private researchers and vendors.

Kaiser Engineers Hanford Company (KEH) was engaged by Pacific Northwest Laboratory (PNL) to develop this engineering report to describe the facility design and construction of the BSIL.

\section{SUUMMARY}

The objective of the Building Systems Integration Laboratory (BSIL) is to provide a facility capable of investigating whole building systems and their interactions on a complete building scale. These systems include building facade types, roofing types, and mechanical/electrical systems and controls. Also investigated will be their relationship to external environmental elements. The facility will be designed to simulate these various conditions as a typical commercial office building with a modular, interchangeable exterior skin, and a flexible interior test area. To accomplish this, the facility will consist of a multi-level steel-framed test building and a steel-framed outer envelope that encloses the entire test building. The facility will include the following unique features:

- Removable and changeable facades of the test building.

- Environmentally controlled annulus around the test building to provide varied environmental conditions. 
- Removable opaque paneis on the outer envelope to provide selective exposure of the test building to the exterior environment.

- Flexible open test area within the test building allowing varied partition configurations and tempered space volume.

- Floor to floor heights that will allow varied ceiling heights.

- Removable floor and roof panels for full building height atrium testing.

- Interchangeable heating, ventilating, and air conditioning (HVAC) systems in test area.

- Interchangeable lighting systems in test area.

The BSIL will consist of $53,656 \mathrm{ft}^{2}$ and be divided into three construction phases. Each phase of the facility will be capable of investigating whole building systems independently of the following phase. Phase 1 will consist of $17,224 \mathrm{ft}^{2}$ and include a muiti-level test building with service core, facility support area, and outer envelope area. Phase 2 will consist of $15,840 \mathrm{ft}^{2}$ and include additional multi-level test building area, facility support area, outer envelope, and a completed service core. Phase 3 will consist of $20,592 \mathrm{ft}^{2}$ and complete the remainder of the facility. It will include additional multi-level test building area, facility support area, and completion of the outer envelope around and above the test building. Phase 3 will also include a 5,000 $\mathrm{ft}^{2}$ storage building.

The BSIL, as described in this report, will have a total estimated cost of approximately $\$ 10,800,000$. Approximate estimated cost, in phases, will be $\$ 2,750,000$ for phase 1, $\$ 2,660,000$ for phase 2, and $\$ 5,430,000$ for phase 3. (See appendix A, Cost Estimate, for details.) 


\section{PURPOSE}

The purpose of the report is to evaluate the programatic requirements for the facility, to develop a preliminary facility design, and approximate facility cost to meet these requirements. It is not the intent of this report to evaluate the need for this facility, or to justify its construction.

\section{DESCRIPTION}

\section{A. Site}

The BSIL facility has been designed for a generic site. Site development required of any site will include excavation, landscaping, parking, and utility services.

\section{B. Architectural/Structural}

\section{Facility Design}

The BSIL will consist of a test building, facility support area, outer envelope area, and a storage building. (See appendix B, Sketches.)

The test building will be a multi-level building with structural framework designed to accept modular removable and interchangeable exterior wall panels of varying facade types. A 20-ft main level floor-to-floor height is also included in the design to allow for flexible ceiling heights to accommodate interior space testing. The second and third levels will have a $15-\mathrm{ft}$ floor-to-floor height. This height will allow enough space above the suspended ceiling for heating, ventilating, and air conditioning (HVAC) ducting, test equipment, and controls. The second and third levels and roof will also have an area where the panels will be removable for atrium design testing.

The outer envelope will enclose the test building to provide an environmentally controlled annulus. It will be constructed in a 
modular form to be compatible with the test building facade panel modules. This will allow specific zones at any level of the test building to be selectively exposed to the natural environment while other zones are environmentally controlled. This will be accomplished by removing a portion of the outer envelope panels and adding panels in the annulus to close off the remainder of the annulus from the natural environment.

To remove and interchange the test building exterior facade panels, the outer envelope panels will be removed as required. The outer envelope panels will be of lightweight material and removable by hand from portable scissor-lift piatform equipment. The test buitding facade and floor panels will require heavy-duty, portable equipment for removal. This equipment is not included in the scope of this project.

The BSIL will also include a facility support area within the lower level. This area will provide space for imnediate support of experimentation in the test building. However, spaces to support scientists and other personnel; such as additional offices, conference rooms, computer rooms, etc., is not included within the BSIL. These areas will be located within existing adjacent facilities.

A service core will be provided within the center of the test building. This core will provide space for egress stairways, a freight elevator, mechanical/electrical space for experimental equipment, and a service shaft for mechanical/electrical and instrumentation control lines. The core will be designed to provide easy access to experimental equipment and controis.

The BSIL will be constructed in 3 phases. Phase 1 will consist of a $12,220 \mathrm{ft}^{2}$ multi-level test building with a service core and penthouse, a $3,820 \mathrm{ft}^{2}$ facility support area in the lower level and 1,184 $\mathrm{ft}^{2}$ of annulus area. (See sketch ES-B67327-A3 in appendix B.) For this phase the support area will include the 
main entry, facility control room, restrooms, janitor closet, mechanical room, and service core. The outer envelope will enclose an 8-ft wide annulus around the south facade and $2 / 3$ of the east and west facades. The steel structure of the outer envelope will extend across the roof for added lateral support. This structure will also provide support for the completed outer envelope in phase 3. For emergency egress, a temporary metal exterior stair will be constructed.

Phase 2 will consist of an additional 11,736 $\mathrm{ft}^{2}$ of multi-level test building with corresponding service core and penthouse, $3,672 \mathrm{ft}^{2}$ of facility support area in the lower level, and $432 \mathrm{ft}^{2}$ of annulus area. (See sketch ES-B67329-A4 in appendix B.) The facility support area will include the addition of a material assembly area, shop, instrumentation/electronic shop, and storage. The service core and penthouse will be completed during this phase. The outer envelope will be relocated from the west facade of phase 1 to the west facade of phase 2 and the south facade will be enclosed. The outer envelope will enclose an $8-\mathrm{ft}$ wide annulus around the entire south facade and $2 / 3$ of the east and west facades. Again, the steel structure of the additional outer envelope will extend across the roof for added lateral support and provide support for the completed enveiope in phase 3.

Phase 3 will complete the facility and consist of an additional $13,824 \mathrm{ft}^{2}$ of the multi-level test building, 4,608 $\mathrm{ft}^{2}$ facility support area in the lower level, and 2,160 $\mathrm{ft}^{2}$ of annulus area. (See sketch ES-B67329-A5, appendix B.) The facility support area will include an additional mechanical room for annulus HVAC, storage, a shipping/receiving area, loading dock, and offices. The outer envelope will be completed during this phase and will enclose the entire test building including the roof.

\section{Program Areas}

The completed BSIL facility will provide a test building, facility support area, and outer envelope area for investigating issues 
related to whole building systems. The administration and other support offices, conference rooms, and computer facilities will be located in existing buildings adjacent to the BSIL. The following program areas will be provided within the completed phase 3 BSIL design. Phasing of these areas is discussed previously under facility design.

\section{Test Building}

The te'st building will house an open test area and service core. The open test area will allow for installation of temporary partitions and suspended ceilings for flexibility of experimental area testing. The open test area will also provide the capability of testing atrium designs. The service core will include a freight elevator, stairs, mechanical/ electrical space for experimental equipment, mechanical/ electrical shaft, and a penthouse for elevator equipment and a portion of the HVAC equipment required for the annulus area.

\section{Eacility Support Area}

The facility support area, located on the lower level of the BSIL, will provide various support services. This area will include the main entry, shipping/receiving area, material assembly area, general shop, instrumentation/electronics shop, storage, three offices, men's and women's restrooms, janitor closet, facility control room, and two mechanical rooms. These areas will support the functional needs of the facility. The material assembly area will be used to assembie test apparatus and then move it to its testing location. The shop and instrumentation/eiectronic shop will provide maintenance of test equipment and electronics. The facility control room will provide space for HVAC and other facility controls.

3. Outer Envelope Area

The outer envelope area will provide an environmentally controiled annulus around the entire test building. The 
envelope will maintain specific environmental conditions as required by investigative experiments.

\section{Storage Building}

The storage building will be used for storing both test building facade panels and the outer envelope panels as they are removed or replaced. This building will not be environmentally controlled.

\section{Facility Structure and Finishes}

The BSIL facility test building will be structured to provide ease of installation and removal of various moduiar test facades. These test facades will be panalized and of all types from precast concrete with varied fenestration to glass curtain walls. Therefore, the test building will be constructed of structural steel columns and beams, with concrete on metal deck floors, metal deck roof, and removable 8-in. thick precast exterior wall panels. Precast concrete panels have been selected as the first test facade because they represent an extreme case for cost and support structure requirements. These panels will include facing studs, R-11 insulation, and interior gypsum board. Also included within the test building will be suspended acoustical tile ceilings and carpeting standard to commercial office buildings. A 36- by 36- $\mathrm{ft}$ area of the second and third floors and roof will be provided with removable precast concrete floor and roof panels for atrium testing. The roofing system will consist of $R-19$ rigid insulation and an elastomeric single-ply membrane.

The service core will include 8 -in. concrete block vertical shaft walls and permanent partition walls constructed of metal studs with gypsum board. The ceiling and floor in the lobby area witl be provided with suspended acoustical tile and carpeting.

The facility support area will be constructed of cast-in-place concrete columns, beams, walls, floor, and ceiling. The partition walls will be constructed of metal studs with gypsum board and 
will be 1 -hr rated at all corridors. Ceilings will be suspended acoustical tile in the corridors, offices, and facility control room and will be suspended gypsum board in the restrooms. Floors will be carpet in the offices and sheet viny? in the corridors, material assembly area, shop, instrumentation/electronics shop, facility control room, janitor closet, and restrooms. All other floors will be sealed concrete.

The outer envelope will be framed with structural tube steel trusses and steet sections. The envelope will consist of modular 5- by 9-ft removabie sandwich paneis assembled of foil paper between two panels of clear double-walled, impact resistant polycarbonate material with ultraviolet resistant surfaces, and a) uminum framing with attachment flanges. These panels will be lightweight, easily interchangeable by hand, and will provide an approximate $U$ value of $0.4 \mathrm{Btu} / \mathrm{hr} / \mathrm{ft}^{2} \mathrm{~F}$. The panels can be reassembled so the opaque foil paper can be removed to provide transparent paneis when required for experimentation. The roof panels will be of the same construction but will not be removable. The annulus enclosed by the envelope will extend $10-\mathrm{ft}$ belowgrade to allow space for HVAC ductwork and other mechanical services to minimize interference with the test building.

The storage building will be a 50 - by $100-\mathrm{ft}$ pre-engineered metal building with $20-\mathrm{ft}$ roof height. The floor will be sealed concrete. The interior will remain unfinished.

\section{Mechanical}

The BSIL facility HVAC system will be comprised of three systems. These systems will operate separateiy and consist of the annulus system, facility support area system, and the test building system.

The annulus HVAC system will be designed to provide heating, cooling, humidity control, and normal air filtration for the annulus area enveloping the test building. The system will be designed to maintain a climate around the test building meeting the 
objectives of a specific experiment within the test building. The system will be controlled such that the roof and each facade of the annulus can be zoned separately. The annulus temperature will be controlled between $40 \mathrm{~F}$ and $80 \mathrm{~F}$. Conditioned air will be circulated throughout each zone of the annulus by air handling units. Air handling units for this system will be located within the lower level mechanical rooms and the penthouse when phase 3 is completed.

The facility support area HVAC system will provide standard heating, cooling, humidity control and air filtration for the facility support area located within the lower level. The system will maintain a safe and comfortable environment for the operating personnel and equipment. Air handling units for this system will be provided within a lower ievel mechanical room.

The test building system will consist of air handling equipment located within the lower level. This system will be designed to be interchangeable, allowing testing of a wide range of components and systems. Other experimental HVAC equipment can also be located within mechanical rooms located on each level of the test building. Ductwork within the test building will be double-walled insulated duct with $f l$ anged connections, sealed and bolted for ease of duct modifications. This will allow duct reconfiguration/alterations to suit the varying requirements of the test building.

The ductwork routing and supports within the annulus area will be as unobstructive as practical in order to permit the test building to meet its objectives. The ductwork mains will be running in the belowgrade area of the annulus, while duct risers will be running vertically at the corners of the outer envelope, to warrant proper air distribution and ambient temperature control. Ductwork will be reconfigurable and designed similar to that for the test building. 
Air handling units for the different systems will consist of a suppiy air fan, hot water heating coils, chilled water cooing coil, humidifier, $80 \%$ efficiency throwaway air filters, mixing box and a return air fan. Outside air will be introduced by the air handling units in varying amounts to maintain a positive ambient air pressure and make up for the air exhausted from the restrooms. Cooling towers will be located at a location away from the test building on the BSIL site.

Standard potable water and sewerlines and connections will be provided for the restrooms and janitor closet located in the lower Tevel.

\section{Electrical}

The electrical system will be sized for electrical testing loads and will be flexible for easy access to interchanging instrumentation systems. The system will be instrumented to investigate power quality and power factor.

Space will be provided in the mechanical shaft and above the suspended ceilings for instrumentation as required. 
APPENDIX A

Cost Estimate

A-1 
KA TSER EMGE MEERS HAMFORO

PACIFIC MORHTHEST LABORAJORY

JOG 10.247100

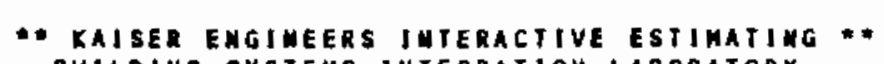

QUILDING SYSTEHS IHTEGRATIOW LABORATORY

KEHRO1 - PROJECT COSI SUHHARY
PACE 1 OF 6

DAIE 08/15/8G 05:50

BY F.C.DAY

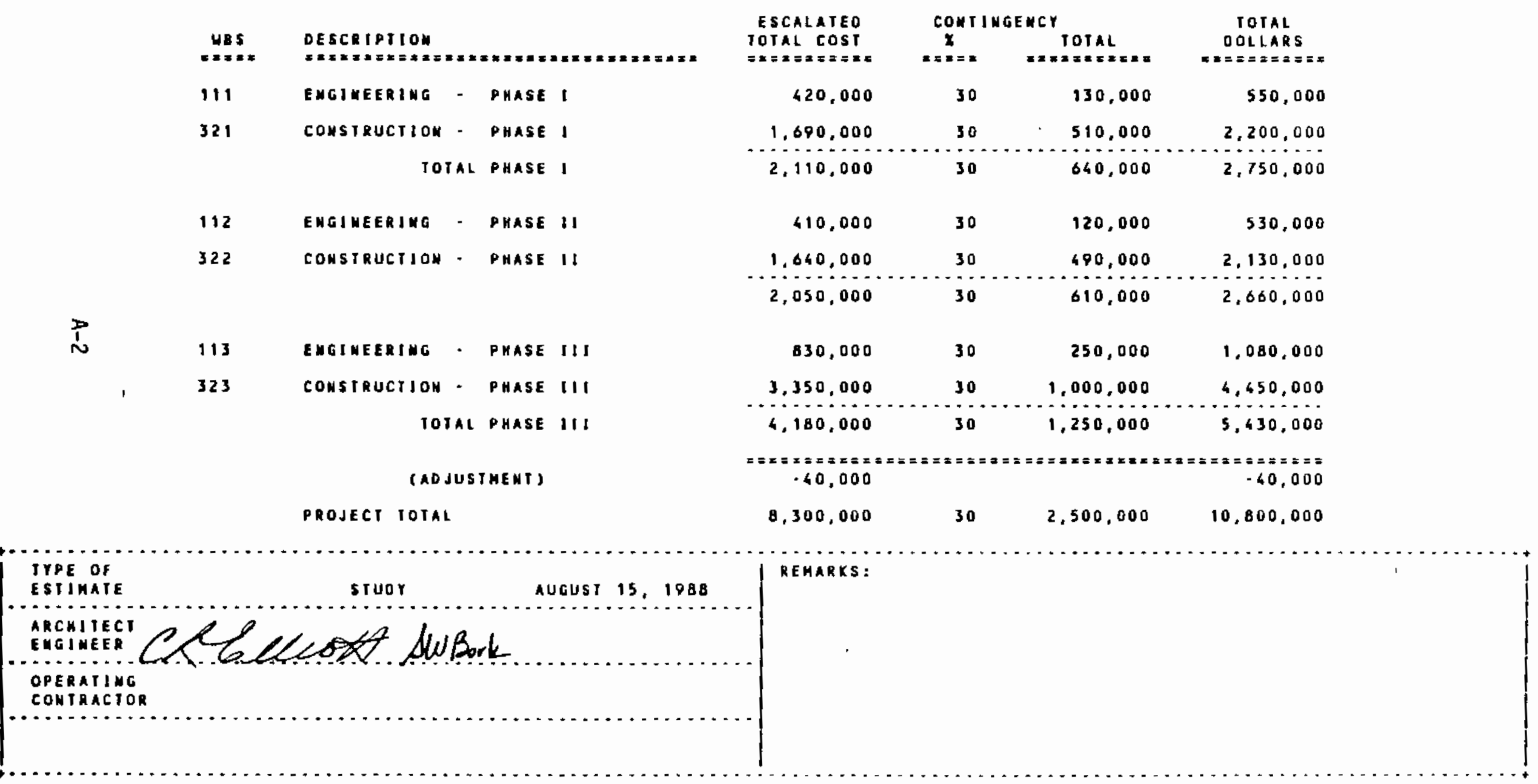

(ROUNOED/ADJUSTEO TO THE HEAREST" 10,000/100,000" - PERCENTAGES NOJ RECALCULAIED JO REFLECT ROUHDING 
KAISER EHGINEERS MAHFORD

PACIFIC NORHIUEST LABORATORY

JOB NO. 247100

UBS DESCRIPJION

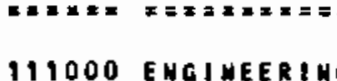

11.2000 EHGIHEERING

I1.2000 ENG INEER ING
113000 EHGINEERING

(PHASE I)

(PHASE 11)

(PHASE III)

SUBTOTAL 1 EWGINEERING

\section{SITEUORK \\ 321002 LAB TEST BUILDING (PHASE I)}

SUBTOTAL 321 PHASE I

322001 LAB TEST OUILING (PHASE II) 322002 ENVELOPE

(PHASE III

T

SUETOTAL 322 PHASE II

323003 SIOAAGE BUILDING (PHASE III) 323002 LAB IEST BUILDING (PHASE IIt) 323003 ENVELOPE (PHASE III)

suatotal 323 Phase ItI

SUBTOTAL 3 CONSIRUCTION

PROJECT TOTAL
* KAISER EHGINEERS INTERACTIVE ESTIMATIMG * *

BUILDING SYSTEMS IHIEGRATION LABORATORY

ST UOY

KEHROZ - WORK GREAKDOWN STRUCIURE SUMHARY

ESTIMATE

DIRECT

Total

$x=x= \pm \approx x=$

TOTAL
INOIRECTS
$=== \pm== \pm= \pm$

Sue

IOTAL

420000

$== \pm= \pm= \pm x$

ESCALATIOH

X TOTAL

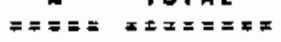

030000

$0 \quad 420000$

410000
$0 \quad 830000$

0.00

0.00
0.00

0.00

0.00

1660000

0.00

132700

1270500

$\begin{array}{rrr}0 & 132700 & 0.00\end{array}$

0.00
0.00
0.00

1693400

290200

0.00

1693400

0.00

1258300

377800

1636100

143600

2396000

811400

3351000

1258300

0.00

0.00

0.00

1636100

0.00
0.00

0.00

2396000

011400

0.00

3351000

6680500

$0 \quad 6680500$

0.00

o
PAGE 2 OF 6

DAIE OB/15/8B OS:50

BY F.C.DAY

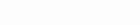

CONT 1 NGENCY

TOIAL $X$ IOTAL

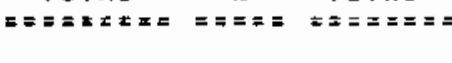

126000

$\begin{array}{lll}420000 & 30 & 126000 \\ 410000 & 30 & 123000 \\ 830000 & 30 & 249000\end{array}$

249000

1660000

$30 \quad 498000$

533000

1079000

2158000

$132700 \quad 30 \quad 39810$

290200

$\begin{array}{rr}30 & 381150 \\ 30 & 87000\end{array}$

1651650

377260

$1693400 \quad 30 \quad 508020$

2201420

$\begin{array}{llll}1258300 & 30 & 377490 & 1635790\end{array}$

377000

113340

2126930

1636100

$30 \quad 490830$

186680

3114800

1054820

4356300

3351000

30

243420

435300

8684650

$30 \quad 2004150$

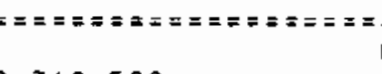

$0,340,500$

8, 340,500

0.00

$==$ 
KAISER ENGI WEERS HANFORO PACIFIC HORTHEEST LABORATORY JOB 10.247100
-* kalser engineers Interactive estimating **

WHOLE BUILDING SYSTENS INTEGRATION LABORATORY

STUDY

KEHROS - ESTIMATE BASIS SHEET
PAGE 3 OF 6

DATE 08/15/BB $12: 40$

BY F.C.DAY

1. DOEUHENTS AMD DRAHIHGS

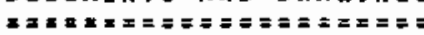

DOCUMENIS: FUNCIIONAL CRIIERIA "BUILOING SYSTEMS JNTEGRATION LABORATORYH (BSIL) FEASIBILJTY STUDY.

DRAUINGS: ES-B67329.A2 ARCH. PLANS A SECTIOH PHASE I, ES-B67239-A3 ARCH. PIAH B SECIJON PHASE It. ES- $667329-A 4$ ARCK. PLAHS 2 SECTIOH PHASE III.

2. ROUNOING - LINE ITEMS:

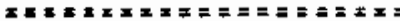

U.S. DEPARTHENT OF ENERGY - DOE ORDER 5100.4 PAGE J-2 SURPARAgRAPH (H), REQUIRES ROUNDING OF A COST ESTIMATE

TO \$10,000 FOR ITEM COST AMO \$100,000 FOR TOIAL COST. REFERENCE: DOE 5IO0.4, FIGURE I-11, DATED 10-31-84.

\section{REMARES}

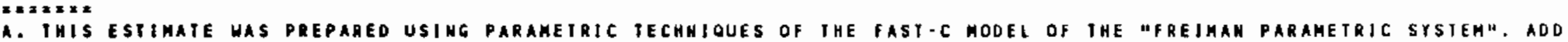

A. IHIS ESTIMATE WAS PREPABEO USING PARAMETRIC TECHA OQUES OF THE TAS

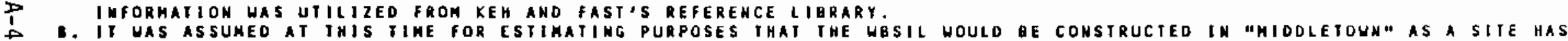
YET JO BE DETERMINED

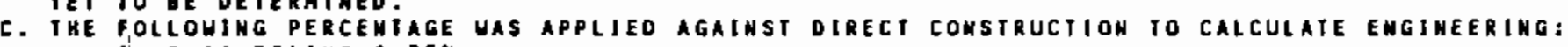
T. ENGINEERING $25 x$

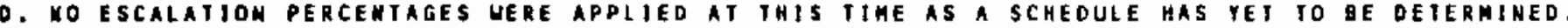

E. FHE FAST-C OUTPUT SHEETS ARE ATTACHED TO SHOW COSTS GENERATED FOR EACH HBS ITEM.

F. PHASE I ESTIMATE CRITERIR:

1. 3 STORY $56, x 54$, IEST STRUCTURE.

2. A 54 X 56. BASEMENT AREA FOR MECHANICAL EOUIPMENT OHLY, RESTROOM AREA, LOADING DOCK, AHD FREIGHT ELEVATOR.

3. OUTER ENYELOPE AROUND $2 / 3$ OF BUILOING WIIH NO ROOF SIRUCIURE.

G. PHASE II ESTIMATE CRITERIA

1. 3 STORY SG, $X$ 10B: TEST STRUCTURE.

2. A S4, X 108, BaSEMENT AREA FOR ADDITIOHAL HECHANICAL AND STORAGE CAPABILITIES

3. EXPANDEO OUIER ENVELOPE AREA.

H. PHASE III ESIIMAIE CRITERIA

1. J STORY 108, X 108. TEST STRUCTURE.

2. A 108. X 108. BASEMENT AREA.

3. A ful EnVElope vith RoOf around test STRUCTURe. 


\section{CAISER ERGIWEERS HANFORD}

$\cos t$

CODE

UAS DESCRIPIIOK

\section{OOO ENGIHEERING}

$\begin{array}{ll}111000 \text { ENGINEERING } & \text { (PHASE I) } \\ 112000 \text { EHGIHERIING } & \text { (PHASE II) } \\ 113000 \text { EHGIHERIING } & \text { (PHASE III) }\end{array}$

TOTAL OOO ENGINEERTING

\section{IMPROVEMENTS IO LAHD}

\section{SITEUORK \\ (PHASE I)}

P

IOTAL 460 IMPROVEMENTS TO LAND

\section{SOI BUILDINGS}

\begin{tabular}{|c|c|c|c|c|}
\hline $\begin{array}{l}321002 \\
321003 \\
322001 \\
322002 \\
323001 \\
323002 \\
323003\end{array}$ & $\begin{array}{l}\text { LAE IEST } \\
\text { ENYELOPE } \\
\text { LAB TEST } \\
\text { ENVELOPE } \\
\text { STORAGE } \\
\text { LAB TES } \\
\text { ENVELOPE }\end{array}$ & $\begin{array}{l}\text { OUIIDING } \\
\text { BUILOING } \\
\text { BUILOING } \\
\text { BUILDING }\end{array}$ & $\begin{array}{l}\text { CPHASE } \\
\text { IPHASE } \\
\text { IPHASE } \\
\text { IPHASE } \\
\text { IPHASE } \\
\text { IPHASE } \\
\text { (PHASE }\end{array}$ & $\begin{array}{l}1) \\
1) \\
113 \\
113 \\
1153 \\
113 \\
11\end{array}$ \\
\hline
\end{tabular}

TOIAL 501 BUILOINGS
PACIFIC MORHTHEST LABORATORY

JOB NO. 247900
"* KaISER EMGIHEERS IHTERACTIVE ESTIMATING *

BUILOING SYSTEHS IWTEGRATION LABORATORY

STUOY

KEHRO4 - COST COOE ACCOUNT SUMHARY
PAGE 4 OF 6

DAIE $08 / 15 / 88 \quad 05: 50$

GY F.C.OAY

\section{ESTJHATE}

DIRECT

TOIAL

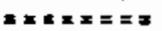

TOTAL
INOTRECTS

SUG
IOTAL

$===== \pm==$

\section{ESCALATION} $x$ TOIAL $== \pm=x=x \pm= \pm x=2$

SUB TOTAL

CONTINGENCY $X$ TOTAL TOTAL

TOTAL DOLLARS

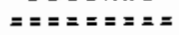

420000
410000
830000

420000

410000

0.00

0.00

0.00

1660000

1660000

0.00

0
0
0
0

420000

410000

830000

$30 \quad 126000$

$30 \quad 123000$

249000

546000

533000

1079000

1660000

498000

2158000

$\begin{array}{lllllllll}132700 & 0 & 132700 & 0.00 & 0 & 132700 & 30 & 39810 & 172510 \\ 132700 & 0 & 132700 & 0.00 & 0 & 132700 & 30 & 39810 & 172510\end{array}$

1270500

290200

377800

143600

2390000

2396000

811400

6547800

132700

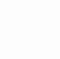

1270500
290200
1258300
377800
143600
2396000
811400

30
30
30
30
30
30
30

$\begin{array}{rr}381150 & 1651650 \\ 87060 & 377260 \\ 377690 & 1635790 \\ 113340 & 491140 \\ 43080 & 186680 \\ 718800 & 3114800 \\ 243420 & 1054820 \\ 1964340 & 8512140\end{array}$

6547800

0.00

6547800

301964340
PROJECT TOIAL

1. 340,500

0
$2,502,150$
$8,340,500$ 


\section{KAISER ENGIHEERS HAMEORD \\ PACIFIC NORHTHEST LABORATORY \\ JOQ MO. 247100}

\section{CSI}

DIV DESCRIPTION

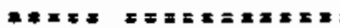

\section{ENGIXEERING}

\section{ENGINEERING}

TOTAL ENGINEEAIHG

\section{CONSTRUCTION}

\begin{tabular}{|c|c|}
\hline 02 & SJTEYORK \\
\hline 05 & HETALS \\
\hline 13 & SPECIAL CONSTRUCTION \\
\hline 15 & MECHANICAL \\
\hline 16 & ELECIPICAL \\
\hline
\end{tabular}

TOTAL COHSTRUCTION

PROJECT TOTAL

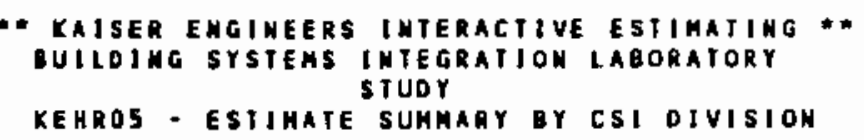

KEHROS - ESIJHATE SUMAAGY BY CSI DIVISION

PAGE 5 OF 6

DAIE $08 / 15 / 88$ 05:50

BY F.C.DAY

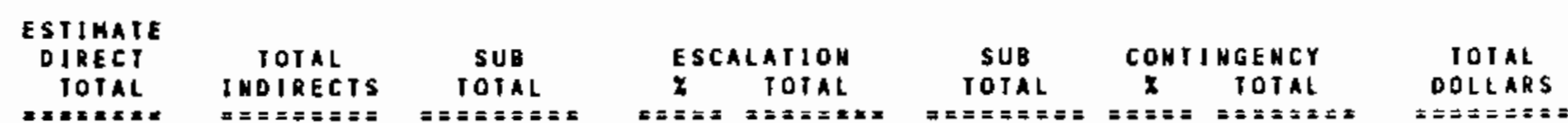

IOTAL

inotrects

$== \pm== \pm=0$

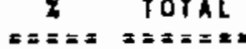

$=\mathbf{=}=\mathbf{=}=\mathbf{=}=$

X TOTAt

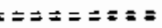

$\begin{array}{lllllllll}1660000 & 0 & 1660000 & 0.00 & 0 & 1660000 & 30 & 498000 & 2158000 \\ 1660000 & 0 & 1660000 & 0.00 & 0 & 1660000 & 30 & 498000 & 2158000\end{array}$

$\begin{array}{rrrrrrrrr}310200 & 0 & 310200 & 0.00 & 0 & 310200 & 30 & 93000 & 603260 \\ 3801700 & 0 & 3801700 & 0.00 & 0 & 3801700 & 30 & 1140510 & 4942210 \\ 113700 & 0 & 113700 & 0.00 & 0 & 113700 & 30 & 34110 & 147810 \\ 2425500 & 0 & 2425500 & 0.00 & 0 & 2425500 & 30 & 727050 & 3153150 \\ 29400 & 0 & 29400 & 0.00 & 0 & 29400 & 30 & 8820 & 38220 \\ 6680500 & 0 & 6680500 & 0.00 & 0 & 6680500 & 30 & 2004150 & 8084650\end{array}$

B. 340,500

0

a, 340,500

0.00

0

340,500

$10,842,650$ 
KAISER ENGINEEAS HAHFORD

PACIFIC MORHTUEST LABORATORY

JOB $\$ 0.247100$

USS DESCRIPTION

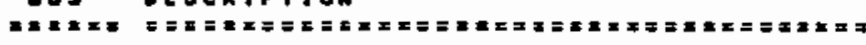

111000 ENGIWEERING

112000 EHG I HEERING

113000 ENGINEERIMG

321001 SITEVORK

321002 LAB IEST RUILOING

321003 ENVELOPE

322001 LAB TEST BUJLOING

322002 ENVELOPE

323001 STORAGE BUILDING

323002 LAO TEST BUILDING

323003 EYVELOPE

(PHASE I)

(PHASE II)

(PHASE III)

PHASE I)

(PHASE T)

(PHASE I?)

(PHASE II)

(PHASE III)

CPHASE DII

(PHASE ISI)
* Kaiser engIneERs Interactive estimating *

BUILOING SYSTEMS INTEGRATION LABORATORY

SIUDY

KEHRO7 - OXSITE IWDIAECT COSIS OY WBS

\begin{tabular}{|c|c|c|c|}
\hline $\begin{array}{l}\text { ESTIKATE } \\
\text { DIRECT } \\
\text { IOTAL } \\
====\approx \times=\end{array}$ & $\begin{array}{r}\text { CONJRACT } \\
x \\
x====\end{array}$ & $\begin{array}{c}\text { AOHINISTRATION } \\
\text { IOTAL } \\
x======\end{array}$ & $\begin{array}{l}\text { BID PAC } \\
\text { PREP. } \\
======x\end{array}$ \\
\hline $\begin{array}{r}420000 \\
410000 \\
830000 \\
132700 \\
1270500 \\
290200 \\
1258300 \\
377800 \\
143600 \\
2396000 \\
811600\end{array}$ & $\begin{array}{l}0.00 \\
0.00 \\
0.00 \\
0.00 \\
0.00 \\
0.00 \\
0.00 \\
0.00 \\
0.00 \\
0.00 \\
0.00\end{array}$ & $\begin{array}{l}0 \\
0 \\
0 \\
0 \\
0 \\
0 \\
0 \\
0 \\
0 \\
0 \\
0\end{array}$ & \\
\hline
\end{tabular}

PAGE 6 OF 6

DAIE O8/15/8Q 05:50

BY F.C.DAY

OIHER

1 NOIRECIS

$x= \pm= \pm=$

TOThL

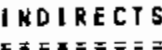

\section{PROJECT TOTAL}




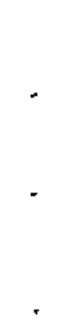




\title{
APPENDIX B
}

\author{
Sketches \\ ES-B67329-A1 \\ ES-B67329-A2 \\ ES-B67329-A3 \\ ES-B67329-A4 \\ ES-B67329-A5
}




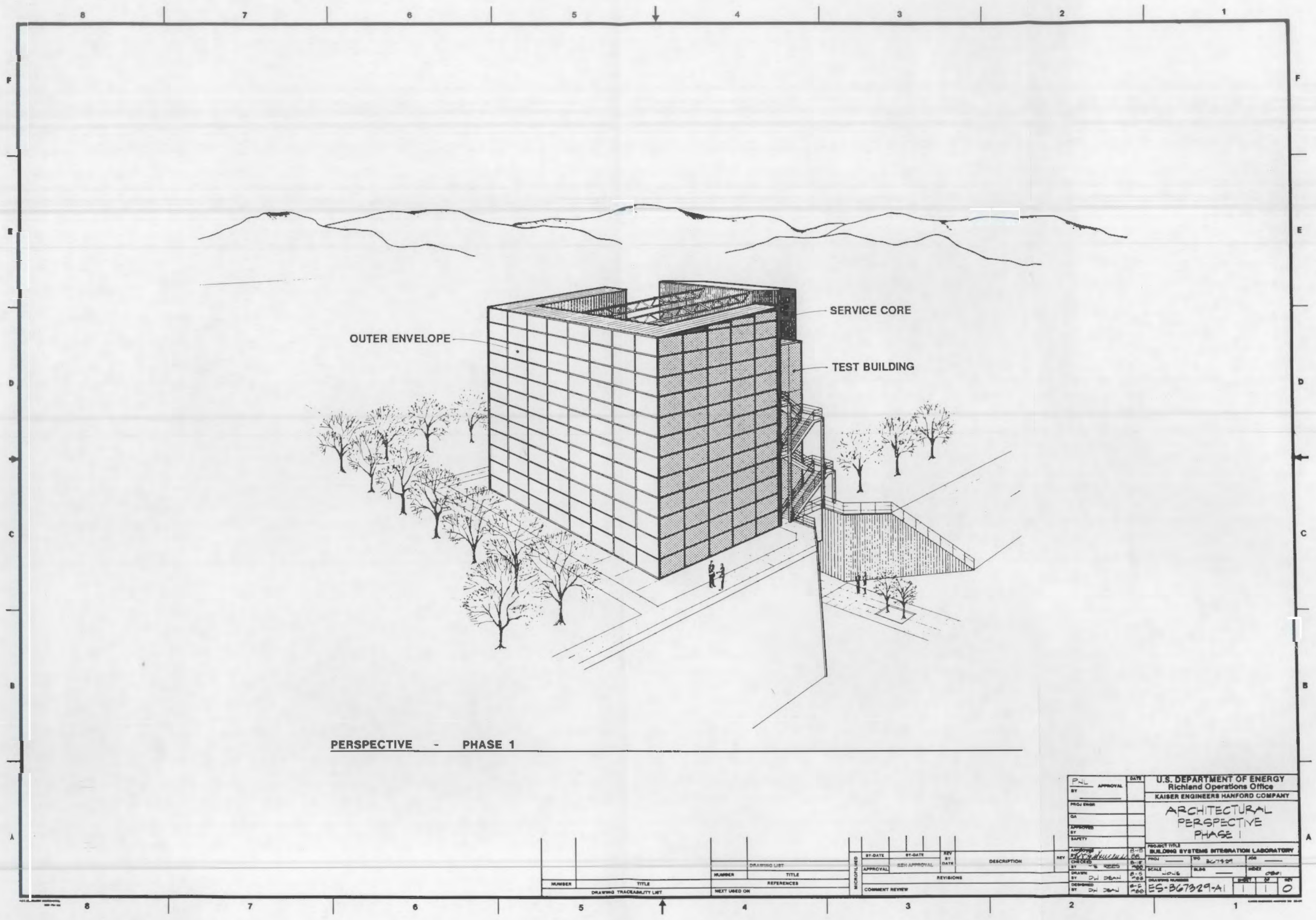




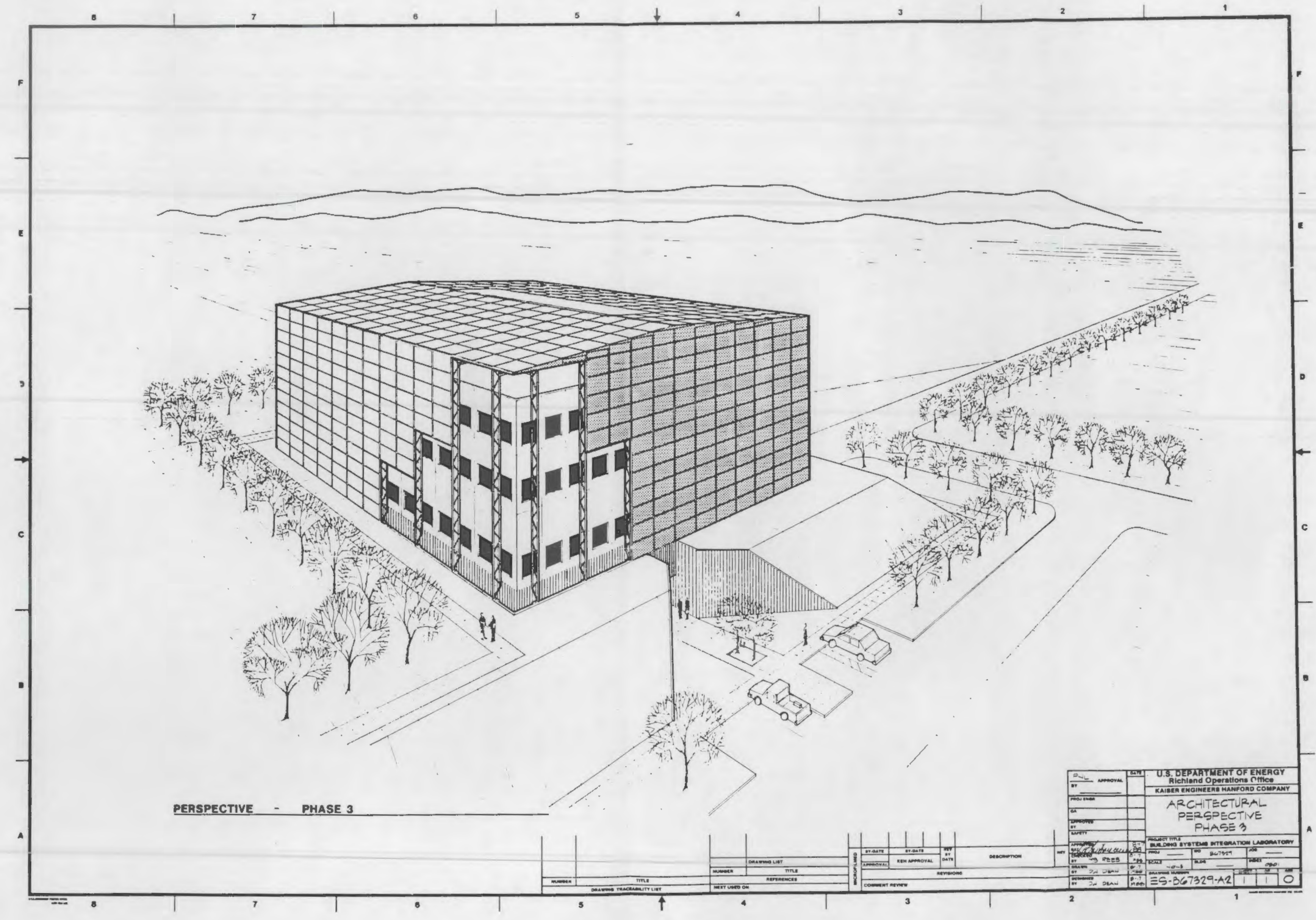




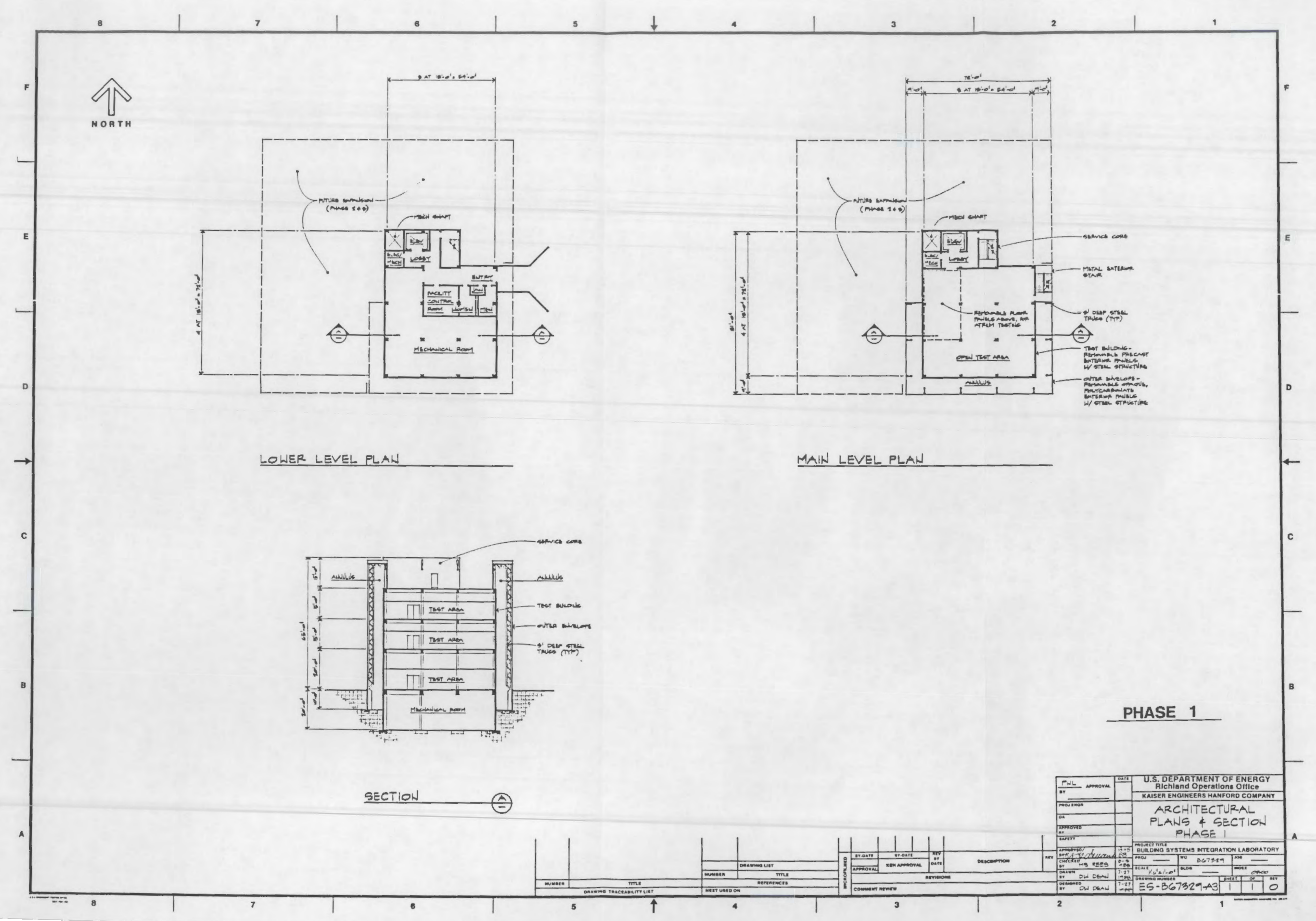




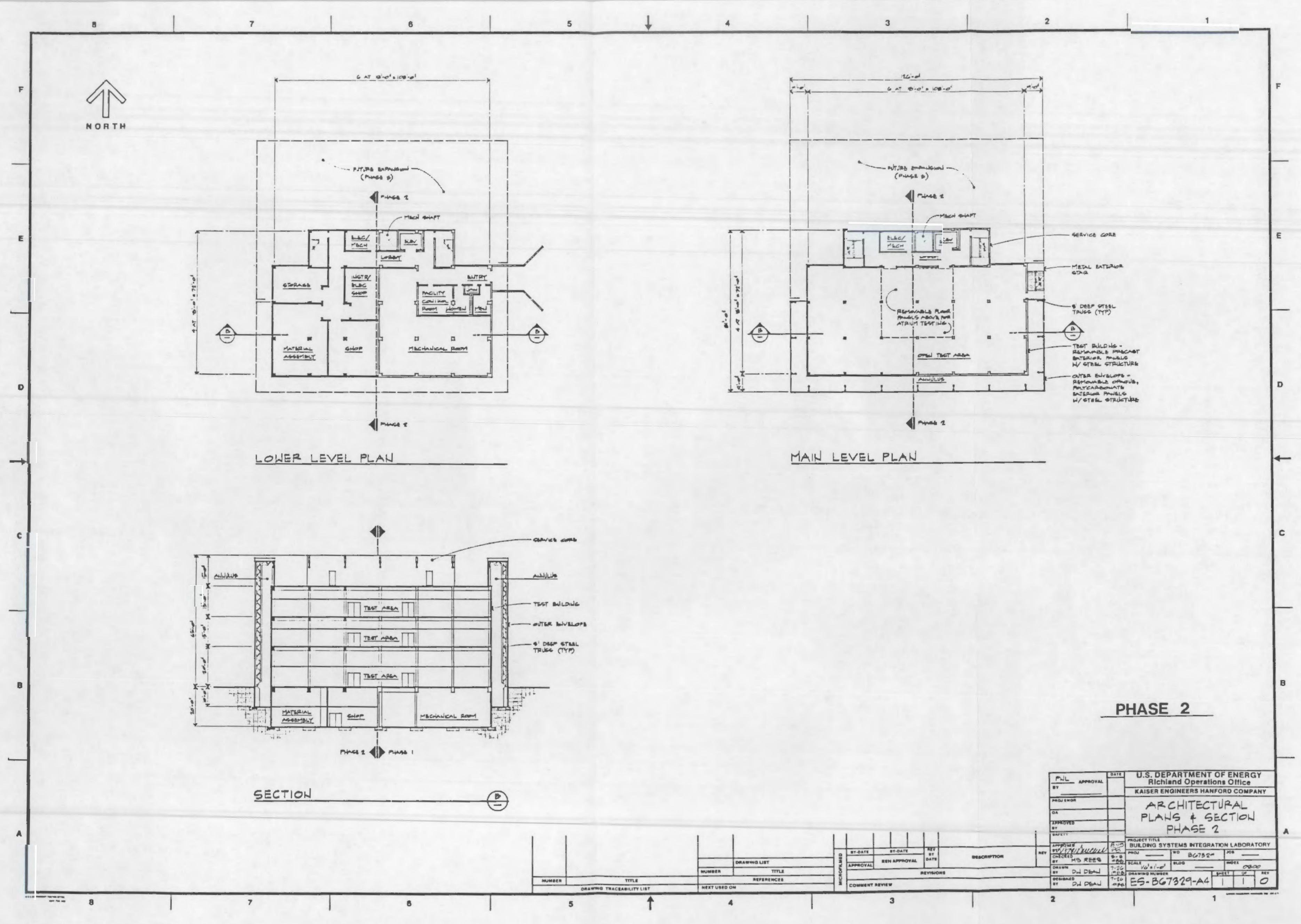




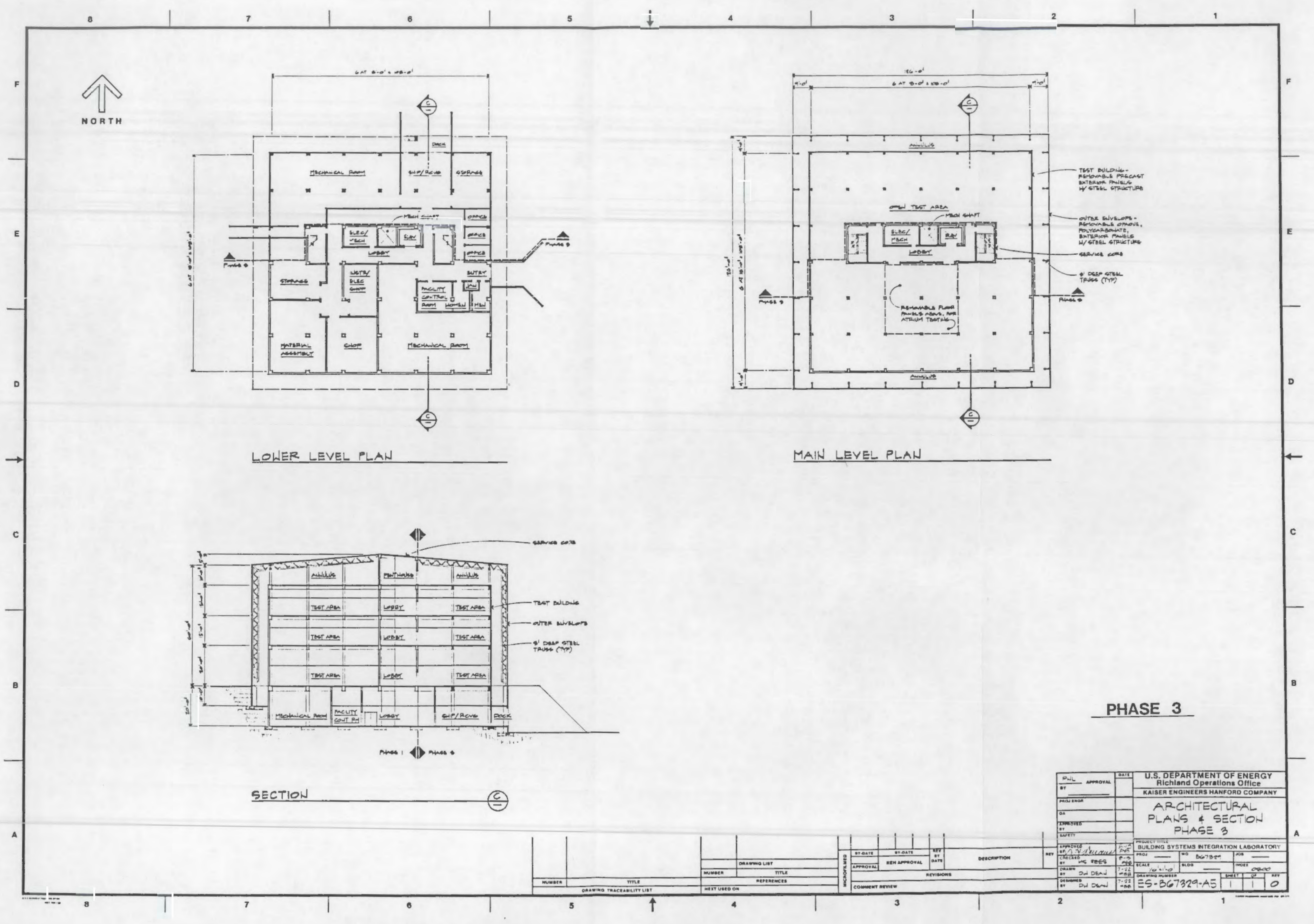




\section{DISTRIBUTION}

No. of

Copies

\section{OFFSITE}

12 DOE/Office of Scientific and Technical Information

$15 \mathrm{M}$. L. Bailey

U.S. Department of Energy

1000 Independence Avenue SW

Forrestal Building, CE-131 5E-098

Washington, DC 20585

\section{J. J. Boulin}

U.S. Department of Energy

1000 Independence Avenue SW

Forrestal Building, CE-131 5E-098

Washington, DC 20585

\section{J. P. Millhone}

U.S. Department of Energy

1000 Independence Avenue SW

Forrestal Building, CE-131 5E-098

Washington, DC 20585

\section{J. A. Smith}

U.S. Department of Energy

1000 Independence Avenue SW

Forrestal Building, CE-131 5E-098

Washington, DC 20585

D. Beranek

Headquarters, USACE

Attention: CEEC-EE

20 Massachusetts Avenue NW

Washington, DC 20314-1000

M. Blatt

Electric Power Research Institute 3412 Hillview Avenue

P.O. Box 10412

Palo Alto, CA 94303

J. R. Brodrick

Gas Research Institute

8600 West Bryn Mawt Avenue

Chicago, IL 60631
No. of

Copies

C. Claar

Pennsylvania State University

104 Engineering A

University Park, PA 16802

L. Flowers

Solar Energy Research Institute

1617 Cole Boulevard

Golden, CO 80401

H. Gordon

Burt Hill Kosar Rittelmann Associates

1056 Thomas Jefferson Street NW

Washington, DC 20007

D. L. Herron

U.S. Army Construction Engineering

Research Laboratory

Attention: CER-ES

2902 Newmark Drive

Interstate Research Park

Champaign, IL 61820

D. Hittle

Department of Mechanical Engineering

Colorado State University

Fort Collins, CO 80521

B. Hunn

Center for Energy Studics

Balcones Research Center

The University of Texas at Austin

10100 Burnet Road

Austin, TX 78758

K. Johnson

Electric Power Research Institute

3412 Hillview Avenue

P.O. Box 10412

Palo Alto, CA 94303

M. Karnitz

Oak Ridge National Laboratory

P.O. Box X

Oak Ridge, TN 37831 
No. of

Copies

\section{J. Klems}

Lawrence Berkeley Laboratory

Building 90, Room 3111

One Cyclotron Road

Berkeley, CA 94720

\section{J. Kreider}

Civil Engineering ECOT-34

University of Colorado

Regent Road

Campus Box 7

Boulder, CO 80309

I. Lewin

Lighting Sciences

7830 East Evan Road

Scottsdale, AZ 85260

N. R. Patterson

Trane Company

Building 17.2

3600 Pammel Creek Road

La Crosse, WI 54601

J. Pouzar

NASA Johnson Space Center

Houston, TX 77058

G. Reistad

Mechanical Engineering Department

Oregon State University

Corvallis, OR 97331

P. R. Rittelmann

Burt Hill Kosar Rittelmann Associates

400 Morgan Center

Butler, PA 16001

J. D. Rivera

D\&R International

962 Wayne Avenue

Silver Spring, MD 20910

R. Sterling

University of Minnesota

CME Building, Room 790

500 Pillsbury Drive SE

Minneapolis, MN 55455
No. of

Copies

S. Treado

National Institute of Standards and

Technology

Building 226, Room A-313

Gaithersburg, MD 20899

J. Warner

Research \& Management Foundation

American Consulting Engineers Council

Suite 802

1015 15th Street NW

Washington, DC 20005

\section{ONSITE}

DOE Richland Operations Office

C. E. Collantes

2 Kaiser Engineers Hanford

D. W. Dean

M. S. Rees

74 Pacific Northwest Laboratory

J. F. Bagley, K1-45

M. R. Brambley, K5-12

D. B. Crawley (50), K5-12

J. W. Currie, K6-66

M. K. Drost (3), K5-12

B. M. Johnson (5), K5-12

R. W. Reilly, K6-61

T. J. Secrest (5), K5-12

G. M. Stokes, K2-51

Publishing Coordination

Technical Report Files (5) 